\title{
The short-term, circumscribed, and conditional effects of cross-partisan conversation*
}

\author{
Erik Santoro $^{\dagger} \quad$ David E. Broockman
}

October 8, 2021

\begin{abstract}
Scholars and activists have raised alarm about affective polarization-voters' increasing dislike for supporters of opposing political parties-and its potential negative implications for democracy. Organizations, activists, and scholars have identified cross-partisan conversations as a promising paradigm for reducing affective polarization and, in turn, bolstering democratic accountability. However, existing theory and empirical work remains equivocal. We argue that cross-partisan conversations have potential to reduce intergroup prejudices between partisans, but that such one-shot interactions are likely to have effects that are short-term (i.e., decay), to be circumscribed within the interpersonal domain and not extend to attitudes relevant to democratic accountability, and to be conditional on topic, diminishing if the conversations dwell on group divides. We support this argument with results from two unique experiments where we paired outpartisan strangers in real time to discuss randomly assigned topics face-to-face over video calls. In Study 1, we found that non-political conversations between outpartisans dramatically decreased affective polarization, reversing over two decades' worth of increases. However, these impacts decayed completely in a follow-up survey. Moreover, the conversations had no effect on outcomes relevant to democratic accountability, such as loyalty to copartisan politicians who violate democratic norms. Study 2 replicated Study 1's results in a more representative sample and included conversations about group divides. We again found large effects of non-political cross-partisan conversations on affective polarization, but that conversations about group divides had no effects. All conversations were again ineffective at changing outcomes relevant to democratic attitudes. Our results support our argument regarding the conditional, short-term, and circumscribed effects of cross-partisan conversations.
\end{abstract}

\footnotetext{
*We acknowledge AllSides and the Civic Health Project for support. We thank Hazel Markus and her lab, Robb Willer and his lab, Doug Ahler, Eran Amsalem, Danny Choi, Robert Blair, Mina Cikara, Alex Coppock, Jamie Druckman, Kurt Gray, Shanto Iyengar, Yanna Krupnikov, Emily Kubin, Matt Levendusky, Benoît Monin, Lilla Orr, Erin Rossiter, Gaurav Sood, Benjamin Warner, Sean Westwood, Mike Yeomans, Gabriel Lenz and seminar participants at UC Berkeley for helpful feedback. All remaining errors are our own. The studies reported herein were approved by the Committee for the Protection of Human Subjects at UC Berkeley and at Stanford University.

${ }^{\dagger}$ PhD Student, Department of Psychology, Stanford University. es antoro@ stan ford.edu.

¥Associate Professor, Charles and Louise Travers Department of Political Science, University of California, Berkeley. dbroockman@berkeley . edu.
} 
Americans who support Democrats and who support Republicans have never disliked each other more, a phenomenon known as affective polarization (Iyengar, Sood and Lelkes, 2012). They cut short Thanksgiving dinners with each other (Chen and Rohla, 2018), avoid dating each other (Huber and Malhotra, 2017), and discriminate against each other (McConnell et al., 2018). Scholars worry about the social consequences of this affective polarization and its potential negative consequences for democracy (Finkel et al., 2020). For example, scholars worry that affective polarization "weaken[s]...willingness to punish one's own party's politicians" (Pierson and Schickler, 2020, p. 50), “increases partisans' willingness to conform to their party's policy positions" (Iyengar et al., 2019, p. 142), and reduces support for legislative bipartisanship (Levendusky, 2018).

These concerns for society and democracy have inspired a number of organizations, activists, and scholars to embrace cross-partisan conversations as a promising paradigm for reducing affective polarization - and, in turn, improving democratic accountability. For instance, a recent New York Times report details a bevy of "classes, apps and message boards...trying to bridge the divide between the left and the right, one conversation at a time.' 11 Understanding the impacts of these conversations and how best to conduct them has the potential to unlock both important practical insights and theoretical lessons. However, as we discuss below, existing theory and empirical work about the impacts of and best practices for such conversations remains somewhat equivocal.

In this paper, we argue that cross-partisan conversations have the potential to reduce intergroup prejudices, but that such one-shot interactions are likely to have effects that are short-term and decay, be circumscribed within the interpersonal domain and not extend to democratic attitudes, and be conditional on topic, diminishing if the conversations dwell on group divides. Supporting this argument, we present results from two unique experiments in which we deployed software we developed to pair outpartisan strangers in real time to discuss a randomly assigned topic face-toface over video calls - a common medium for such conversations. 2

\footnotetext{
${ }^{1}$ See www.nytimes.com/2019/11/03/us/trump-voters-liberals.html

${ }^{2}$ See, e.g., www.livingroomconversations.org/ and www.mycountrytalks.org/.
} 
In Study 1, we paired participants with an outpartisan participant to discuss a non-political topic, their perfect day. In a Placebo condition, participants were not told they were talking with an outpartisan; in an Aware - Non-Political condition, participants were informed just before the conversation began that their conversation partner was an outpartisan. In Study 2, we recruited a more representative sample of participants and randomized them into four conditions, two that replicated Study 1 as well as two additional conditions inspired by research regarding the potential pitfalls of explicit discussions of group divides (e.g., Paluck, 2010): an Aware - Positive Political condition asking participants to talk about why they favored their party and an Aware - Negative Political condition asking participants to talk about why they did not favor the other party. Table 1 summarizes the conditions.

Table 1: Conditions in Studies 1 and 2

\begin{tabular}{|c|c|c|c|c|}
\hline Condition & Conversation Prompt & $\begin{array}{l}\text { Informed Partner } \\
\text { was Outpartisan? }\end{array}$ & $\begin{array}{c}\text { Included in } \\
\text { Study } 1 ?\end{array}$ & $\begin{array}{c}\text { Included in } \\
\text { Study 2? }\end{array}$ \\
\hline $\begin{array}{l}\text { Placebo (Blind - } \\
\text { Non-Political) }\end{array}$ & Discuss perfect day & - & $\checkmark$ & $\checkmark$ \\
\hline $\begin{array}{c}\text { Aware - } \\
\text { Non-Political }\end{array}$ & Discuss perfect day & $\checkmark$ & $\checkmark$ & $\checkmark$ \\
\hline $\begin{array}{c}\text { Aware - Positive } \\
\text { Political }\end{array}$ & $\begin{array}{l}\text { Discuss why a } \\
\text { member of inparty }\end{array}$ & $\checkmark$ & - & $\checkmark$ \\
\hline $\begin{array}{c}\text { Aware - Negative } \\
\text { Political }\end{array}$ & $\begin{array}{l}\text { Discuss why not a } \\
\text { member of outparty }\end{array}$ & $\checkmark$ & - & $\checkmark$ \\
\hline
\end{tabular}

After the conversations in both studies, we asked items tapping intergroup attitudes (e.g., affective polarization), outcomes relevant to democratic accountability (e.g., support for inpartisan politicians who violate democratic norms), and about posited mechanisms. In Study 1 we also conducted a follow-up survey three months after the conversations to see if the effects persisted.

In both studies, cross-partisan conversations about non-political topics caused very large decreases in affective polarization-enough to reverse two decades worth of increase. However, 
supporting our argument about the short-term effects of cross-partisan conversations, these effects decayed to zero in our long-term follow up three months later. Supporting our argument about the circumscribed effects of cross-partisan conversations, we also found no evidence of any effects on items relevant to democratic accountability in either study. Finally, supporting our argument about the conditional effects of cross-partisan conversations, Study 2 found that talking about group divides diminished the effect on affective polarization to near zero.

In the context of the literature (reviewed below), several features make our experiments notable: our experiments involve real, face-to-face interactions between real outpartisans (not confederates); our research design allows us to isolate the causal effects of these conversations; we examine often-hoped-for effects on attitudes relevant to democratic accountability (in addition to intergroup prejudices); we examine long-run effects, a rare feature of experiments on any form of intergroup contact (Paluck, Green and Green, 2019); and we test the effects of novel conversation topics, varying whether participants discuss group divides (and how).

Our findings are significant for at least four reasons. First, our findings confirm the promise of cross-partisan conversations, and in so doing suggest optimism about even 'shallow' intergroup contact: we found large declines in affective polarization despite that many of the traditionally understood necessary conditions for contact to reduce intergroup prejudice were not met in this setting. This is all the more surprising given that the intervention was only a brief conversation between untrained laypeople. Second, however, our findings indicate that further research is necessary to understand how to make these effects endure. Our finding of complete decay was not a foregone conclusion in light of other studies which have found that brief conversations can durably reduce prejudice for at least 4.5 months (e.g., Kalla and Broockman, 2021a). Further research could attempt to apply this research's insights to cross-partisan conversations to see if the effects would endure further. Third, our findings question many scholars' and practitioners' assumption that interventions which reduce affective polarization will have salutary consequences for democratic accountability (for a review and critique of these claims, see Broockman, Kalla and West- 
wood, 2020; Voelkel et al. 2021). We found no such effects. Finally, consistent with field research in other domains (Paluck, 2010), our results suggest that explicit discussions of group divides may undermine the salutary effects of intergroup contact. This result complements other recent research on the benefits of highlighting similarities between outpartisans (e.g., Ahler, 2014, Ahler and Sood, 2018; Levendusky and Stecula, Forthcoming; Orr and Huber, 2020) to suggest that, to that extent intergroup conversations discuss topics related to group differences (e.g., politics or partisanship), such discussions may wish to focus on similarities between groups.

\section{Theoretical Perspectives and Existing Evidence}

Theoretically, the effects of and best practices for cross-partisan conversations are not clear ex ante.

Should we expect effects at all? Should we expect cross-partisan conversations to reduce intergroup prejudice (e.g., affective polarization) at all? It may seem obvious that they should: at one level, the contact hypothesis suggests that contact between outgroups should do so (Allport, 1954, Pettigrew and Tropp, 2006, Warner, Horstman and Kearney, 2020). Moreover, even brief interventions involving humanizing narratives about outgroup members can durably reduce prejudice (e.g., Kalla and Broockman, 2021a), consistent with the person positivity effect (Sears, 1983).

However, some literature also suggests certain conditions may be necessary for intergroup contact to reduce prejudice: equal status, intergroup cooperation, common goals, and support from authorities. These conditions may be difficult to meet in one-off conversations between outpartisan strangers. Moreover, the fact that individuals often cut short interactions with outpartisans (Chen and Rohla, 2018) suggests that such contact may be unpleasant and so only exacerbate prejudice (Enos, 2014; MacInnis and Page-Gould, 2015, although see Mutz, (2002); Amsalem, Merkley and Loewen (2021)).

Despite this theoretical ambiguity, organizations and activists are investing tremendous effort into organizing cross-partisan conversations. Since it is of greatest interest to practitioners to find 
scalable ways to reduce affective polarization, in this paper we try to look at the least time- and effort-intensive cross-partisan conversation intervention: what is the effect of simply having a conversation with an outpartisan stranger? In the context of partisanship, where Democrats and Republicans often eschew social interaction and live in increasingly distinct geographies (e.g., Chen and Rohla, 2018), such an interaction may be one of the few such interactions individuals have recently had. Understanding this question is also of theoretical import: there is surprisingly little research that examines the long-run effects of randomly assigned intergroup contact of any sort (see Paluck, Green and Green, 2019), meaning that whether brief cross-partisan conversations durably reduces affective polarization helps fill a gap in the literature on intergroup contact more broadly.

Conditional Effects. We argue that there will be effects of cross-partisan conversations, but that these effects will be conditional on the topics discussed. In contexts such as politics where there are salient divides that are perceived to separate the groups (e.g., views towards politicians or on issues), one possibility is that contact can reduce prejudice by highlighting unexpected similarities between groups. Indeed, existing research has already found that information regarding political similarities between partisans' demographics or views on issues can reduce affective polarization (e.g., Ahler and Sood, 2018; Orr and Huber, 2020), and so we would expect conversations that provide information about such similarities to reduce affective polarization. We argue that such effects should also result from learning of non-political similarities as well. To test this, our experiments created a situation in which participants would have the opportunity to identify similarities unrelated to politics: namely, participants discussed their perfect day, a topic shown to quickly develop rapport (Aron et al., 1997). Consistent with the contact hypothesis, we expected that even such a "minimal" cross-partisan could reduce intergroup prejudices between partisans.

At the same time, many practitioners encourage cross-partisan conversations to focus on group divides, as no doubt do many naturally occurring cross-partisan conversations as well. We therefore chose to also study conversations that focus on group divides, as their effects are even more 
ambiguous on the basis of existing research. On one hand, research in other contexts suggests that discussing group divides might backfire by increasing the salience of group divisions (Paluck, 2010), or at the very least not reduce polarization. On the basis of this research, we hypothesized that the salutary effects of cross-partisan contact would be conditional on whether the conversations avoid discussions of group differences. At the same time, this is by no means obvious: there is more agreement between partisans than they expect (Ahler, 2014), and so even discussions ostensibly focused on divides between partisan groups may surface more common points of agreement between individual members of those groups than individuals expect. Moreover, on a normative basis, practitioners may believe that cross-partisan conversations should focus on discussions of differences, in hopes of moderating opinions. We therefore included a condition focusing on divides (Aware - Positive Political) in Study 2, in which we ask participants to each discuss why they support their party. $!^{3}$

However, we also implemented a second condition that focused on group divides but in a manner we thought might paradoxically surface more agreement. In particular, in an Aware Negative Political condition we asked participants to discuss why they don't identify with the other party. Although it might seem obvious that listening to an outgroup member describe deficiencies of one's own group would produce backlash, we anticipated such conversations might actually be a more productive way to discuss partisan group divides for two reasons. In light of the fact that partisanship is characterized more by negative feelings towards the outparty than positive feelings towards one's inparty (for review, see Iyengar et al., 2019), we expected that it might be easier for participants to describe why they dislike their outparty than why they like their inparty; and, second, we expected it would be less unpleasant to hear negative sentiments about one's (often not particularly liked) inparty than positive sentiments about the (typically highly disliked) outparty.

\footnotetext{
${ }^{3}$ We thought that discussion of a particular issue instead of the overall group divide would be be too likely to often result in participants simply agreeing on the issue (given cross-partisan agreement on many issues), which would not involve discussing an actual divide and would result in reductions in affective polarization that would be too obviously expected ex ante. See Rossiter (2021) for work looking at the effects of discussing a specific political issue.
} 
Short-term effects. Even if cross-partisan conversations had immediate impacts on prejudice, though, it is not obvious whether or not these impacts would endure. Paluck, Green and Green's (2019) recent review finds that, despite the voluminous literature on intergroup contact, relatively few experiments have measured the long-term effects of randomly assigned intergroup contact. On the one hand, several studies find that a brief conversation with a trained canvasser can have impacts that endure for at least 4.5 months (e.g., Kalla and Broockman, 2021a), a finding consistent with a broader literature on the enduring effects of psychologically-informed interventions (Walton and Wilson, 2018). However, such interventions often contain components explicitly designed to lead their effects to persist, leaving it unclear theoretically whether cross-partisan conversations between laypeople would have these effects. Our evidence therefore speaks to the under-studied question of the necessary conditions for such brief interventions to have enduring effects. Because such conversations are unlikely to provide new information that citizens effortfully process (Petty and Cacioppo, 1986, Coppock, 2021) absent explicit instructions that lead them to do so, we hypothesized that such conversations are typically likely to have only short-term effects.

Circumscribed effects. Finally, would any immediate reductions in intergroup prejudice "spill over" into other attitudes relevant for democratic accountability? We argue that such conversations are likely to have effects circumscribed to the political domain, not having the knock-on effects for attitudes relevant to democratic accountability that many hope. Practitioners and prior literature alike (for review, see Broockman, Kalla and Westwood, 2020; Voelkel et al., 2021) widely expect that interventions which reduce affective polarization would bolster democratic accountability. Nevertheless, little prior evidence has demonstrated this common assumption. We expect individuals to be 'cognitive misers' who, absent prompting to do so, would not think through the implications of any changes in affective polarization or feelings towards the outparty for other attitudes related to democratic accountability (e.g., Coppock and Green, 2021). We therefore expect the effects of cross-partisan conversations to be circumscribed to the interpersonal domain, especially absent any attempt to explicitly link the interpersonal domain to attitudes relevant to 
democratic accountability.

In summary, experimentally manipulating cross-partisan conversations offers the chance to learn about the necessary conditions for contact to reduce prejudice in a novel context, as well as to understand its potential long-term impacts and downstream implications for democracy.

Existing evidence. Despite conflicting theoretical expectations regarding the likely effects of cross-partisan conversations and the importance of understanding them, existing empirical research directly on the topic of cross-partisan conversations is also somewhat ambiguous, not speaking to the key claims our argument makes. In a recent review, Iyengar et al. (2019) note that "there have been no systematic evaluations" of cross-partisan conversations. A small number of relevant studies have appeared since this recent review. We review these studies in more detail in Appendix B, categorizing relevant studies into four categories.

First, as we review there, only one other study has examined the impacts of cross-partisan conversations directly. In an important working paper, Rossiter (2021) studies text-based crosspartisan conversations. Our study builds on Rossiter's (2021) work in several ways: we measure effects on outcomes relevant to democratic accountability; we measure long-run effects; we measure effects of different conversation topics, which vary the presence of discussions of partisan group divides; and, inspired by research about the differences between conversations involving text or also including speech and images (Schroeder, Kardas and Epley, 2017), our conversations take place face-to-face, over video calls instead of text.

There are also several studies, listed in Table OA7, which study interventions that include both conversations with outpartisans and other components. These studies are largely interested in the effects of these interventions, not cross-partisan conversations; accordingly, they all manipulate multiple components beyond cross-partisan conversations, leaving the impacts of cross-partisan conversations ambiguous.

Finally, several studies reviewed in Table OA8 study vicarious, imagined, simulated, or selfreported contact between outpartisans. These studies provide valuable insight and underscore 
scholars' interest in the potential of cross-partisan conversations, but do not study how real outpartisans interact with each other in real conversations. In addition, none of these studies examine long-run effects, effects on attitudinal polarization, nor effects on democratic accountability.

There are also several studies tangentially related to affective polarization or interpersonal conversation we non-exhaustively review in Table OA9, none of which examine the effects of crosspartisan conversations on affective polarization nor democratic accountability.

In the context of this literature on both cross-partisan conversation and intergroup contact more generally (see Paluck, Green and Green, 2019), our study is therefore unique across several important dimensions.

\section{Study 1}

Study 1 provides our first investigation into the effects of cross-partisan conversations, comparing a non-political conversation with an outpartisan to a placebo condition.

\section{Research Design}

Study 1 took place in 2021. Online Appendix Figure OA1 summarizes the methods and exclusions in Study 1 that we describe below.

\section{Screener Survey}

We began by recruiting participants to "qualify for a 30 minute survey with a video call" on Prolific and Amazon Mechanical Turk. In this screener survey, we asked participants their party identification, their interest and availability to do a study involving a video conversation at specific dates on times, three attention checks, and for them to conduct a test of whether their computer was compatible with our software to have video conversations. To avoid selecting participants who were 
unusually open to cross-partisan exchanges, we did not tell participants we wanted them to talk to an outpartisan specifically nor to talk about politics.

We screened out prospective participants who were not interested in having a conversation or had a suspicious IP address; had bot-like free response questions (as determined by the first author); started the survey more than once (using their participant identification number and their IP address) or did not finish the survey; failed two or more attention checks and identified as a Democrat, or failed one attention check and identified as a Republican; identified as an Independent or did not provide their party identification; or identified as a Democrat and (during some periods when we had a surplus of Democratic participants) did not have a compatible system.

Among qualifying participants, we assigned participants to time windows when they said they were available (and for those who were not available at any times, we assigned them a random time to give them the option of taking the study); due to an excess of interested Democratic participants, we randomly dropped Democrats when there was a large excess of them available at that time, prioritizing those who were free at that time and had a compatible system.

We sent participants an email or message through the recruiting platform indicating the day and time the full study would take place, and another reminder right before the study was to take place. (Several days usually elapsed between when participants completed the screener survey and their assigned day for the main conversation survey.)

Before launching the main conversation survey, we filed a pre-analysis plan. $4^{4}$

\section{Conversation Survey}

On the date and time assigned to each participant, we sent them an invitation to immediately begin the video conversation survey. Some participants received a message asking them to come back

\footnotetext{
${ }^{4}$ Pre-analysis plan is available at https: / / aspredicted.org/blind.php?x=ud7a62. After cleaning the data from the conversation survey but before examining the results, we filed an amended analysis plan that clarified several ambiguities in our original plan. The amended analysis plan is available at https://osf.io/q3hkx/ ?view_only=6575d00b686c418eb5591b66ca3ad628
} 
to the survey later if there were too many members of their party already waiting to be paired. After consenting to the study, in which participants were invited to "participate in a research study between strangers" and that this would involve talking "over video about an assigned topic," we asked participants several baseline measures, then told participants they would be soon entering a video call platform, AllSides, where they were to have a 10 minute conversation with someone also taking the survey.

The survey then displayed a link participants were instructed to click to join the video call. When participants clicked the link, they were directed to a custom landing page we created. The random assignment and partner matching took place in real time in the moments after participants clicked this link and before the landing page loaded. To assign participants to a condition, our software first checked if any other participants of the other party were available (i.e., were still waiting to be paired). If there were no available outpartisans, the random assignment to condition then took place: the software randomly assigned participants to either the Placebo or Aware Non-Political conditions. If there were available outpartisans, participants were matched with the outpartisan survey participant who had been waiting the longest for a conversation partner and inherited this participant's random assignment. (To account for this procedure, our standard errors are clustered by dyad.)

After this matching and assignment process completed (essentially instantaneously), participants arrived on a custom landing page that told them the topic of the conversation, which in all cases in Study 1 was "What does the "perfect day' look like to you?" (Aron et al., 1997). The website also told all participants "You will be matched with someone." If participants had been randomly assigned to the Aware - Non-Political condition, the sentence went on to say "who feels closer to the [OUTPARTY] party. (You told us you feel closer to the [INPARTY] party.)" The experimental manipulation in Study 1 is therefore whether participants were aware that they were talking with an outpartisan, given that a conversation began. This allowed us to hold constant the ability of participants to be matched with an outpartisan given the specific time at which they ap- 
peared and for their computer software to be working. Below, we show that this manipulation had a very large effect on whether participants believed they were talking with an outpartisan.

After this page displayed for 12 seconds, participants were redirected to a video chat room on the Allsides Connect website (allsidesconnect.com), a video platform which graciously agreed to allow us to use their platform for our studies. This chat room was specific to them and their partner. The instructions on the screen in the room again told participants the topic of the conversation and, if the participants were in the Aware - Non-Political condition, reminded them that one participant identified as a Democrat and one identified as a Republican. The site also asked participants to wait up to 5 minutes for a partner to arrive (as some participants were the first instead of the second in their pair). All conversations were between two participants only, one Democrat and one Republican. Participants received no further instructions about how to have the conversation as we were interested in the effect of conversations between untrained lay people for this initial investigation, rather than seeking to evaluate any one particular set of further instructions.

After having the conversation, participants were instructed to continue with the survey (which could only advance after 5 minutes had elapsed). After indicating whether or not the conversation happened, participants then completed a series of dependent measures, detailed below. At the end, participants were debriefed and thanked.

A median of three months (to be exact, 84 days) after the surveys took place, we contacted participants asking them to complete a follow-up survey. The follow-up survey contained a subset of the outcome variables on the original conversation survey (asked in the exact same manner), as well as an additional measure, "Importance of Cross-Party Dialogue" (see below). Although the follow-up survey invitation told participants they qualified because they had taken a previous study with us, the invitation and survey made no reference to the specific nature of the study ${ }^{5}$

\footnotetext{
${ }^{5}$ Our research design leaves open the question of whether reminding individuals about the conversation might lead to different results. However, it is by no means obvious that a long-term follow-up survey which made no reference to a previous intervention would find no long-term effects; for example, Kalla and Broockman (2021a) find effects of a
} 


\section{Outcome Variables and Other Measures}

We asked our outcome variables on the conversation survey after the conversation had ended. We also asked a subset of these variables in the three-month follow-up survey.

Manipulation checks. We first asked a series of manipulation checks about what happened in the conversations, as well as whether participants thought that their partner was an outpartisan. These were our main manipulation checks, as the Aware - Non-Political condition was identical to the Placebo condition except for informing participants that they were speaking to an outpartisan.

Intergroup prejudice. We asked several measures to tap intergroup prejudices.

As we pre-registered, our first primary outcome was our primary measure of affective polarization, outpartisan affect: a feeling thermometer measuring affect towards outpartisan voters (Druckman and Levendusky, 2019). 6

We also asked a second primary outcome measure about respect meta-perceptions: "In general, how respectful do you think people who vote for [outparty]s are of people who vote for [inparty]s?" from "not at all respectful" to "very respectful." We developed this measure in light of recent research suggesting the importance of meta-perception in explaining, and reducing, political polarization (Lees and Cikara, 2020).

Finally, we also asked two questions we pre-registered as secondary outcomes. First, we measured humanization of the outparty (measured using the question: "People can vary in how humanlike they seem. Some people seem highly evolved whereas others seem no different from lower animals", and then asking participants to move a sliding scale corresponding to the 'ascent of man' measure adapted from Kteily et al. (2015) (for prior use in a partisan context, see Martherus et al.,

conversation intervention 4.5 months later on such an ostensibly unrelated survey.

${ }^{6}$ Affective polarization is often defined as the difference in affect towards the outparty minus the inparty. We focus on the warmth towards outpartisans component for simplicity and because the conversations did not target reducing feelings of warmth towards one's own inparty; in the results section, we verify that none of the conversations had significant effects on warmth towards one's own inparty. 
2021). Second, we measured warmth towards inparty voters (which we asked to ensure that inparty affect was not also increasing in tandem; we measured this using a feeling thermometer).

Outcomes relevant to democratic accountability. One of the notable features of our study is that we examine the potential for cross-partisan conversations to have positive downstream effects for outcomes relevant to democratic accountability, as many scholars and organizations hope. There are no widely-agreed upon measures of this concept as such impacts have rarely been studied, and so we measure a wide variety of outcomes in this area.

First, our third and final primary outcome assesses choosing an outpartisan candidate aligned on issues. To measure this, we displayed a table to participants that showed two hypothetical candidates for office, the candidates' parties, and the candidates' positions on two issues (gun rights and abortion). The inpartisan candidate had issue positions opposite the participant.7 and the outpartisan candidate had the same issue positions as the participant. Inspired by the worry that affective polarization would "weaken...willingness to punish one's own party's politicians" (Pierson and Schickler, 2020, p. 50) for taking incongruent positions, we asked participants which candidates they would vote for, and measured whether participants assigned to the Aware - NonPolitical condition would be more likely to select the candidate aligned with their issue views instead of their party ${ }^{8}$

All our remaining outcomes in this area were pre-registered as secondary outcomes unless otherwise noted.

Second, to see whether conversations might lead to less polarized policy views, we measured participants' views on several issues and computed an index of how often their policy attitudes were consistent with the outparty rather than inparty (e.g., a Republican having a liberal view on abortion). In the literature on affective polarization, this is sometimes referred to as attitudinal polarization; this is relevant to democratic accountability because it speaks to "partisans' willing-

\footnotetext{
${ }^{7}$ Participants' issue views were measured pre-treatment, before the conversation began.

${ }^{8}$ In Little, Schnakenberg and Turner's (2020) framework, this measures both divergence and desensitization.
} 
ness to conform to their party's policy positions" rather than hold their party accountable for these positions (Iyengar et al., 2019, p. 142).

Third, to test the hypothesis that reducing affective polarization with cross-partisan conversations might increase support for legislative bipartisanship (Levendusky, 2018), we adapt a vignette from Harbridge and Malhotra (2011, Study 2). The vignette tells participants about an actual Member of Congress of their party and it is randomly assigned whether they learn about the year of votes when this copartisan member cast party-line votes or often cast votes with the outparty (i.e., in a bipartisan manner). We test whether the Aware - Non-Political treatment causes participants to be additionally approving of the bipartisan-voting relative to the party-line-voting Member of Congress.

Fourth, to test the hypothesis that the conversations might make participants more willing to vote for outpartisan politicians in order to avoid voting for copartisan politicians who violated democratic norms, we adapt a series of items from Voelkel et al. (2021). These items ask how likely participants would be to vote for copartisan candidates who commit various norm violations (e.g., would ignore unfavorable court rulings by outparty judges). We form an additive index of these items ("Prioritize Norms over Partisanship").

Fifth, we asked participants how likely they would be to talk to an outpartisan neighbor about politics; and sixth, we asked about the importance of cross-partisan dialogue, in particular asking individuals three items about how important they thought it was for members of their party to engage in conversation with outparty members (e.g., "Talk to people who vote for [OUTPARTY] about politics."). We categorize these outcomes as relevant to democratic accountability because conversations between citizens are thought to help limit elite influence and organize collective action (e.g., Druckman and Nelson, 2003). To measure the importance of cross-partisan dialogue, we created an additive index of multiple items which only appeared in the follow-up survey; this measure was not pre-registered.

Seventh, we asked participants if they wanted to subscribe to a newsletter that provides biparti- 
san news to test the hypothesis that the conversations might reduce selective exposure to congenial information.

Eighth and (finally) ninth, we asked about warmth towards outpartisan and inpartisan politicians on a feeling thermometer. These were registered as tertiary outcomes. We classify them as relevant to democratic accountability because they speak to the likelihood of engaging in party-line voting.

Mechanisms. Study 1 asked about two potential mechanisms. The first, perceived similarity, was measured with the question: "How similar is the typical [OUTPARY MEMBER] to you?" from 'not at all similar' to 'extremely similar.' We hypothesized that the knowingly talking to an outpartisan about the perfect day might increase perceived similarity by revealing commonalities between the participant and their conversation partner, and thereby decrease partisan animus.

Second, we asked whether one's partner was perceived as engaged in deep listening with the questions: "My partner shared a story about their perspective" and "My partner asked me about what I thought." In light of work suggesting that perspective-getting might reduce prejudice (e.g., Kalla and Broockman, 2021a b), we theorized that the extent to which partisans perceived their partner listening might decrease affective polarization.

Moderators. As we pre-registered, we examine moderation of the treatment effects across three moderators that we asked about prior to treatment: frequency of having conversations with outparty; an index of political knowledge (Zaller, 1992); and two items from an index of receptiveness to opposing views (Minson, Chen and Tinsley, 2020).

\section{Analytical approach}

As we pre-registered, we used linear regressions to estimate effects on all variables, regressing each outcome on an indicator for treatment assignment (with Placebo as the baseline) and pre-treatment 
covariates to increase precision (Gerber and Green, 2012) 9 Thanks to these pre-treatment covariates, the effective sample size and statistical power of our study is considerably larger. All standard errors are clustered at the dyad level given the random assignment procedure.

Due to the number of dependent variables we examine, we pre-registered an approach for adjusting our $p$-values for multiple comparisons using the approach outlined in Anderson (2008). In particular, we do not adjust the $p$-values for our three primary outcomes. We adjust all of the $p$-values for the remaining outcomes, including our secondary outcomes, tertiary outcomes, mechanisms, manipulation checks, and moderation tests. ${ }^{10}$ We also separately adjust the $p$-values for all of the hypotheses tested on our three-month follow-up survey. Under Anderson's (2008) procedure, the resulting adjusted $p$-values can be interpreted as controlling the false discovery rate; for example, using the traditional threshold of $0.05,5 \%$ of adjusted $p$-values under this threshold within each domain are expected to be false positives.

We rescaled all dependent variables to standard deviation one, so all estimates we report are in standard deviations. The estimates are therefore equivalent to the Cohen's $d$ effect size.

Exclusions. Because of the unpredictability of how many participants of each party would show up for the study at any given time and the need to match participants with outpartisans, a number of participants in the conversation survey were not ultimately matched with an outpartisan because none arrived in time. We exclude observations from our analyses where participants never clicked the link to be randomly assigned and join the conversation platform, were never matched with a conversation partner or, due to technical problems, were unable to begin a conversation. We include all cases where a conversation began, and so our estimates are complier average causal

\footnotetext{
${ }^{9}$ The covariates are the baseline value of the dependent variable being estimated (where available), age, gender, education, race and ethnicity, party identification, and party ideology. For the test of support for bipartisanship, the coefficient of interest is the interaction between the bipartisanship treatment in the vignette and the conversation condition; for all other hypotheses the coefficient of interest is the coefficient on the treatment indicator. For our tests of moderation, we included interactions between our posited moderators and the treatment indicator.

${ }^{10}$ This is a more conservative approach than we pre-registered, which was to adjust by domain. We made this decision before looking at results.
} 
effects (i.e., "CACE”; Gerber and Green, 2012). We identify these cases using questions we asked participants immediately after the conversation about whether a conversation took place and if not why not, as well as data from the Allsides platform on whether two people joined the Allsides room they were assigned. In cases where we received conflicting information from participants or from the Allsides platform about whether a conversation began, we resolved discrepancies by manually reviewing a recording of the audio from their Allsides conversation room, which we captured with participants' prior consent. ${ }^{11}$ We determined all of these exclusion criteria and which individual recordings we would and would not exclude blind to treatment assignment and prior to examining the results. Online Appendix Figure OA1 provides a graphical overview of the recruitment process and the exclusion criteria.

\section{Study 1 Results}

\section{Sample Characteristics}

$N=7,940$ participants completed the screener, of whom we invited $N=1,374$ to the conversation survey. $N=986$ began the conversation survey. Finally, $N=478$ participants were able to successfully begin a conversation, of whom $N=218$ were in the Placebo group and $N=260$ were in the Aware - Non-Political group. Table OA1 shows the demographics of the sample at each stage and a balance check. The Placebo conversations lasted a median of 11.7 minutes; the Aware - Non-Political conversations lasted a median of 12.0 minutes.

We see some evidence that individuals assigned to the Aware - Non-Political group may have been slightly more likely to begin a conversation $(p=0.055)$ and to return to the follow-up survey $(p=0.048)$, but a test for differential attrition by covariates was insignificant, as assessed by a joint hypothesis test on the interactions between covariates and treatment assignment on a regression predicting attrition (Gerber and Green, 2012) $(p=0.28)$. A balance check finds that the groups

\footnotetext{
${ }^{11}$ Recordings were not captured for a small number of participants due to a coding error, so we rely solely on their self-reports for these cases.
} 
who began a conversation in each condition were generally similar on baseline political covariates (see Table OA1). This balance check did find that men were slightly over-represented in the Aware - Non-Political condition, perhaps indicating that men were especially interested in having the Aware - Non-Political relative to the Placebo conversation; however, gender is not a significant predictor of our outcomes and we find similar effect estimates for men and women on the items where we did find effects.

\section{Estimated Treatment Effects}

Figure 1 shows the results of Study 1. The results are grouped into subfigures by substantive outcome area. The leftmost column in each subfigure shows the outcome variable being estimated. The next column indicates whether the outcome was measured immediately after the conversation or in the follow-up survey we conducted approximately three months afterward. The center of the plot shows the point estimate for the effect of the Aware - Non-Political condition, with estimates surrounded by standard errors (thick lines) and 95\% confidence intervals (thin lines). Finally, the rightmost column shows the adjusted $p$-values; as described above, these are adjusted using Anderson's (2008) False Discovery Rate correction procedure. All variables are oriented such that positive coefficients correspond with the expected direction of the effects.

Appendix Table OA3 provides the precise numerical results and the categorization of each outcome (as, e.g., primary, secondary, etc.). Table OA5a shows the raw means of the primary outcomes by condition.

Manipulation checks. Figure 1a shows the results on the manipulation check items. As the Aware - Non-Political condition only differed from the Placebo condition by informing participants that they were talking with an outpartisan, the main manipulation check of interest was an item asking participants if they thought they just spoke to an outpartisan. Reassuringly, we found large effects on this item $\left(d=0.81, p_{\text {adjusted }}=0.001\right)$, indicating that the manipulation was successful.

We also found that participants in both conditions were similarly likely to talk about their 
Figure 1: Study 1 Results

(a) Manipulation Checks

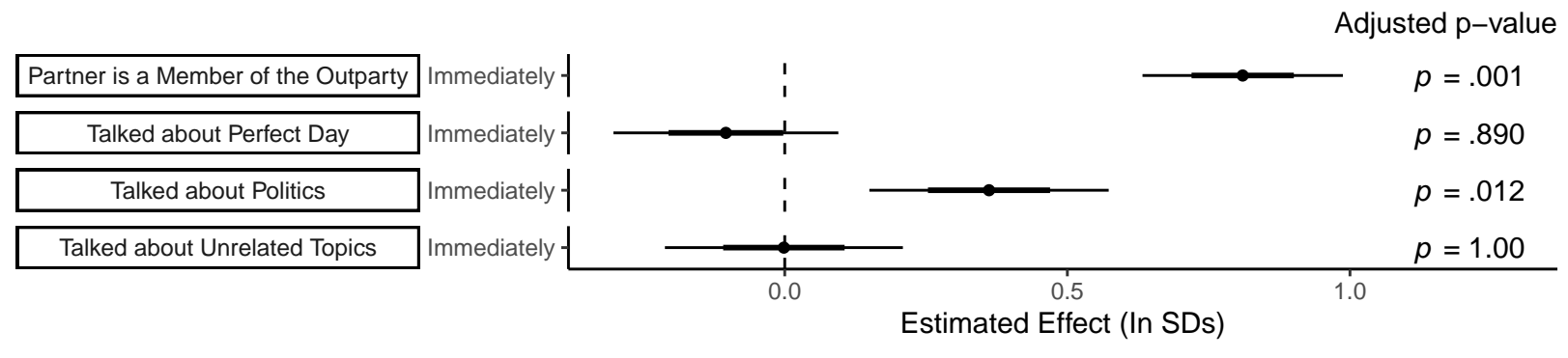

(b) Intergroup Prejudice Outcomes

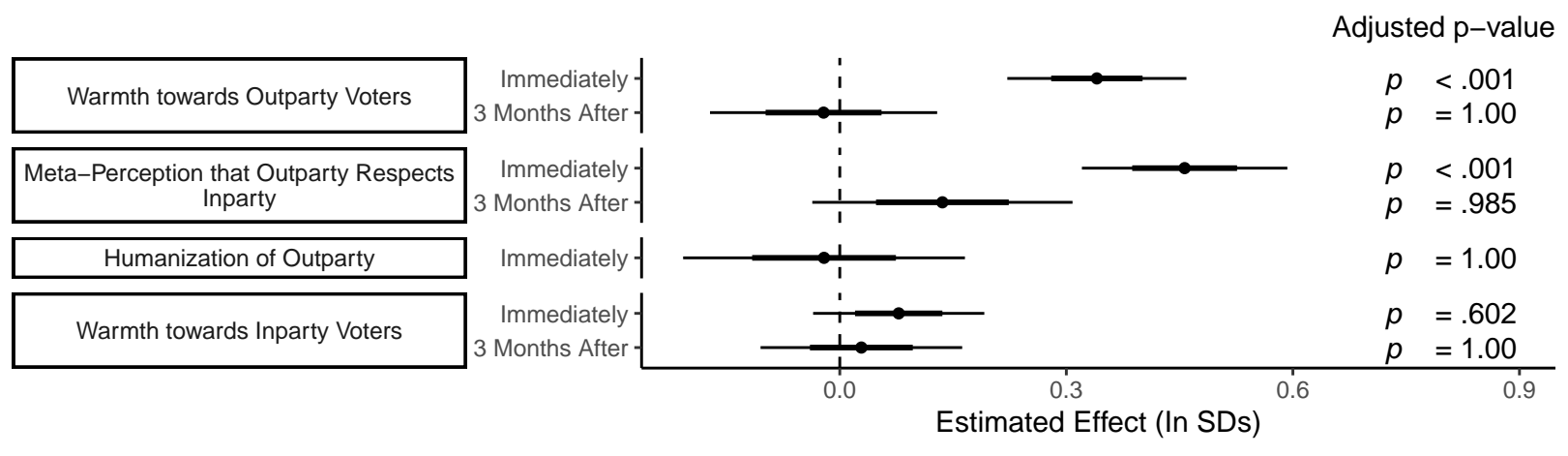

(c) Outcomes Relevant to Democratic Accountability

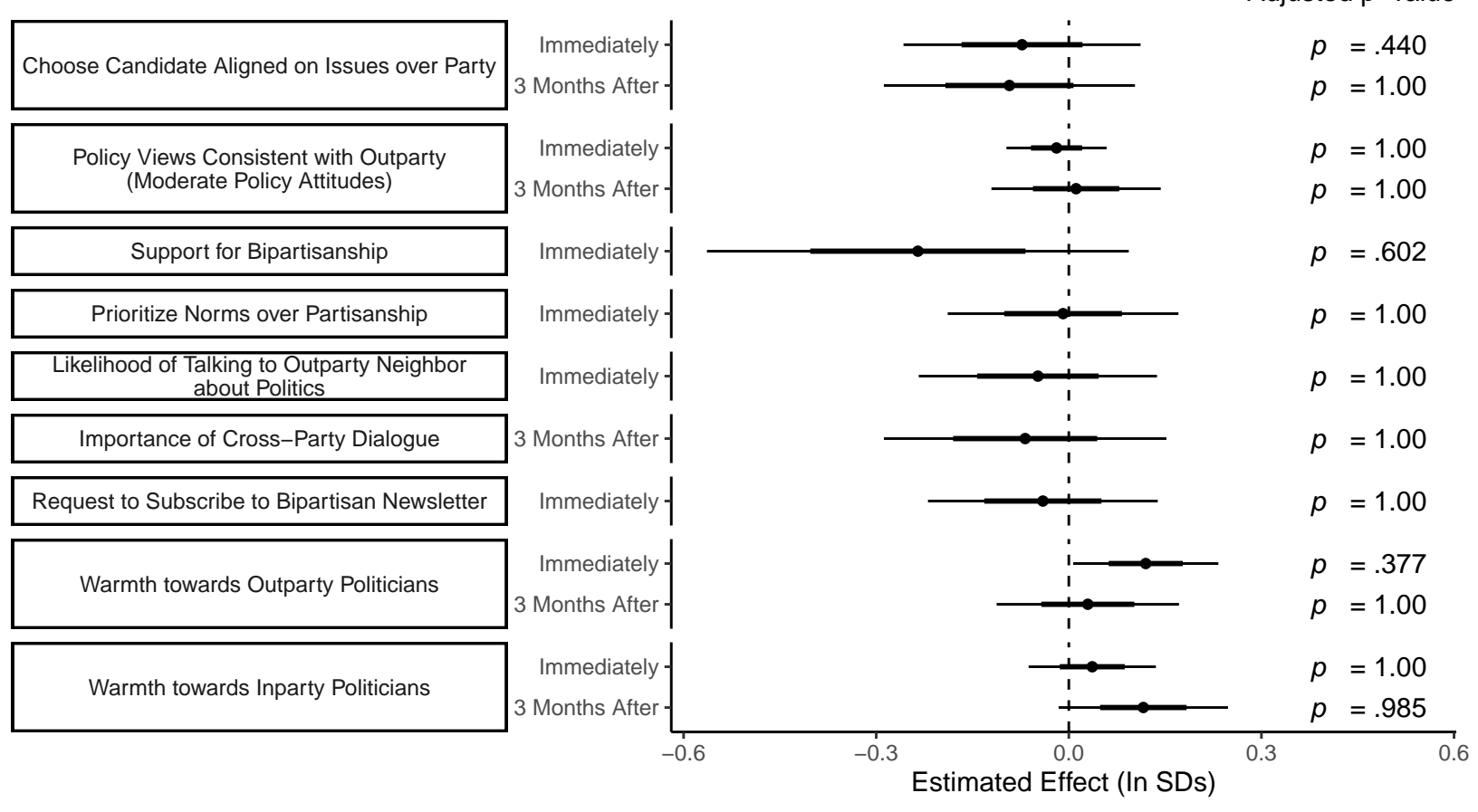

Notes: Points show the estimated effects of the Aware - Non-Political condition (relative to the placebo condition) in Study 1. Standard errors (thick lines) and 95\% confidence intervals (thin lines) surround the point estimates. Adjusted p-values are across all tests besides the primary outcomes using the procedure outlined in Anderson (2008). See Table OA3 for numerical results. 
perfect day and similarly likely to talk about unrelated topics, suggesting that treatment is not confounded with following the assigned conversation topics.

Though all participants were told to talk about their perfect day, participants in the Aware Non-Political condition were more likely to say they had talked about politics $\left(p_{\text {adjusted }}=0.012\right)$, but only $24 \%$ somewhat or strongly agreed that they did so.

Intergroup prejudice (e.g., affective polarization). Figure $1 \mathrm{~b}$ shows the estimated effects of the Aware - Non-Political condition on intergroup prejudice (e.g., affective polarization).

The first row in Figure $1 \mathrm{~b}$ shows the estimated effects on our primary outcome of interest and most direct measure of affective polarization, warmth towards outparty voters. We find that assignment to the Aware - Non-Political condition caused a sizable increase in warmth towards outparty voters $(d=0.34, p<0.0001)$. In terms of thermometer degrees, this is an effect of 9 degrees, meaning that the conversations reduced the equivalent of over two decades of increase in affective polarization, as chronicled by Iyengar, Sood and Lelkes (2012). ${ }^{12}$ However, the next row shows that this large reduction in affective polarization completely evaporated in our three-month follow-up survey $\left(d=-0.02, p_{\text {adjusted }}=1\right)$.

The second group of rows shows that the Aware - Non-Political condition also dramatically increased meta-perceptions of respect: participants in the treatment group were much more likely to think that outpartisans respected members of their own party $\left(d=0.45, p_{\text {adjusted }}=0.001\right)$. The next row shows that this result does not persist in our three-month follow-up, however.

We found no effect on a different secondary outcome, humanization of the outparty ${ }^{13}$

Finally, we found no effect on warmth towards inparty voters, a tertiary outcome; this shows that the Aware - Non-Political condition did not simply increase positive affect generally, and indicates that there are effects on affective polarization defined as outparty warmth minus inparty

\footnotetext{
${ }^{12}$ The total increase in affective polarization Iyengar, Sood and Lelkes (2012, Table A1) observe in the three decades from 1978 to 2008 is 15.35 degrees for Democrats and 10.16 degrees for Republicans, for an average of 12.76. The effect size we estimate is two-thirds this size.

${ }^{13}$ This might be due to a ceiling effect, as participants across conditions already rated outpartisans a 78 out of 100 , where 100 is the most humanized.
} 
warmth, as we found effects on the former but not the latter.

Outcomes Relevant to Democratic Accountability. Figure $1 \mathrm{c}$ shows the estimated effect of the Aware - Non-Political condition on the outcomes we measured relevant to democratic accountability. As described above, these outcomes span a broad range, reflecting the broad range of negative impacts scholars have worried affective polarization might have for democracy-impacts many therefore hope that cross-partisan conversations might ameliorate.

The results in Figure 1c, however, are consistently null. Across all nine outcomes, we find no evidence that assignment to the Aware - Non-Political condition improved outcomes relevant to democratic accountability: we found no evidence that having a cross-partisan conversation caused individuals to be more likely to prioritize issue agreement over partisanship when selecting a candidate; to embrace policy views associated with the outparty; to support legislative bipartisanship; to avoid voting for copartisan candidates who violated democratic norms; to express openness to talk to outpartisans about politics; to say that it is important for outpartisans to discuss politics; or to seek out more level media coverage. One item in this area achieved statistical significance at conventional levels (warmth towards outparty politicians), but this estimate was not significant after adjusting for multiple comparisons ( $p_{\text {unadjusted }}=0.039, p_{\text {adjusted }}=0.377$ ) and returned to baseline in the long-term follow-up. We also did not find effects on warmth towards inparty politicians in either the short- or long-term.

Overall, then, despite the large decreases in affective polarization (i.e., large increases in warmth towards outpartisans) we found, we find no evidence that these increases had knock-on effects for outcomes relevant to democratic accountability.

Potential Mechanisms and Moderators. Appendix Figure OA2 reports results from our tests for potential mechanisms and moderators.

Regarding mechanisms, we found suggestive evidence that the Aware - Non-Political condition caused participants to see the outparty as more similar, consistent with our theoretical reasoning. Although the point estimate was large, this result was marginally significant at conventional levels 
before adjusting for multiple comparisons and not after doing so $\left(d=0.18, p_{\text {unadjusted }}=0.050\right.$, $\left.p_{\text {adjusted }}=0.377\right)$. We do not perform a formal test for mediation because the sequential ignorability assumption would not be plausible in this context (Bullock, Green and $\mathrm{Ha}, 2010)$, but future research could seek to manipulate this mediator with additional conditions to more conclusively determine its role.

We also saw some directional evidence that the items from the receptiveness to opposing views index (Minson, Chen and Tinsley, 2020) moderated the effect of the Aware - Non-Political condition, although this was not statistically significant. ${ }^{14}$

\section{Summary of Study 1}

In summary, Study 1 found that cross-partisan conversations about a non-political topic can dramatically reduce affective polarization, and boost respect meta-perceptions (or the perception that the outparty respects members of the inparty). However, consistent with our argument about the short-term nature of these effects, we found that these effects decayed. Moreover, consistent with our argument that the effects would be circumscribed within the political domain, we also found that, even in the short term, the conversations did not appear to have positive knock-on effects for a broad range of attitudes relevant to democratic accountability. These effects may have arisen due to increases in perceived similarity, although our evidence on the mechanism responsible was inconclusive.

Study 1 left open several questions, including about the potentially conditional nature of these

\footnotetext{
${ }^{14}$ In response to feedback, we also conducted several post hoc tests for moderation of the effects on warmth towards outparty voters, none of which found significant evidence. First, we found no evidence that effects were larger when participants were paired with a conversation partner of the same demographics (race, ethnicity, or gender). In fact, we found that being paired with a participant from a different gender identity may have led to larger effect on outparty warmth (interaction $p_{\text {unadjusted }}=0.039$ ). Second, we found similar effects among Democratic and Republican respondents (see also Appendix Figure OA7). Finally, we found some evidence that the effects were largest among participants who felt most negatively towards the outparty at baseline. This result is not statistically significant, but indicates that the salutary effects on warmth towards outparty voters are not driven by simply strengthening pre-existing positive affect; the effects are, if anything, largest for those who have the most negative views of outpartisans to begin with.
} 
effects, which we investigate in Study 2.

\section{Study 2}

Study 2 builds on Study 1 in two important ways. First, Study 2 had two additional treatment conditions in addition to the conditions in Study 1. As discussed above, while the treatment condition in Study 1 encouraged a non-political conversation, Study 2's new conditions were inspired by the observation that many 'depolarization' groups encourage partisans to explicitly discuss group divides, i.e., discussing salient differences between groups (rather than, e.g., issues where there is substantial cross-partisan agreement) ${ }^{15}$ However, inspired by research regarding the potential pitfalls of such discussions (Paluck, 2010), we hypothesized that this might undermine the potential for cross-partisan conversations to reduce prejudice. To test this hypothesis, we included a Aware Positive Political condition, in which participants discussed why they identify with their own party, and a Aware - Negative Political condition, in which participants discussed why they do not identify with the other party. These conditions are elaborated below. Second, Study 2's participants were recruited with Facebook ads (Zhang et al., 2020), providing a more representative sample.

\section{Research Design}

We recruited participants to Study 2 in 2021. Online Appendix Figure OA3 summarizes the methods and exclusions in the first half of Study 2; as described below, we updated the technology setup (mirroring Study 1) halfway through Study 2, and so Figure OA1 describes the second half of Study 2.

\footnotetext{
${ }^{15}$ See, e.g., livingroomconversations.org braverangels.org and https:// openmindplatform.org/
} 


\section{Screener}

Participants were first recruited via Facebook ads to a screener survey. In this screener, we asked participants a suite of measures to assess political beliefs (party identification, political ideology, political knowledge), baseline scores for several outcome measures (see below), moderators (see below), demographics (age, education, gender, race and ethnicity, residency, citizenship), their interest and availability to do a video study, system compatibility, and their contact information.

We screened out those who were not interested in having a conversation or did not say they were available; identified as an Independent; were Democrats who failed an IP validation logic and failed the compatibility check; or, were Republicans and were not on their phones, had a duplicate IP address or email address, or had an invalid email address. Of these, we assigned participants to a time window they were available. We sent participants an email and text indicating the day and time the conversation survey would take place, and reminded them the day of.

Before beginning the conversation survey, we filed a pre-registration.

\section{Conversation Survey}

The conversation survey proceeded in a similar manner to Study 1. After consenting, participants then were told they would be soon entering a video call platform, AllSides, where they were to have a 10 minute conversation with someone also taking the survey.

Experimental Conditions and Random Assignment. Table 1 gives an overview of the experimental conditions in Study 2 and how they compare to the conditions in Study 1. As in Study 1, Study 2 had the Placebo condition, where participants were matched with an outpartisan to talk about their perfect day, but were not told they were matched with an outpartisan, and a Aware - Non-Political condition, where they were informed that they were discussing their perfect day with an outpartisan. We also added two new conditions to Study 2. First, in the Aware - Positive Political condition, we instructed participants to talk with each other about why they were a mem-

\footnotetext{
${ }^{16}$ Our pre-registration is available at https : / / aspredicted. org/blind.php? $\mathrm{x}=43 \mathrm{v} 3 \mathrm{vh}$.
} 
ber of the party that they were ${ }^{17}$ Second, in the Aware - Negative Political condition, participants discussed why they did not identify with the other party ${ }^{18}$

We employed the same matching procedures as Study 1. However, before we deployed updates to the software halfway through Study 2, if participants were in any of the treatment conditions, we told them they would be having a conversation with an outparty member (though they were not told about what) in the survey itself prior to them clicking the link (instead of using a landing page); the remainder of the participants were told the party of the partner (if in the treatment condition), and the conversation prompt, on the landing page after clicking on the link (as happened in Study 1).

After having the conversation or waiting for at least 5 minutes for a partner to arrive, participants were told to continue with the survey (they could only advance after 5 minutes). After indicating whether or not the conversation happened, participants then took a series of measures, detailed below. At the end, participants were debriefed and thanked.

\section{Outcome Variables and Other Measures}

Study 2 included several outcome variables also asked in Study 1 in an identical manner; for brevity, we only list them here: perception that partner is a member of the outparty, whether they talked about the perfect day, whether they talked about politics (manipulation checks); warmth towards outparty voters, meta-perception that outparty respects inparty, warmth towards inparty voters (intergroup prejudice outcomes); importance of cross-party dialogue, policy views consistent with outparty, prioritize norms over partisanship, warmth towards outparty politicians, and warmth towards inparty politicians (outcomes relevant to democratic accountability).

Study 2 included three outcome measures not included in Study 1. The first two outcomes were

\footnotetext{
${ }^{17}$ The exact prompt was "If you feel closer to the Democratic Party, what do you like about the Democratic Party? If you feel closer to the Republican Party, what do you like about the Republican Party?"

${ }^{18}$ The exact prompt was "If you feel closer to the Democratic Party, what do you not like about the Republican Party? If you feel closer to the Republican Party, what do you not like about the Democratic Party?"
} 
in the intergroup prejudice category. First, we formed an index of three measures of comfort with outpartisans (social distance): how upset (not at all upset to extremely upset) participants would feel if their son or daughter married a member of the outparty and how comfortable they were of having outparty friends and neighbors (not at all comfortable to extremely comfortable) (Iyengar, Sood and Lelkes, 2012).

Second, participants were asked if they felt respected by their partner, i.e., "My partner respected me," "My partner respected my feelings," "My partner did not respect my opinions" (reverse-scored) from "strongly disagree" to "strongly agree" Santoro and Markus (adapted from 2021). We created an additive index from the three items. ${ }^{19}$

The third new outcome was categorized as an outcome relevant to democratic accountability, whether participants expressed a behavioral intention to engage with outparty. We measured this with three items: participants were asked to indicate the extent to which they would be interested in having another conversation with a member of the outparty, if they would learn from such a conversation, and of the participants who indicated they had a conversation, if they would be interested in meeting up with their partner again. An index was formed with all three items.

Moderators. Study 2 also contained several additional pre-registered moderators measured prior to the conversation: extroversion and openness to experience (Gosling, Rentfrow and Swann Jr. 2003); frequency of previous political conversation with the outparty (measured as in Study 1); self-monitoring (Snyder, 1974); and a political knowledge index (Zaller, 1992).

Mechanism Measures. After the conversations, Study 2 also collected three pre-registered potential mediators: anxiety during the conversation (an additive index was formed of five items that asked the extent to which participants felt "nervous", "tense", "worried", "threatened", "anxious"; (based in part on Watson, Clark and Tellegen, 1988), whether people felt listened to by their partner (an additive index was formed of four items that asked the extent to which participants agreed they felt "listened to", "heard", "understood", and "seen"; we formed an additive index),

\footnotetext{
${ }^{19}$ Though we pre-registered this item as a mechanism, we categorize this as an intergroup measure in our analysis.
} 
and warmth felt towards their partner ("How do you feel towards your conversational partner? Please rate your feelings on a scale of 0 to 100 , where 0 means the most unfavorable / cold, and 100 means the most favorable / warmest.").

We asked the manipulation check items, the mechanism items, one behavioral intention item, and the respect items of the participants who indicated they had a conversation.

\section{Analytical approach}

We used the same analytical approach as detailed in Study 1: we used linear regressions with indicators for treatments $\mathrm{s}^{20}$ and clustered standard errors (Gerber and Green, 2012): ${ }^{21}$ we follow the same approach for adjusting our $p$-values for multiple comparisons (Anderson, 2008); and we again rescaled all dependent variables to standard deviation one, so all estimates we report are in standard deviations.

Exclusions. We employed the same exclusions as in Study 1 with the following exceptions: we use whether participants clicked the survey page where the link appeared, rather than appearing on the landing page, to help determine whether a participant was treated; we excluded a small number of participants who were paired with partners in a different treatment condition due to a coding error; and we excluded participants who had participated in a logistical pilot we conducted and we allowed to participate in the full conversation survey erroneously.

We determined all of these exclusion criteria seeking to be as consistent as possible with Study 1. Figures $\mathrm{OA} 1$ and $\mathrm{OA} 3$ provide a graphical overview of the recruitment process and exclusion criteria.

\footnotetext{
${ }^{20}$ The placebo condition served as a referent. Figure OA6 reports the comparison between the Aware - Positive Political vs. Aware - Negative Political conditions, as registered. Finally, in post-hoc tests discussed below and reported in Figure OA5, we collapsed across the two political conditions and compared them to the Aware - NonPolitical and placebo conditions.

${ }^{21}$ The covariates are the baseline value of the variable where available, age, education, gender, race/ethnicity, party identification, and ideology (the last three were added post-hoc to be consistent with Study 1).
} 


\section{Study 2 Results}

\section{Sample Characteristics}

$N=2,540$ participants completed the screener. $N=833$ began the conversation survey. Finally, $N=338$ participants were able to successfully begin a conversation. Table OA2 shows the demographics of the sample at each stage. As determined by the recordings, the Placebo conversations lasted a median of 13.4 minutes; the Aware - Non-Political conversations lasted a median of 13.6 minutes; the Aware - Positive Political conversations lasted a median of 13.7 minutes; and the Aware - Negative Political conversations lasted a median of 17.9 minutes. That participants spent more time speaking in the Aware - Negative Political condition is consistent with our expectation that participants would have an easier time speaking about what they did not like about the other party than what they liked about their own.

Reversing the pattern found in Study 1, participants in the Placebo condition were directionally more likely to have a conversation compared to those in the Aware - Non-Political condition ( $p=.547)$, and participants in the Aware - Negative Political condition were less likely to have a conversation compared to the placebo condition $(p=.034)$; but there was no evidence of difference in attrition by condition overall $(F(603)=1.63, p=.181)$. There was also no evidence of differential attrition by covariates, as assessed by a joint hypothesis test on the interactions between covariates and treatment assignment on a regression predicting attrition (Gerber and Green, 2012) $(p=.731)$. Finally, Table OA2 shows that baseline covariates were balanced among the experimental groups.

\section{Estimated Treatment Effects}

Figure 2 shows Study 2's results. The results are grouped into subfigures by substantive outcome area. The leftmost column in each subfigure shows the outcome variable being estimated. The next column indicates which condition's effects are being estimated (always relative to the 
Placebo condition). The center of the plot shows the point estimate for the effect of each condition relative to the placebo group, with estimates surrounded by standard errors (thick lines) and 95\% confidence intervals (thin lines). Finally, the rightmost column shows the adjusted $p$-values; as described above, these are adjusted using Anderson's (2008) False Discovery Rate correction procedure. Except for the manipulation checks (where predictions go in opposite directions for different conditions), all variables are oriented such that positive coefficients correspond with the expected direction of the effects.

Appendix Table $\mathrm{OA} 4$ provides the precise numerical results and categorizes the outcomes by whether they are primary, secondary, etc. Table OA5b shows the raw means of the primary outcomes by condition.

Manipulation checks. First, Figure 2a shows the effects of each condition on the manipulation checks. The results indicate that the manipulations were broadly successful. As expected, participants in the Aware - Positive Political and Aware - Negative Political conditions were aware they were talking with an outpartisan. These effects dwarfed that of the Aware - Non-Political condition, which, although directionally in the right direction, did not reach statistical significance after adjusting for multiple comparisons $\left(p_{\text {unadjusted }}=0.049, p_{\text {adjusted }}=0.246\right)$. In addition, participants appeared to comply with their assigned conversation topics: those in the Aware - Non-Political condition were similarly likely as those in the Placebo condition to talk about their perfect day (the topic assigned to both conditions), whereas those in the Aware - Positive Political and Aware - Negative Political conditions were much less likely to say so. By contrast, those in the Placebo and Aware - Non-Political conditions were similarly likely to say they talked about politics, but participants in the Aware - Positive Political and Aware - Negative Political conditions were much more likely to say they talked about politics.

Intergroup prejudice. Next, Figure $2 \mathrm{~b}$ shows the results on intergroup prejudice. Similar to Study 1, we found large, positive effects of the Aware - Non-Political condition versus Placebo on warmth towards the outparty $(d=0.41, p<0.001)$. However, neither political condition had 
Figure 2: Study 2 Results

(a) Manipulation Checks

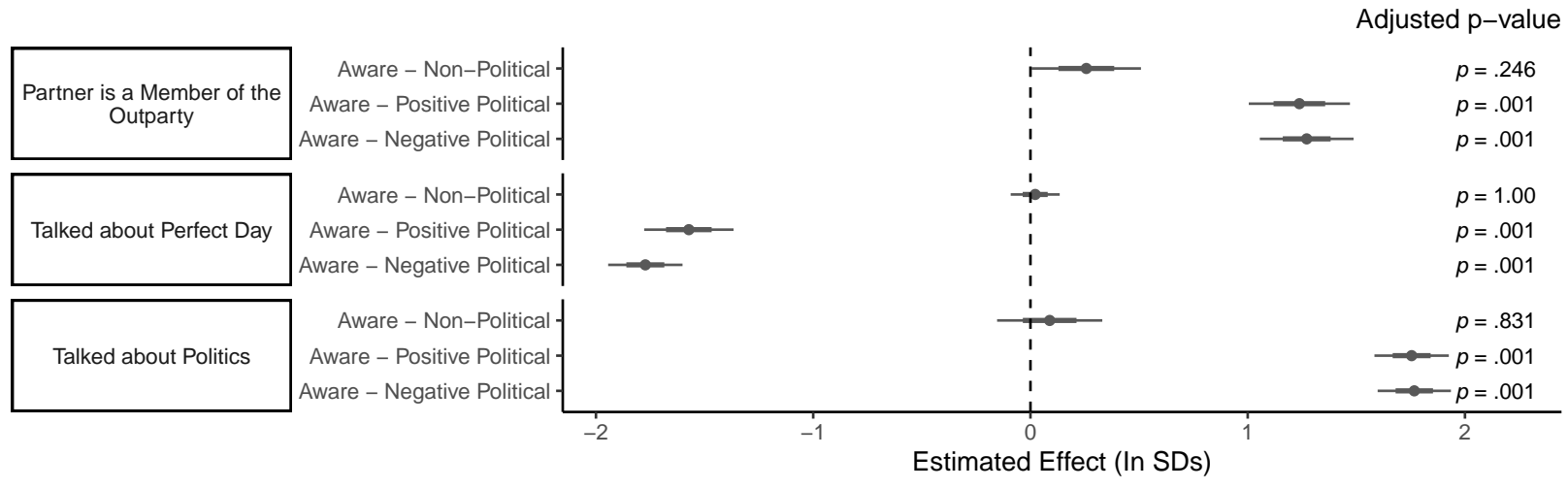

(b) Intergroup Prejudice Outcomes

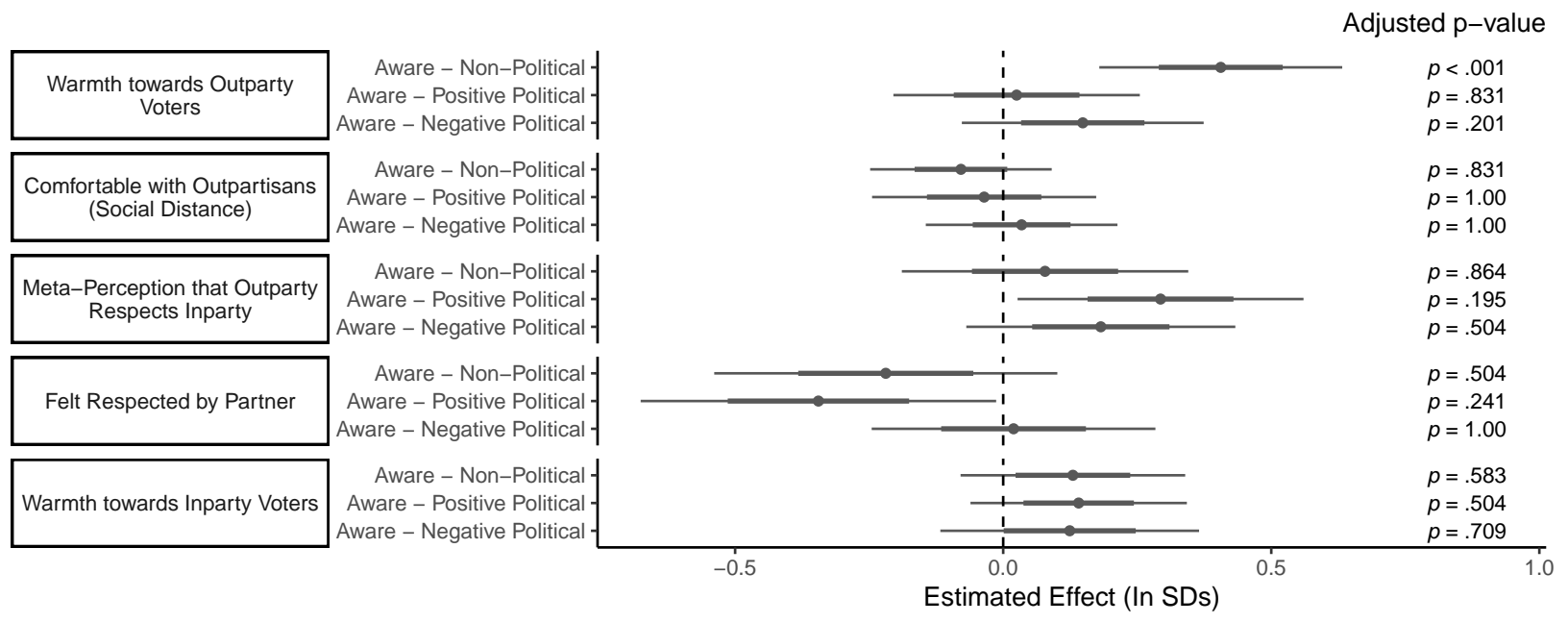

(c) Outcomes Relevant to Democratic Accountability

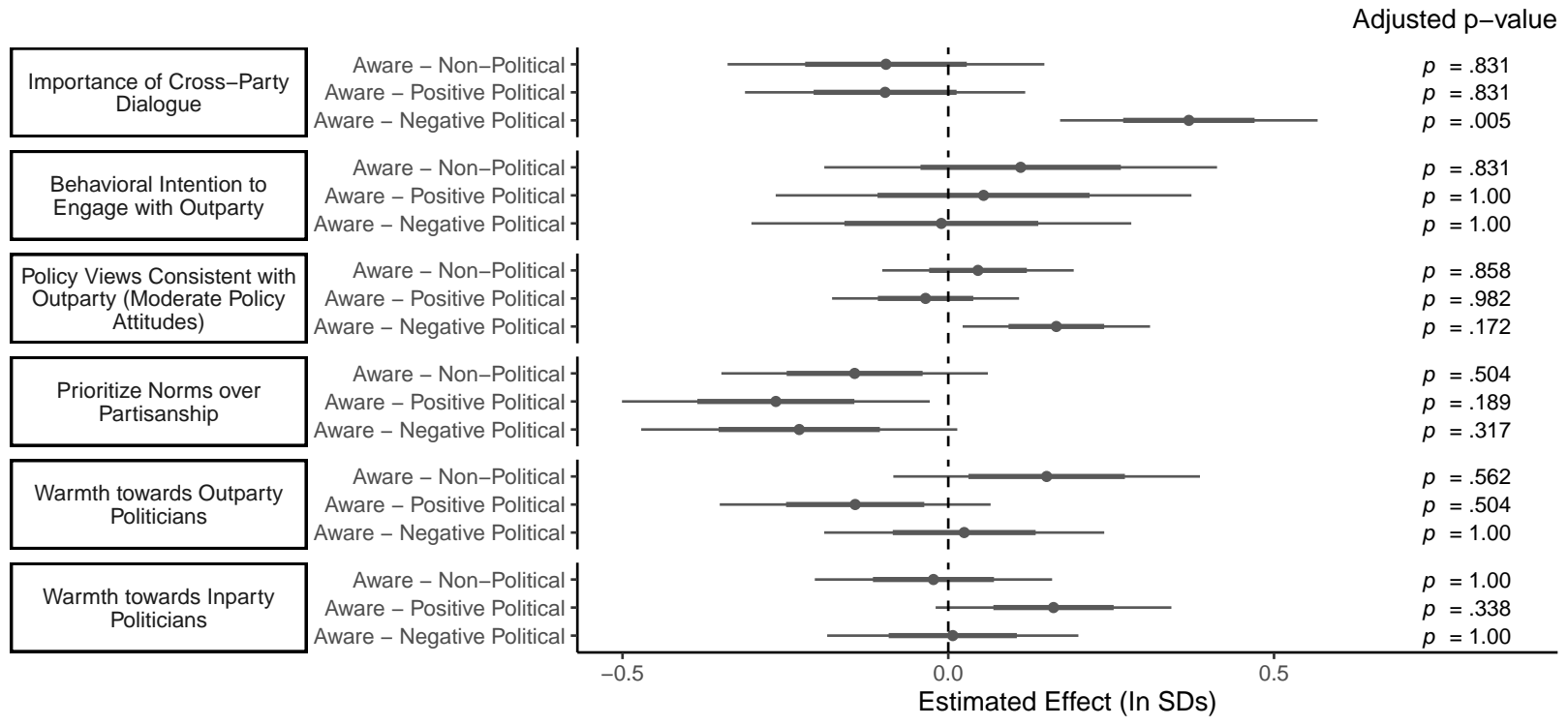

Notes: Points show the estimated effects of each of the conditions (shown on the y-axis labels) relative to the placebo condition in Study 2. Stgindard errors (thick lines) and $95 \%$ confidence intervals (thin lines) surround the point estimates. Adjusted p-values are adjusted across all nonprimary outcomes using the procedure outlined in Anderson (2008). As described in the text, p-values for primary outcomes are not adjusted. 
statistically significant effects on outparty warmth.

Moreover, we can statistically distinguish the effects of the Aware - Non-Political condition from the political conditions. Figure OA5 shows that while mean warmth towards outparty voters in the political conditions does not differ from Placebo $\left(p_{\text {adjusted }}=0.40\right)$, it is significantly lower than in the Aware - Non-Political treatment group ( $\left.p_{\text {adjusted }}=0.015\right)$. This indicates that the discussions of group divides reduced the effects of the conversations on affective polarization, possibly to zero.

No other measure of intergroup prejudice reached significance after correcting for multiple hypothesis testing, including the meta-perception that the outparty respects one's own party $(d=$ $\left..08, p_{\text {unadjusted }}=.573, p_{\text {adjusted }}=.994\right)$, although the point estimates on these items were also not significantly different than the significant effects we found in Study 1.

Outcomes relevant to democratic accountability. Similar to Study 1, we found consistently null results on outcomes relevant to democratic accountability, with one exception.

We found null results on behavioral intentions to engage with the outparty, on holding policy views consistent with the outparty, on prioritizing norms over partisanship when voting, and on views towards outparty politicians.

Surprisingly, there were limited exceptions to this pattern of null results for the Aware - Negative Political condition. First, this condition increased perceptions regarding the importance of cross-partisan dialogue, a secondary outcome. This result remains highly significant even after correcting for multiple comparisons $\left(d=0.37, p_{\text {unadjusted }}<0.001, p_{\text {adjusted }}=0.005\right)$. We also found suggestive evidence that this condition may have reduced attitudinal polarization by causing voters to express policy views more consistent with the outparty (i.e., that were more moderate); this result invites replication as it was not significant after multiple comparison adjustments $\left(d=0.17, p_{\text {unadjusted }}=0.03, p_{\text {adjusted }}=0.17\right)$. The point estimate on the effect of the Aware Negative Political condition on outparty warmth was also positive, although far from significance $(d=0.15, p=0.201)$. Although preliminary, these counterintuitive results are consistent with our 
motivations for including the Aware - Negative Political condition: respondents may be more open to discussing pitfalls of the political parties than their virtues (see also Klar and Krupnikov, 2016). We return to this in the discussion section.

Mechanisms. Appendix Figure OA4a shows our findings for potential mechanisms and moderators. We generally find no evidence for any of our posited mechanisms: anxiety during the conversation, warmth towards one's conversation partner, or feeling listened to by one's partner. This suggests that the potential mechanism we identified in Study 1, perceived similarity, may be most worthy of future research. One exception to the pattern of null results on mechanisms in Study 2 is that we found evidence of a negative effect of the Aware - Positive Political condition on feeling listened to in the conversation. This result survives a multiple comparison adjustment $\left(d=-0.67, p_{\text {unadjusted }}<0.001, p_{\text {adjusted }}=0.004\right)$.

Moderation. Appendix Figure OA4b finds no significant evidence of moderation across any of the pre-registered moderators, except for one marginally significant negative interaction between extroversion and the Aware - Positive Political condition.

\section{Summary of Study 2}

Study 2 extended Study 1's results in a more representative sample and with two new conditions that involved discussing group divides (over partisanship and politics). Overall, Study 1 replicated the promise of non-political discussions across partisan lines, finding that such conversations dramatically increased warmth towards outpartisans. On the other hand, supporting our argument about how the effects of cross-partisan conversation are conditional on conversation topic (in particular whether group divides are the focus), political conversations about group divides had no effects, a difference we can statistically distinguish from the non-political conversations. Again supporting our argument regarding the circumscribed effects of non-political conversations, we also again found no downstream consequences of this increased warmth for outcomes relevant to democratic accountability. 
One potentially surprising pattern in the results of Study 2 is that the Aware - Negative Political condition appeared more promising than the Aware - Positive Political conditions across several metrics (see also Figure OA6). We found that those in the Aware - Negative Political condition spent more time talking to their partner, were more likely to say that cross-partisan conversations were important, and may have even expressed less polarized policy attitudes and greater warmth towards the outparty (the latter two which were not significant). We also found evidence that, by contrast, those in the Aware - Positive Political condition felt less listened to. Although the estimated effect of the Aware - Negative Political condition on warmth towards outpartisans was far from statistically significant $(d=0.15, p=0.20)$, this constellation of promising results suggests future research into this approach is warranted.

\section{Discussion}

As concern about affective polarization has grown among scholars, activists, and organizations, so has excitement about the potential of cross-partisan conversations to reduce it. However, the effects of such conversations remain theoretically ambiguous, and have been subject to relatively little prior research. We argued that cross-partisan conversations have potential to reduce intergroup prejudices, but that such one-shot interactions are likely to have short-term effects that decay, would be circumscribed within the interpersonal domain and not extend to democratic attitudes, and would be conditional on topic, diminishing if the conversations dwell on group divides. We presented two unique experiments supporting this argument in which we matched outpartisans to have face-to-face video conversations about randomly assigned topics.

Our results suggest several implications for efforts to reduce affective polarization and for research on intergroup prejudice and intergroup contact more generally. First, our findings both confirm the promise of and indicate limits of cross-partisan conversations: such conversations appear able to temporarily reduce prejudice against outpartisans, but may not lastingly shift it absent com- 
plementary manipulations. In light of a recent review finding that very few studies of intergroup contact both feature random assignment and track long-run effects (Paluck, Green and Green, 2019), our finding of immediate large effects followed by complete decay is notable. However, in light of other studies which have found that brief conversations can durably reduce prejudice when one conversation partner is trained in specific techniques (e.g., Kalla and Broockman, 2021a), our results point to the need for further study of the necessary conditions for conversations to reduce prejudice in a durable rather than evanescent manner.

Second, our findings question many scholars' and practitioners' assumption that interventions which reduce affective polarization will have salutary consequences for democratic accountability; we found no such effects, in line with other recent findings on the effects of other interventions (Broockman, Kalla and Westwood, 2020; Voelkel et al., 2021). This suggests that future research may wish to examine conversation prompts which more explicitly elicit discussion of political elites or democratic norms.

Third, consistent with field research in other domains (Paluck, 2010), our results suggest that explicit discussions of group divides may undermine the salutary effects of intergroup contact in the political domain. This finding complements those from other studies which find that highlighting unexpected interpartisan similarities can reduce multiple forms of polarization (e.g., Ahler, 2014, Ahler and Sood, 2018, Orr and Huber, 2020), as well as studies that find having partisans dwell on issues where there is likely to be agreement across parties can reduce polarization (e.g., Rossiter, 2021; Levendusky and Stecula, Forthcoming). Along these lines, our evidence suggested that conversations that avoided group divides may have increased perceived similarity.

Fourth, though, for practitioners who see normative value in having partisans discuss their differences, our findings regarding the impacts of having partisans discuss what they dislike about the other party (i.e., the Aware - Negative Political condition) were surprisingly promising. We thought that this condition might paradoxically make it easier for individuals to find common ground—as most individuals do not like their party particularly strongly—and provide participants 
with more to talk about—-since many do have reasons for disliking the other party. Consistent with this, we found that participants spent longer on these conversations than the other topics, and that they later were more likely to rate cross-partisan dialogue as important after having them. These findings resonate with research on the benefits of exposure to cross-cutting views (Mutz, 2002). Indeed, in a qualitative review of some of the conversation audio recordings, we found that many of the Aware - Negative Political conversations featured individuals agreeing with the criticisms or shortcomings that their conversation partner mentioned about their own party, which may have disconfirmed stereotypes about the other party's extreme views. In future research, we plan to measure perceptions of outparty similarity and further disentangle this potential mechanism.

Finally, our results point to the need for further experimentation on the necessary conditions for conversations to reduce prejudice generally. Other studies have found that brief conversations can durably reduce prejudice when one conversation partner is trained in specific conversational techniques (e.g., Kalla and Broockman, 2021a). For example, might approaches for making others feel listened to (e.g., Santoro and Markus, 2021; Itzchakov et al., 2020) or being more receptive (e.g., Yeomans, Schweitzer and Brooks, forthcoming; Yeomans et al., 2020) make the conversations more impactful or memorable? Or might more sustained engagement or the presence of a skilled moderator, do so? Such questions about whether it is possible to instruct laypeople to have more productive cross-partisan conversations than they are by default remain a question for future research. Relatedly, research will be necessary to understand how to scale these conversation. Although a number of non-profits have already had success rolling out interventions that include cross-partisan conversations, research is only beginning to understand how best to scale such interventions.

There are several limitations to our work. First, although face-to-face online conversations are important to study in their own right, our results might have differed if we had studied other mediums of conversations-such as phone conversations, in-person conversations, etc. Second, although we chose to study conversations between outpartisan strangers given this is the model 
adopted by most non-profits attempting to reduce affective polarization, it might be the case that our findings do not generalize to conversations between friends, co-workers, or relatives, and future research should explore this. This might also aid scalability. Third, future studies could benefit from more unobtrusive measures, such as behavioral measures. The null results of some conditions in Study 2 suggests that our positive results were not due to demand. However, although we asked some questions about behavioral intentions, and if respondents wanted to subscribe to a newsletter, what is possible in a survey context is inherently limited.

Taken together, we find that merely having a conversation about a non-political topic with an outpartisan reduces affective polarization. However, these results are short-term, and decay to effectively zero after three months; are circumscribed, and largely do not extend to democratic accountability; and conditional, shrinking substantially, potentially to zero, when the conversations broach group divides.

\section{References}

Ahler, Douglas J. 2014. "Self-fulfilling misperceptions of public polarization." The Journal of Politics 76(3):607-620.

Ahler, Douglas J and Gaurav Sood. 2018. "The parties in our heads: Misperceptions about party composition and their consequences." The Journal of Politics 80(3):964-981.

Allport, Gordon W. 1954. The Nature of Prejudice. Cambridge, MA: Addison-Wesley.

Amsalem, Eran, Eric Merkley and Peter John Loewen. 2021. "Does Talking to the Other Side Reduce Inter-party Hostility? Evidence from Three Studies." Political Communication 0(0):118.

Anderson, Michael L. 2008. "Multiple inference and gender differences in the effects of early 
intervention: A reevaluation of the Abecedarian, Perry Preschool, and Early Training Projects." Journal of the American statistical Association 103(484):1481-1495.

Aron, Arthur, Edward Melinat, Elaine N Aron, Robert Darrin Vallone and Renee J Bator. 1997. "The experimental generation of interpersonal closeness: A procedure and some preliminary findings.” Personality and social psychology bulletin 23(4):363-377.

Broockman, David E., Joshua L. Kalla and Sean Westwood. 2020. "Does Affective Polarization Undermine Democratic Norms or Accountability? Maybe Not." Working paper, available at https://osf.io/9btsq/.

Bullock, John G, Donald P Green and Shang E Ha. 2010. "Yes, but what's the mechanism?(don't expect an easy answer)." Journal of personality and social psychology 98(4):550.

Chen, M Keith and Ryne Rohla. 2018. "The effect of partisanship and political advertising on close family ties." Science 360(6392):1020-1024.

Coppock, Alexander. 2021. Persuasion in Parallel. Chicago Studies in American Politics Chicago: University of Chicago Press. Forthcoming.

Coppock, Alexander and Donald P. Green. 2021. "Do Belief Systems Exhibit Dynamic Constraint?" Journal of Politics .

Druckman, James N and Kjersten R Nelson. 2003. "Framing and deliberation: How citizens' conversations limit elite influence.” American Journal of Political Science 47(4):729-745.

Druckman, James N and Matthew S Levendusky. 2019. "What do we measure when we measure affective polarization?" Public Opinion Quarterly 83(1):114-122.

Enos, Ryan D. 2014. "Causal effect of intergroup contact on exclusionary attitudes." Proceedings of the National Academy of Sciences 111(10):3699-3704. 
Finkel, Eli J, Christopher A Bail, Mina Cikara, Peter H Ditto, Shanto Iyengar, Samara Klar, Lilliana Mason, Mary C McGrath, Brendan Nyhan, David G Rand et al. 2020. "Political sectarianism in America." Science 370(6516):533-536.

Gerber, Alan S and Donald P Green. 2012. Field experiments: Design, analysis, and interpretation. WW Norton.

Gosling, Samuel D, Peter J Rentfrow and William B Swann Jr. 2003. "A very brief measure of the Big-Five personality domains." Journal of Research in personality 37(6):504-528.

Harbridge, Laurel and Neil Malhotra. 2011. "Electoral incentives and partisan conflict in Congress: Evidence from survey experiments.” American Journal of Political Science 55(3):494-510.

Huber, Gregory A and Neil Malhotra. 2017. "Political homophily in social relationships: Evidence from online dating behavior." The Journal of Politics 79(1):269-283.

Itzchakov, Guy, Netta Weinstein, Nicole Legate and Moty Amar. 2020. “Can high quality listening predict lower speakers' prejudiced attitudes?” Journal of experimental social psychology 91:104022.

Iyengar, Shanto, Gaurav Sood and Yphtach Lelkes. 2012. "Affect, not ideology a social identity perspective on polarization." Public Opinion Quarterly 76(3):405-431.

Iyengar, Shanto, Yphtach Lelkes, Matthew Levendusky, Neil Malhotra and Sean J. Westwood. 2019. "The origins and consequences of affective polarization in the United States." Annual Review of Political Science 22:129-146.

Kalla, Joshua and David Broockman. 2021a. "Which narrative strategies durably reduce prejudice? Evidence from field and survey experiments supporting the efficacy of perspective-getting." American Journal of Political Science . 
Kalla, Joshua L. and David E. Broockman. 2021b. "Voter outreach campaigns can reduce affective polarization among implementing political activists." Working paper, available at https:// osf.io/5yahr/.

Klar, Samara and Yanna Krupnikov. 2016. Independent politics. Cambridge University Press.

Kteily, Nour, Emile Bruneau, Adam Waytz and Sarah Cotterill. 2015. "The ascent of man: Theoretical and empirical evidence for blatant dehumanization.” Journal of personality and social psychology 109(5):901.

Lees, Jeffrey and Mina Cikara. 2020. "Inaccurate group meta-perceptions drive negative out-group attributions in competitive contexts.” Nature Human Behaviour 4(3):279-286.

Levendusky, Matthew and Dominik Stecula. Forthcoming. We Need to Talk: How Cross-Party Dialogue Reduces Affective Polarization. Cambridge University Press.

Levendusky, Matthew S. 2018. "Americans, not partisans: Can priming American national identity reduce affective polarization?" The Journal of Politics 80(1):59-70.

Little, Andrew T., Keith Schnakenberg and Ian R. Turner. 2020. "Motivated reasoning and democratic accountability." Working paper, available at https://osf.io/preprints/ socarxiv/esfy6/.

MacInnis, Cara C and Elizabeth Page-Gould. 2015. "How can intergroup interaction be bad if intergroup contact is good? Exploring and reconciling an apparent paradox in the science of intergroup relations." Perspectives on Psychological Science 10(3):307-327.

Martherus, James L, Andres G Martinez, Paul K Piff and Alexander G Theodoridis. 2021. "Party animals? Extreme partisan polarization and dehumanization." Political Behavior 43(2):517540. 
McConnell, Christopher, Yotam Margalit, Neil Malhotra and Matthew Levendusky. 2018. "The economic consequences of partisanship in a polarized era." American Journal of Political Science 62(1):5-18.

Minson, Julia A, Frances S Chen and Catherine H Tinsley. 2020. "Why won't you listen to me? Measuring receptiveness to opposing views.” Management Science 66(7):3069-3094.

Mutz, Diana C. 2002. "Cross-cutting social networks: Testing democratic theory in practice." American Political Science Review 96(1):111-126.

Orr, Lilla V and Gregory A Huber. 2020. "The policy basis of measured partisan animosity in the United States." American Journal of Political Science 64(3):569-586.

Paluck, Elizabeth Levy. 2010. "Is it better not to talk? Group polarization, extended contact, and perspective taking in eastern Democratic Republic of Congo." Personality and Social Psychology Bulletin 36(9):1170-1185.

Paluck, Elizabeth Levy, Seth A Green and Donald P Green. 2019. "The contact hypothesis reevaluated." Behavioural Public Policy 3(2):129-158.

Pettigrew, Thomas F and Linda Tropp. 2006. “A Meta-Analytic Test of Intergroup Contact Theory.” Journal of Personality and Social Psychology 90(5):751-783.

Petty, Richard E and John T Cacioppo. 1986. "The elaboration likelihood model of persuasion." Advances in experimental social psychology 19:123-205.

Pierson, Paul and Eric Schickler. 2020. “Madison's Constitution Under Stress: A Developmental Analysis of Political Polarization.” Annual Review of Political Science 23:37-58.

Rossiter, Erin. 2021. "The Consequences of Interparty Conversation on Outparty Affect and Stereotypes." Working Paper, available at http://erossiter.com/files/ conversations.pdf. 
Santoro, Erik and Hazel Rose Markus. 2021. "How Do You Listen?: The Relationship Between How Men Listen and Women's Power and Respect in the US.'.

Schroeder, Juliana, Michael Kardas and Nicholas Epley. 2017. “The humanizing voice: Speech reveals, and text conceals, a more thoughtful mind in the midst of disagreement." Psychological science 28(12):1745-1762.

Sears, David O. 1983. “The person-positivity bias.” Journal of Personality and Social Psychology 44(2):233-250.

Snyder, Mark. 1974. "Self-monitoring of expressive behavior." Journal of personality and social psychology 30(4):526.

Voelkel, Jan G, James Chu, Michael Stagnaro, Joe Mernyk, Chrystal Redekopp, Sophia Pink, James Druckman, David Rand and Robb Willer. 2021. "Interventions Reducing Affective Polarization Do Not Improve Anti-Democratic Attitudes." Working paper, available at https: //osf.io/7evmp/.

Walton, Gregory M and Timothy D Wilson. 2018. "Wise interventions: Psychological remedies for social and personal problems.” Psychological review 125(5):617.

Warner, Benjamin R, Haley Kranstuber Horstman and Cassandra C Kearney. 2020. "Reducing political polarization through narrative writing." Journal of Applied Communication Research 48(4):459-477.

Watson, David, Lee Anna Clark and Auke Tellegen. 1988. "Development and validation of brief measures of positive and negative affect: the PANAS scales." Journal of personality and social psychology 54(6):1063.

Yeomans, Michael, Julia Minson, Hanne Collins, Frances Chen and Francesca Gino. 2020. “Con- 
versational receptiveness: Improving engagement with opposing views." Organizational Behavior and Human Decision Processes 160:131-148.

Yeomans, Michael, Maurice E. Schweitzer and Alison Wood Brooks. forthcoming. "The Conversational Circumplex: Identifying, Prioritizing, and Pursuing Informational and Relational Motives in Conversation.”.

Zaller, John R. 1992. The Nature and Origins of Mass Opinion. New York: Cambridge University Press.

Zhang, Baobao, Matto Mildenberger, Peter D Howe, Jennifer Marlon, Seth A Rosenthal and Anthony Leiserowitz. 2020. "Quota sampling using Facebook advertisements." Political Science Research and Methods 8(3):558-564. 


\section{ONLINE APPENDIX}

\section{A Appendix Figures and Tables}

Figure OA1: Summary of Study 1 and Study 2, Part 2 Methods and Exclusions

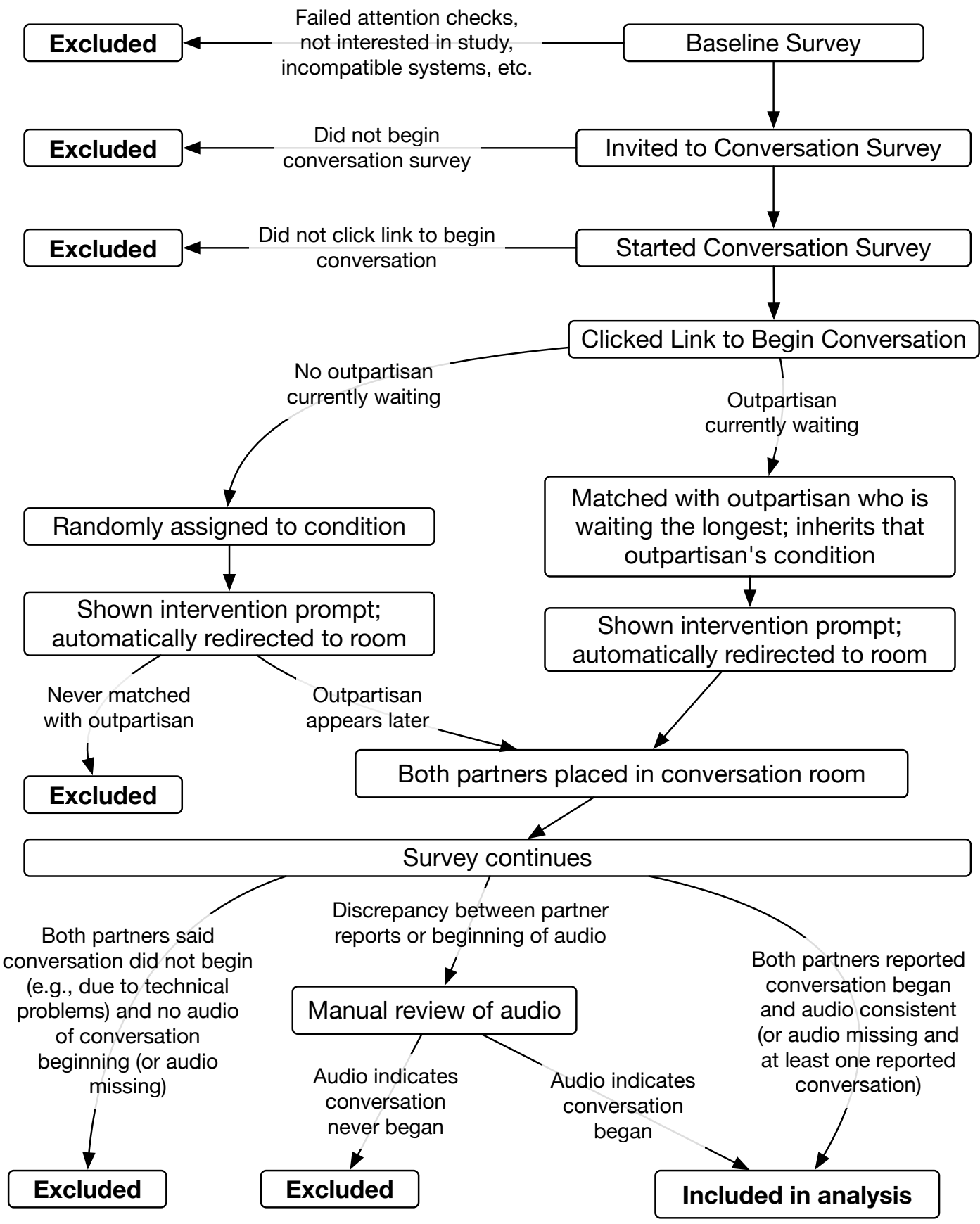


Figure OA2: Study 1: Additional Results

(a) Potential Mechanisms

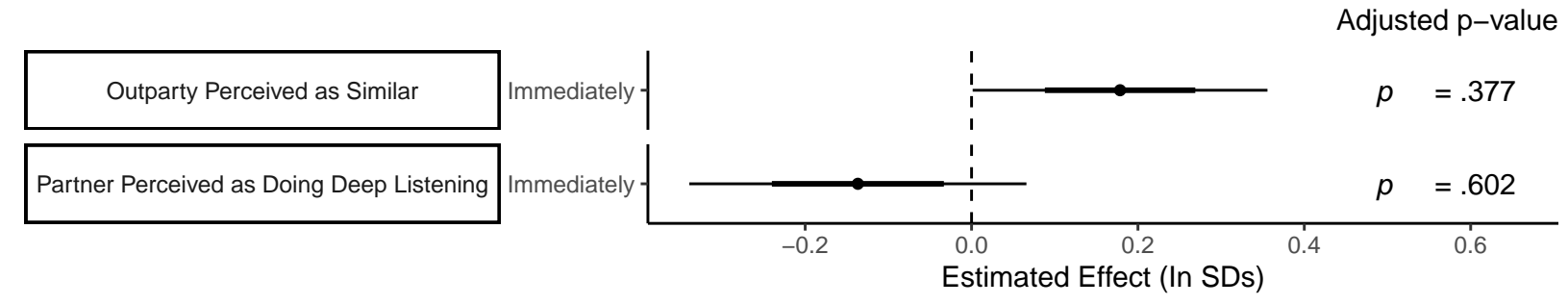

Notes: Points show the estimated effects of the Aware - Non-Political condition in Study 1. Standard errors (thick lines) and 95\% confidence intervals (thin lines) surround the point estimates. Adjusted p-values are adjusted across all measures besides the primary outcomes, which are not adjusted as described in the text.

(b) Moderators

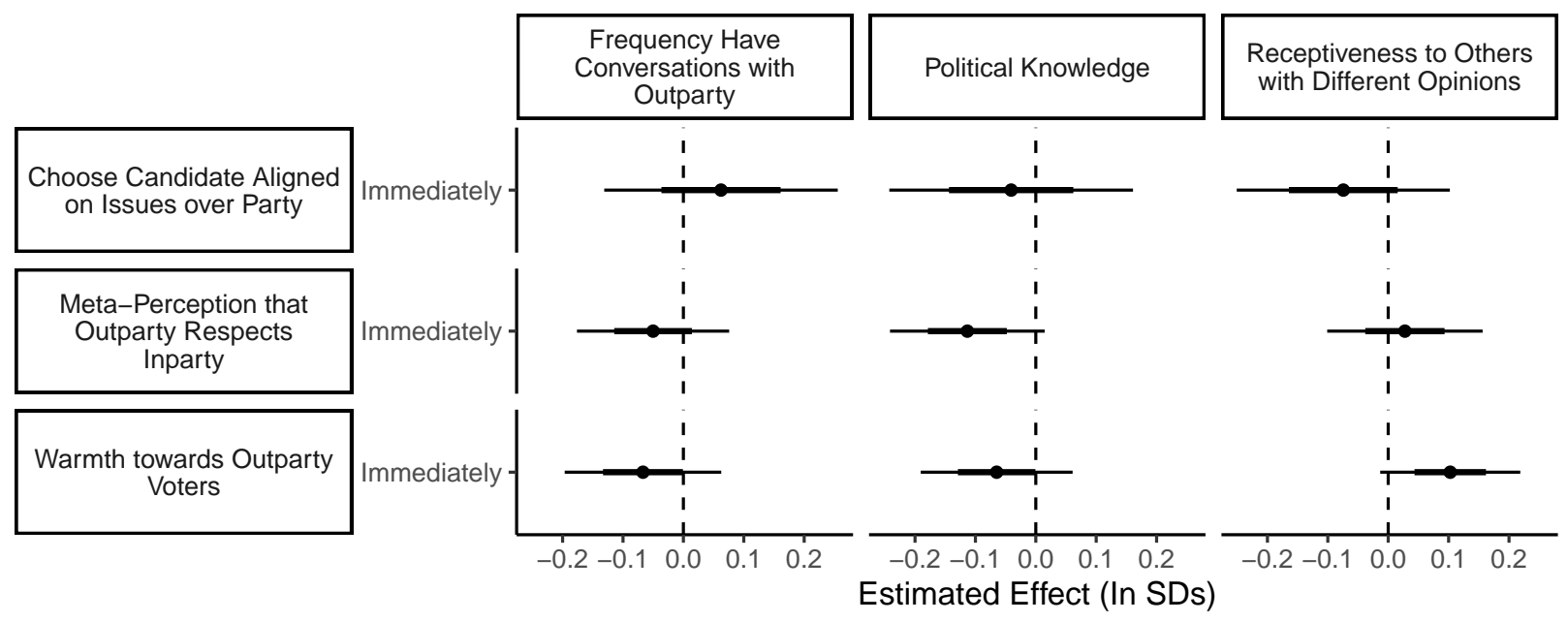

Notes: Points show the coefficient on an interaction term between the Aware - Non-Political condition and the moderator shown in the labels at top. The labels at right show the dependent variable. Standard errors (thick lines) and 95\% confidence intervals (thin lines) surround the point estimates. Adjusted p-values are adjusted among all non-primary hypothesis tests. 
Figure OA3: Summary of Study 2, Part 1 Methods and Exclusions

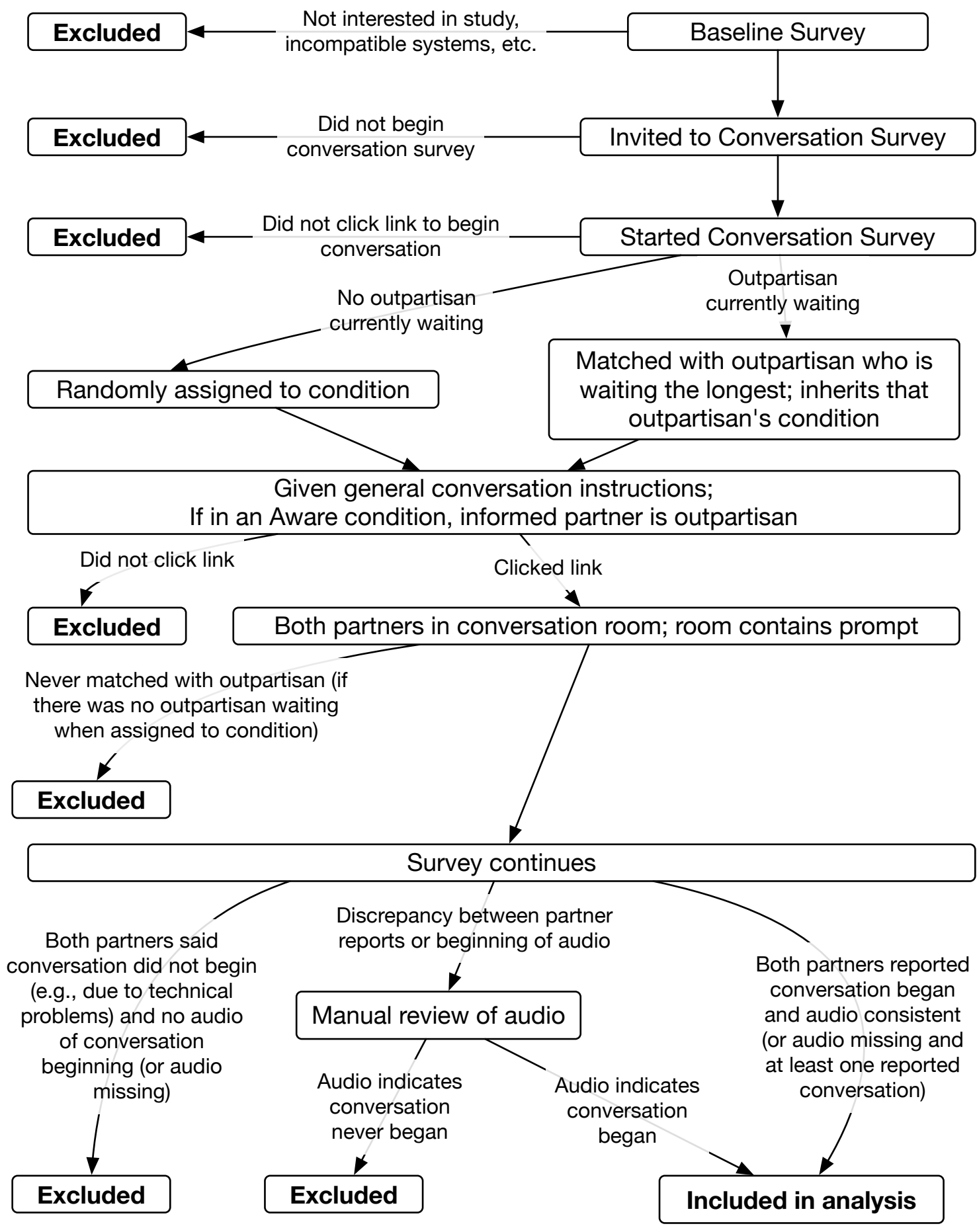


Figure OA4: Study 2: Additional Results

(a) Potential Mechanisms

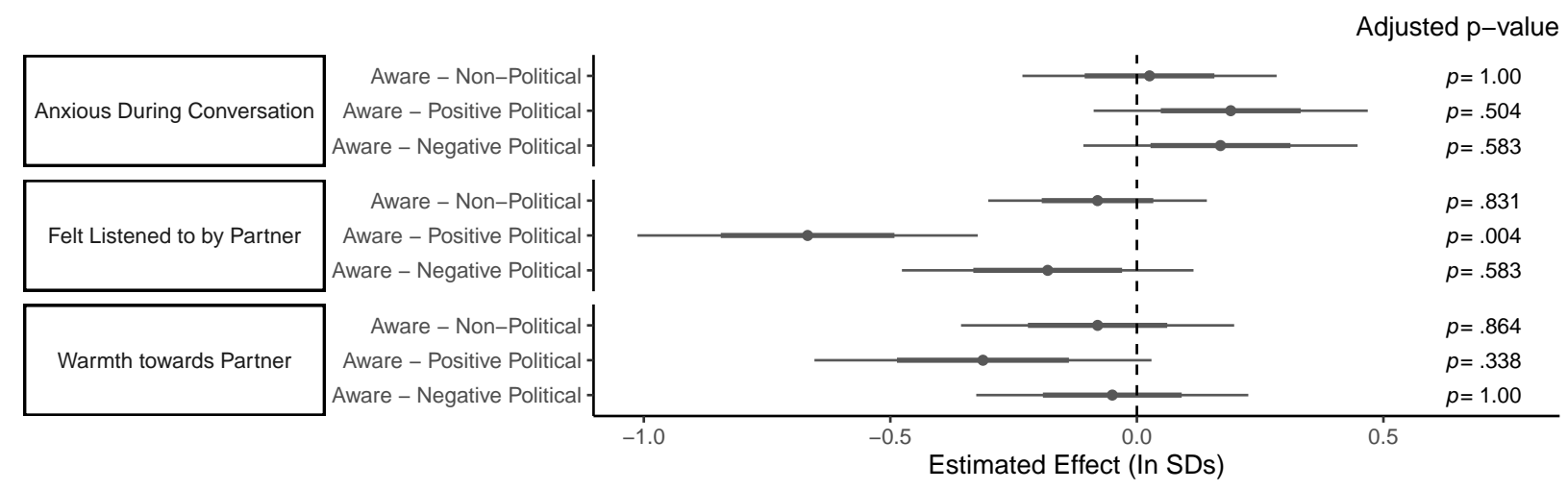

Notes: Points show the estimated effects of each condition in Study 2. Standard errors (thick lines) and $95 \%$ confidence intervals (thin lines) surround the point estimates. Adjusted p-values are adjusted across all measures, including mechanisms, besides primary outcomes.

(b) Moderators

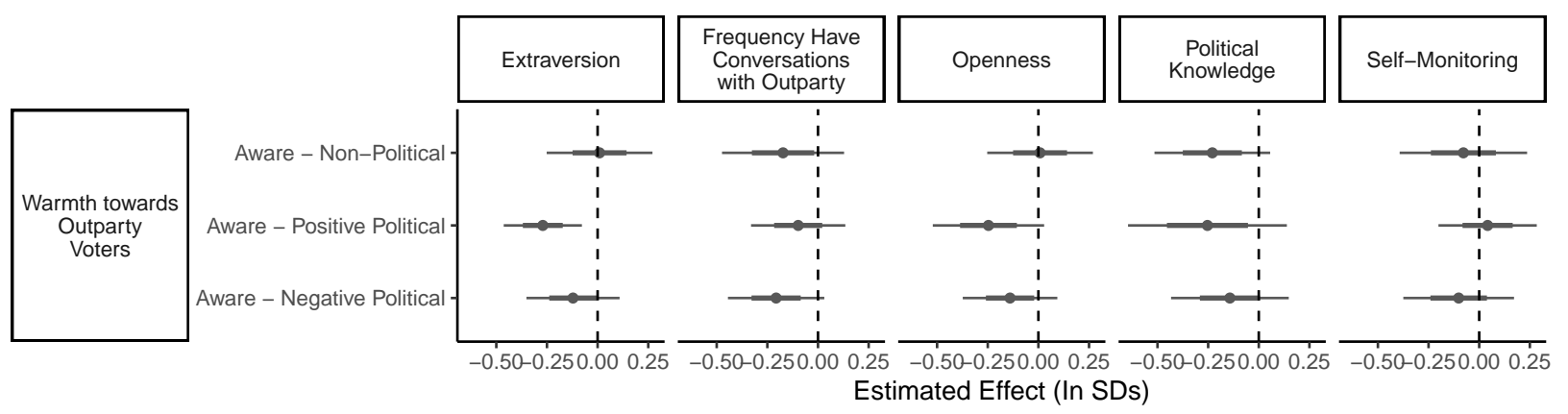

Notes: Points show the coefficient on an interaction term between each condition (left) and the moderator (top). Standard errors (thick lines) and 95\% confidence intervals (thin lines) surround the point estimates. Adjusted p-values are adjusted among all measures, including moderators, besides primary outcomes. 
Figure OA5: Study 2: Pooled effects of political conditions

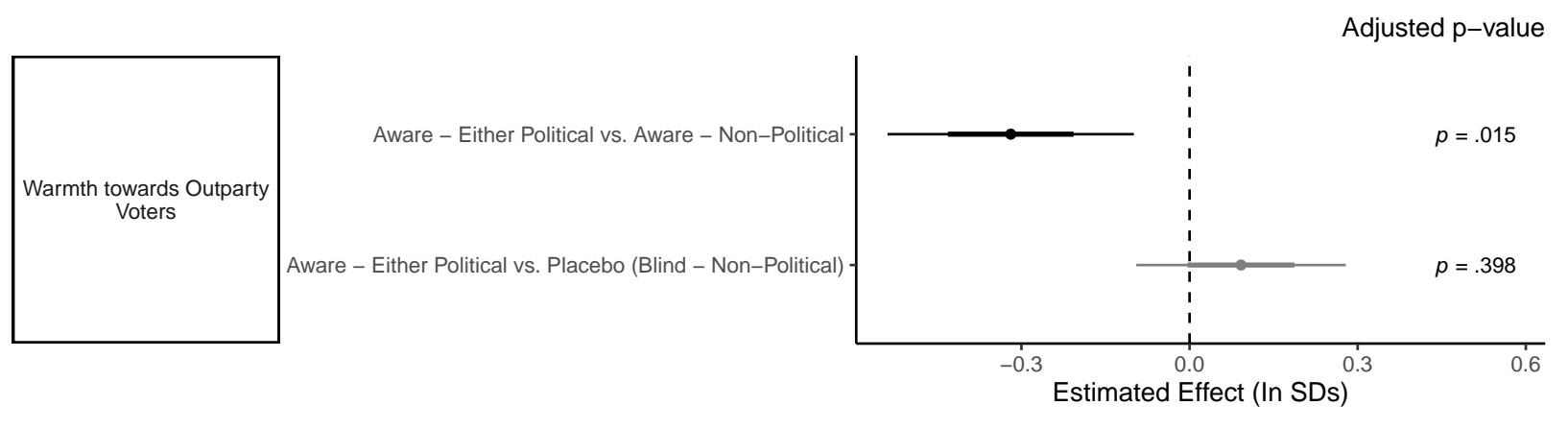

Points show the estimated effects of the Aware - Non-Political condition in Study 2. Standard errors (thick lines) and 95\% confidence intervals (thin lines) surround the point estimates. Adjusted pvalues are adjusted among all post-hoc comparisons. The first coefficient shows the effects of either political condition (pooled) versus the Aware - Non-Political group. The second coefficient shows the effects of either political condition (pooled) versus the placebo group. 
Figure OA6: Study 2: Comparing Effects of Aware - Positive Political vs. Aware - Negative Political Conditions

(a) Manipulation Checks

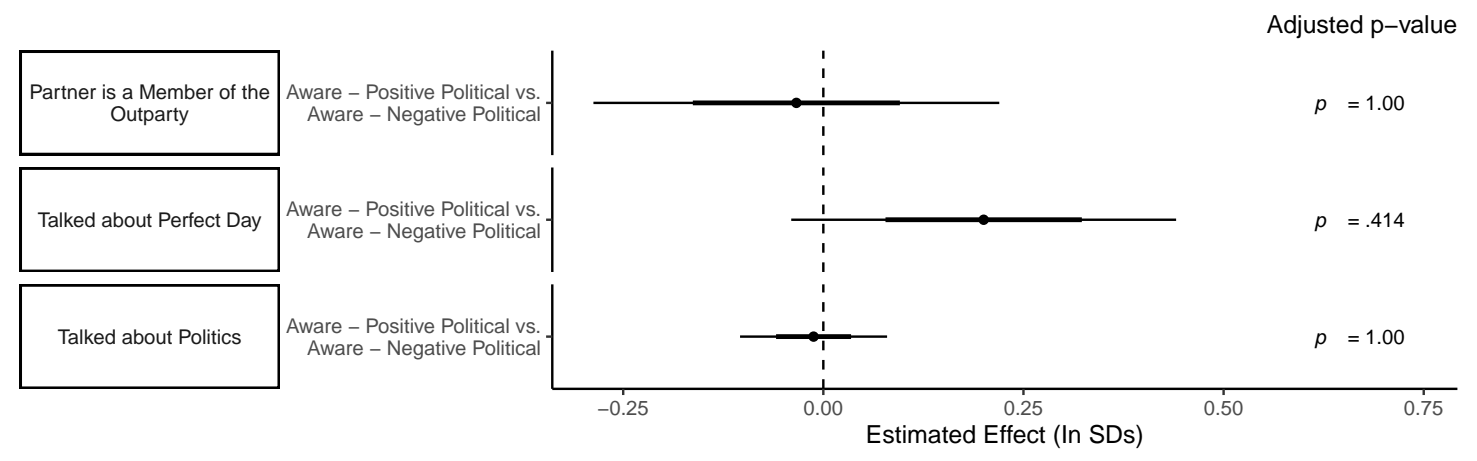

(b) Intergroup Prejudice Outcomes

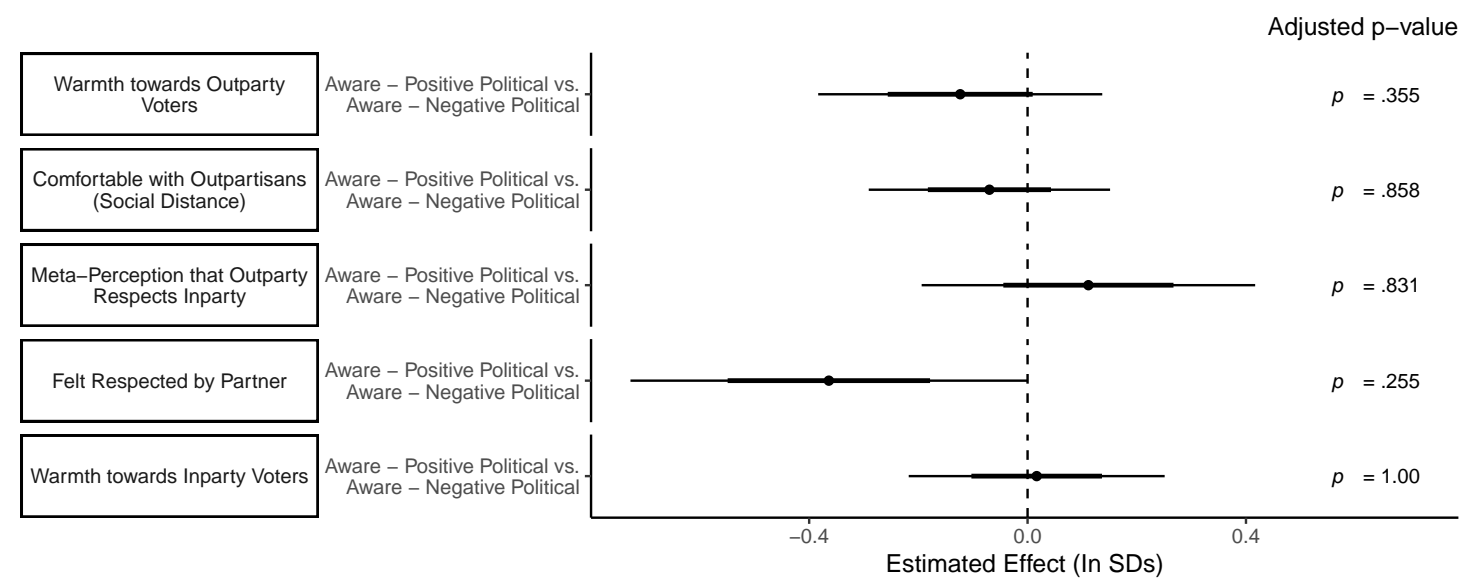

(c) Outcomes Relevant to Democratic Accountability

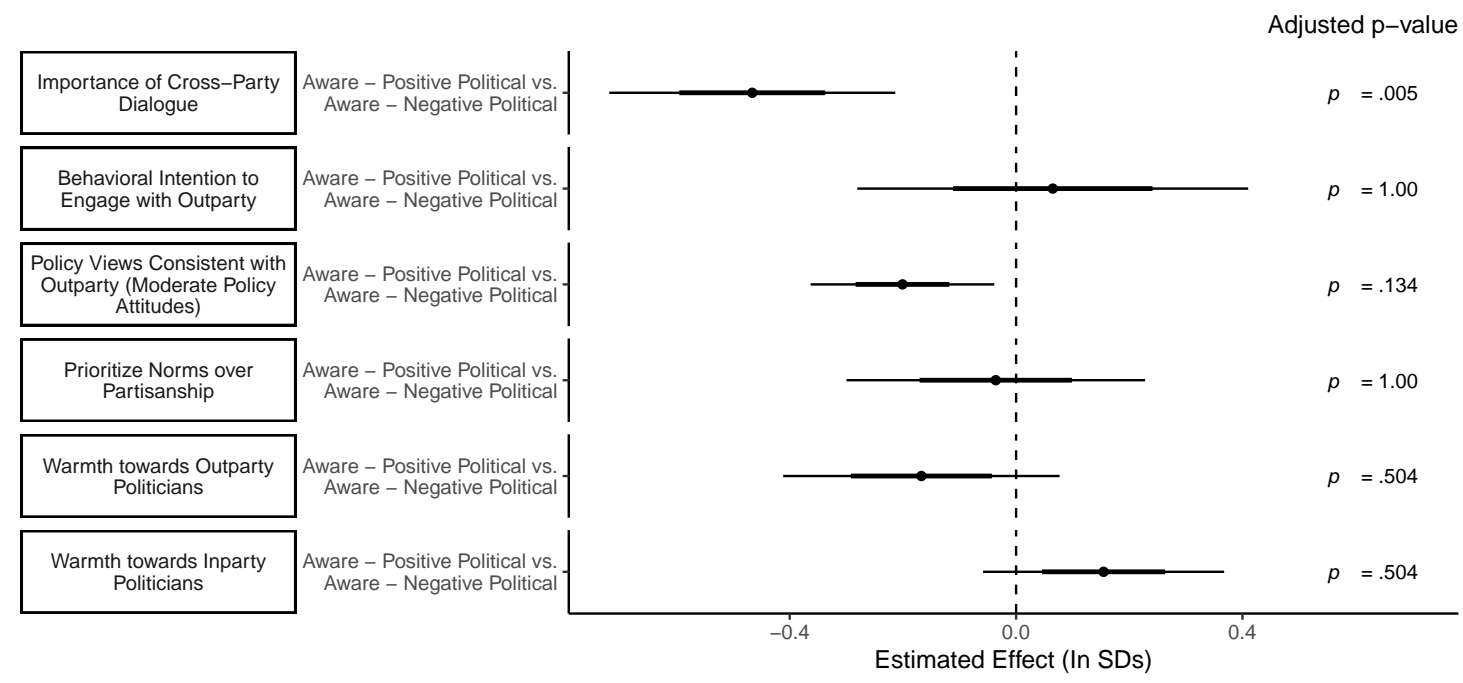

Notes: Points show the estimated differences between the effects of the Aware - Positive Political and Aware - Negative Political conditions in Study 2. Standard errors (thick lines) and 95\% confidence intervals (thin lines) surround the point estimates. Adjusted p-values are adjusted across all non-primary outcomes using the procedure outlined in Anderson (2008). As described in the text, p-values for primary outcomes are not adjusted. 
Figure OA7: Raw Means of Warthm Towards Outparty, with 95\% Confidence Intervals

(a) Study 1
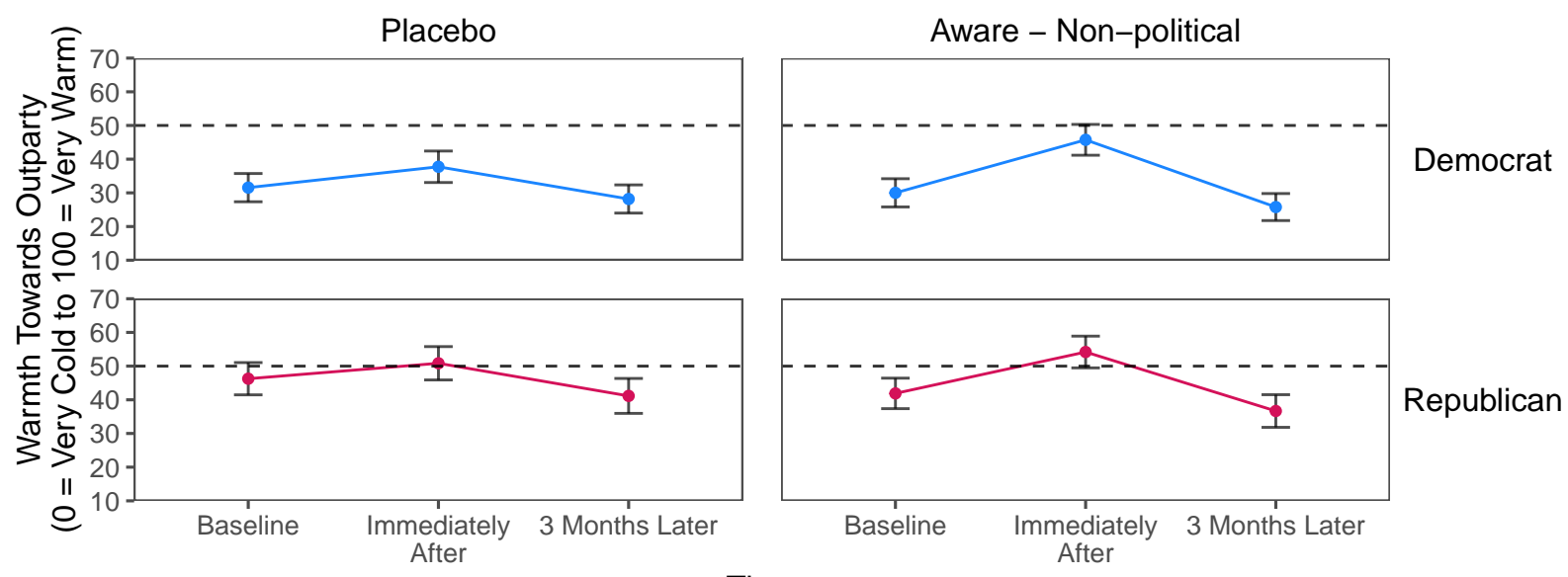

Time

(b) Study 2
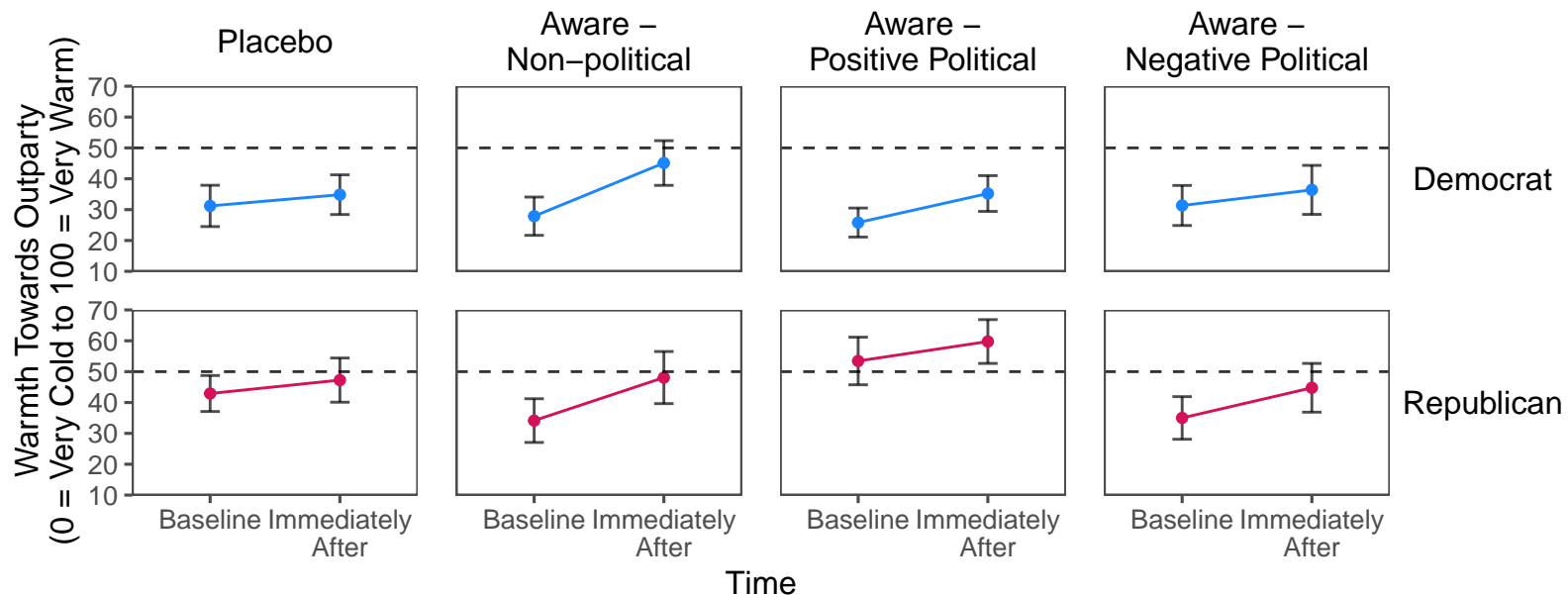

Notes: Note that because the data are repeated observations of the same individuals, the 95\% confidence intervals shown in the Figure cannot be used to assess the strength of the statistical evidence for differences between time points or between conditions. 
Table OA1: Study 1: Demographic Composition of Samples

\begin{tabular}{|c|c|c|c|c|c|c|c|c|}
\hline & \multirow[b]{2}{*}{$\begin{array}{l}\text { Completed } \\
\text { Screener }\end{array}$} & \multirow[b]{2}{*}{$\begin{array}{c}\text { Entered } \\
\text { Conversation } \\
\text { Room }\end{array}$} & \multicolumn{3}{|c|}{ Began Conversation (Used in Analyses) ${ }^{\dagger}$} & \multicolumn{3}{|c|}{$\begin{array}{l}\text { Started Follow-Up Survey (Used } \\
\text { in Follow-Up Survey Analyses) }\end{array}$} \\
\hline & & & All & Placebo & $\begin{array}{l}\text { Aware - } \\
\text { Non- } \\
\text { Political }\end{array}$ & All & Placebo & $\begin{array}{c}\text { Aware - } \\
\text { Non- } \\
\text { Political }\end{array}$ \\
\hline $\mathrm{N}$ & 7,904 & 986 & 478 & 218 & 260 & 419 & 184 & 235 \\
\hline Education: College or post-graduate & - & $61.26 \%$ & $62.13 \%$ & $59.17 \%$ & $64.62 \%$ & $62.77 \%$ & $60.87 \%$ & $64.26 \%$ \\
\hline Education: High school or less & - & $9.43 \%$ & $8.79 \%$ & $11.47 \%$ & $6.54 \%$ & $8.11 \%$ & $9.78 \%$ & $6.81 \%$ \\
\hline Education: Some college & - & $29.31 \%$ & $29.08 \%$ & $29.36 \%$ & $28.85 \%$ & $29.12 \%$ & $29.35 \%$ & $28.94 \%$ \\
\hline Race/Ethnicity: African American & - & $13.79 \%$ & $10.04 \%$ & $9.17 \%$ & $10.77 \%$ & $7.88 \%$ & $7.61 \%$ & $8.09 \%$ \\
\hline Race/Ethnicity: Asian & - & $7.81 \%$ & $7.11 \%$ & $9.63 \%$ & $5 \%$ & $6.92 \%$ & $9.78 \%$ & $4.68 \%$ \\
\hline Race/Ethnicity: Hispanic/Latino & - & $4.06 \%$ & $4.18 \%$ & $3.21 \%$ & $5 \%$ & $4.3 \%$ & $2.72 \%$ & $5.53 \%$ \\
\hline Race/Ethnicity: Multiple Selected & - & $5.38 \%$ & $5.44 \%$ & $5.5 \%$ & $5.38 \%$ & $5.49 \%$ & $4.89 \%$ & $5.96 \%$ \\
\hline Race/Ethnicity: Native American & - & $0.3 \%$ & $0 \%$ & $0 \%$ & $0 \%$ & $0 \%$ & $0 \%$ & $0 \%$ \\
\hline Race/Ethnicity: Other & - & $0.71 \%$ & $0.42 \%$ & $0 \%$ & $0.77 \%$ & $0.48 \%$ & $0 \%$ & $0.85 \%$ \\
\hline Race/Ethnicity: Pacific Islander & - & $0.2 \%$ & $0.21 \%$ & $0 \%$ & $0.38 \%$ & $0.24 \%$ & $0 \%$ & $0.43 \%$ \\
\hline Race/Ethnicity: White & - & $67.75 \%$ & $72.59 \%$ & $72.48 \%$ & $72.69 \%$ & $74.7 \%$ & $75 \%$ & $74.47 \%$ \\
\hline Gender: Female & - & $49.29 \%$ & $50.63 \%$ & $57.8 \%$ & $44.62 \%$ & $51.79 \%$ & $61.41 \%$ & $44.26 \%$ \\
\hline Gender: Male & - & $49.59 \%$ & $48.12 \%$ & $41.28 \%$ & $53.85 \%$ & $47.26 \%$ & $38.04 \%$ & $54.47 \%$ \\
\hline Gender: Prefer to self describe & - & $1.12 \%$ & $1.26 \%$ & $0.92 \%$ & $1.54 \%$ & $0.95 \%$ & $0.54 \%$ & $1.28 \%$ \\
\hline Age (mean), in years & - & 38.68 & 39.99 & 39.59 & 40.33 & 40.95 & 40.88 & 41.00 \\
\hline $\begin{array}{l}\text { Party identification: Closer to Democratic } \\
\text { Party }\end{array}$ & $13.42 \%$ & $13.08 \%$ & $11.3 \%$ & $14.22 \%$ & $8.85 \%$ & $10.98 \%$ & $13.59 \%$ & $8.94 \%$ \\
\hline $\begin{array}{l}\text { Party identification: Closer to Republican } \\
\text { Party }\end{array}$ & $6.12 \%$ & $9.63 \%$ & $12.34 \%$ & $11.93 \%$ & $12.69 \%$ & $11.46 \%$ & $9.78 \%$ & $12.77 \%$ \\
\hline $\begin{array}{l}\text { Party identification: Not very strong } \\
\text { Democrat }\end{array}$ & $18.41 \%$ & $18.46 \%$ & $14.85 \%$ & $15.6 \%$ & $14.23 \%$ & $15.27 \%$ & $15.22 \%$ & $15.32 \%$ \\
\hline $\begin{array}{l}\text { Party identification: Not very strong } \\
\text { Republican }\end{array}$ & $8.88 \%$ & $13.59 \%$ & $18.41 \%$ & $20.18 \%$ & $16.92 \%$ & $18.85 \%$ & $20.65 \%$ & $17.45 \%$ \\
\hline Party identification: Strong Democrat & $31.05 \%$ & $26.88 \%$ & $23.85 \%$ & $20.64 \%$ & $26.54 \%$ & $23.63 \%$ & $21.2 \%$ & $25.53 \%$ \\
\hline Party identification: Strong Republican & $11.56 \%$ & $18.26 \%$ & $19.25 \%$ & $17.43 \%$ & $20.77 \%$ & $19.81 \%$ & $19.57 \%$ & $20 \%$ \\
\hline Party identification: Neither & $10.54 \%$ & $0 \%$ & $0 \%$ & $0 \%$ & $0 \%$ & $0 \%$ & $0 \%$ & $0 \%$ \\
\hline Party identification: Not Listed & $0.01 \%$ & $0.1 \%$ & $0 \%$ & $0 \%$ & $0 \%$ & $0 \%$ & $0 \%$ & $0 \%$ \\
\hline
\end{tabular}

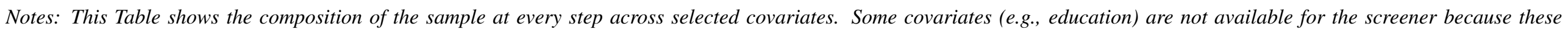
demographics were only asked about at the beginning of the conversation survey and were not asked on the screener.

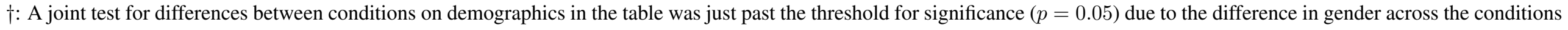

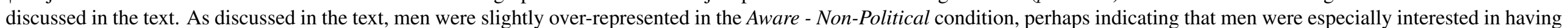

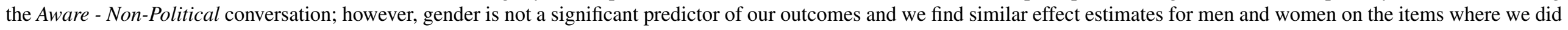
find effects. Removing gender, the test is no longer significant $(p=0.24)$.

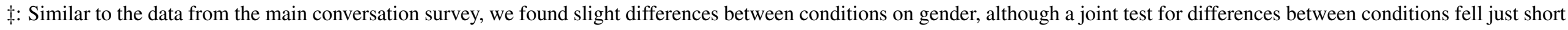
of significance $(p=0.05)$. Removing gender, the test is no longer significant. 
Table OA2: Study 2: Demographic Composition of Samples

\begin{tabular}{|c|c|c|c|c|c|c|c|}
\hline & \multirow[b]{2}{*}{$\begin{array}{c}\text { Completed } \\
\text { Screener and } \\
\text { Provided Email }\end{array}$} & \multirow[b]{2}{*}{$\begin{array}{l}\text { Clicked Page } \\
\text { Containing } \\
\text { Link to } \\
\text { Conversation }\end{array}$} & \multicolumn{5}{|c|}{ Began Conversation (Used in Analyses) $\dagger$} \\
\hline & & & All & Placebo & $\begin{array}{l}\text { Aware - } \\
\text { Non- } \\
\text { Political }\end{array}$ & $\begin{array}{l}\text { Positive } \\
\text { Political }\end{array}$ & $\begin{array}{l}\text { Negative } \\
\text { Political }\end{array}$ \\
\hline $\mathrm{N}$ & 2,541 & 607 & 338 & 100 & 74 & 83 & 81 \\
\hline Education: College or post-graduate & $63.72 \%$ & $70.68 \%$ & $72.19 \%$ & $74 \%$ & $72.97 \%$ & $69.88 \%$ & $71.6 \%$ \\
\hline Education: High school or less & $8.42 \%$ & $7.25 \%$ & $6.21 \%$ & $6 \%$ & $5.41 \%$ & $6.02 \%$ & $7.41 \%$ \\
\hline Education: Some college & $27.86 \%$ & $22.08 \%$ & $21.6 \%$ & $20 \%$ & $21.62 \%$ & $24.1 \%$ & $20.99 \%$ \\
\hline Race/Ethnicity: African American & $3.74 \%$ & $2.64 \%$ & $2.66 \%$ & $6 \%$ & $2.7 \%$ & $0 \%$ & $1.23 \%$ \\
\hline Race/Ethnicity: Asian & $5.94 \%$ & $7.91 \%$ & $7.99 \%$ & $7 \%$ & $8.11 \%$ & $8.43 \%$ & $8.64 \%$ \\
\hline Race/Ethnicity: Hispanic/Latino & $3.19 \%$ & $3.13 \%$ & $2.96 \%$ & $3 \%$ & $2.7 \%$ & $2.41 \%$ & $3.7 \%$ \\
\hline Race/Ethnicity: Multiple Selected & $6.77 \%$ & $7.74 \%$ & $7.1 \%$ & $5 \%$ & $5.41 \%$ & $13.25 \%$ & $4.94 \%$ \\
\hline Race/Ethnicity: Native American & $0.35 \%$ & $0.16 \%$ & $0.3 \%$ & $0 \%$ & $0 \%$ & $1.2 \%$ & $0 \%$ \\
\hline Race/Ethnicity: Not Listed & $0.04 \%$ & $0 \%$ & $0 \%$ & $0 \%$ & $0 \%$ & $0 \%$ & $0 \%$ \\
\hline Race/Ethnicity: Other & $1.65 \%$ & $1.98 \%$ & $1.78 \%$ & $1 \%$ & $2.7 \%$ & $3.61 \%$ & $0 \%$ \\
\hline Race/Ethnicity: Pacific Islander & $0.16 \%$ & $0 \%$ & $0 \%$ & $0 \%$ & $0 \%$ & $0 \%$ & $0 \%$ \\
\hline Race/Ethnicity: White & $78.16 \%$ & $76.44 \%$ & $77.22 \%$ & $78 \%$ & $78.38 \%$ & $71.08 \%$ & $81.48 \%$ \\
\hline Gender: Female & $56.67 \%$ & $51.73 \%$ & $48.52 \%$ & $44 \%$ & $45.95 \%$ & $50.6 \%$ & $54.32 \%$ \\
\hline Gender: Male & $42.07 \%$ & $47.45 \%$ & $51.18 \%$ & $56 \%$ & $54.05 \%$ & $48.19 \%$ & $45.68 \%$ \\
\hline Gender: Not Listed & $0.12 \%$ & $0 \%$ & $0 \%$ & $0 \%$ & $0 \%$ & $0 \%$ & $0 \%$ \\
\hline Gender: Prefer to self describe & $1.14 \%$ & $0.82 \%$ & $0.3 \%$ & $0 \%$ & $0 \%$ & $1.2 \%$ & $0 \%$ \\
\hline Age (mean), years & 45.47 & 44.55 & 43.63 & 44.15 & 41.93 & 42.81 & 45.38 \\
\hline $\begin{array}{l}\text { Party identification: Closer to Democratic } \\
\text { Party }\end{array}$ & $17.24 \%$ & $14.66 \%$ & $13.31 \%$ & $12 \%$ & $16.22 \%$ & $19.28 \%$ & $6.17 \%$ \\
\hline $\begin{array}{l}\text { Party identification: Closer to Republican } \\
\text { Party }\end{array}$ & $9.09 \%$ & $12.69 \%$ & $15.38 \%$ & $12 \%$ & $18.92 \%$ & $14.46 \%$ & $17.28 \%$ \\
\hline $\begin{array}{l}\text { Party identification: Not very strong } \\
\text { Democrat }\end{array}$ & $13.7 \%$ & $10.21 \%$ & $9.17 \%$ & $10 \%$ & $5.41 \%$ & $8.43 \%$ & $12.35 \%$ \\
\hline $\begin{array}{l}\text { Party identification: Not very strong } \\
\text { Republican }\end{array}$ & $8.5 \%$ & $12.69 \%$ & $15.38 \%$ & $14 \%$ & $14.86 \%$ & $15.66 \%$ & $17.28 \%$ \\
\hline Party identification: Strong Democrat & $38.17 \%$ & $32.78 \%$ & $28.99 \%$ & $28 \%$ & $29.73 \%$ & $25.3 \%$ & $33.33 \%$ \\
\hline Party identification: Strong Republican & $13.3 \%$ & $16.97 \%$ & $17.75 \%$ & $24 \%$ & $14.86 \%$ & $16.87 \%$ & $13.58 \%$ \\
\hline
\end{tabular}

Notes: This Table shows the composition of the sample at every step across selected covariates.

$\dagger$ : A joint test for differences between conditions on demographics in the table is insignificant $(p=0.44)$. 
Table OA3: Numerical Results and Variable Classification: Study 1

\begin{tabular}{|c|c|c|c|c|c|c|c|c|}
\hline Category & Measure Name & Time Period & DV Type & Estimate & SE & $\mathbf{t}$ & $\begin{array}{l}\text { Unadjusted } \\
\text { p-value }\end{array}$ & $\begin{array}{l}\text { Adjusted } \\
\text { p-value }\end{array}$ \\
\hline $\begin{array}{l}\text { Democratic } \\
\text { Accountability }\end{array}$ & $\begin{array}{l}\text { Choose Candidate Aligned on Issues } \\
\text { over Party }\end{array}$ & Immediately & Primary & -0.073 & 0.094 & -0.774 & 0.44 & 0.44 \\
\hline $\begin{array}{l}\text { Democratic } \\
\text { Accountability }\end{array}$ & $\begin{array}{l}\text { Likelihood of Talking to Outparty } \\
\text { Neighbor about Politics }\end{array}$ & Immediately & Secondary & -0.048 & 0.095 & -0.509 & 0.612 & 1 \\
\hline $\begin{array}{l}\text { Democratic } \\
\text { Accountability }\end{array}$ & $\begin{array}{l}\text { Policy Views Consistent with Outparty } \\
\text { (Moderate Policy Attitudes) }\end{array}$ & Immediately & Secondary & -0.019 & 0.04 & -0.481 & 0.631 & 1 \\
\hline $\begin{array}{l}\text { Democratic } \\
\text { Accountability }\end{array}$ & Prioritize Norms over Partisanship & Immediately & Secondary & -0.009 & 0.092 & -0.098 & 0.922 & 1 \\
\hline $\begin{array}{l}\text { Democratic } \\
\text { Accountability }\end{array}$ & $\begin{array}{l}\text { Request to Subscribe to Bipartisan } \\
\text { Newsletter }\end{array}$ & Immediately & Secondary & -0.04 & 0.091 & -0.442 & 0.659 & 1 \\
\hline $\begin{array}{l}\text { Democratic } \\
\text { Accountability }\end{array}$ & Support for Bipartisanship & Immediately & Secondary & -0.235 & 0.168 & -1.403 & 0.162 & 0.602 \\
\hline $\begin{array}{l}\text { Democratic } \\
\text { Accountability }\end{array}$ & $\begin{array}{l}\text { Choose Candidate Aligned on Issues } \\
\text { over Party }\end{array}$ & 3 Months After & Post-Hoc & -0.093 & 0.1 & -0.927 & 0.355 & 1 \\
\hline $\begin{array}{l}\text { Democratic } \\
\text { Accountability }\end{array}$ & Importance of Cross-Party Dialogue & 3 Months After & Post-Hoc & -0.068 & 0.112 & -0.606 & 0.546 & 1 \\
\hline $\begin{array}{l}\text { Democratic } \\
\text { Accountability }\end{array}$ & $\begin{array}{l}\text { Policy Views Consistent with Outparty } \\
\text { (Moderate Policy Attitudes) }\end{array}$ & 3 Months After & Post-Hoc & 0.011 & 0.067 & 0.168 & 0.867 & 1 \\
\hline $\begin{array}{l}\text { Democratic } \\
\text { Accountability }\end{array}$ & Warmth towards Inparty Politicians & 3 Months After & Post-Hoc & 0.116 & 0.067 & 1.724 & 0.086 & 0.985 \\
\hline $\begin{array}{l}\text { Democratic } \\
\text { Accountability }\end{array}$ & Warmth towards Outparty Politicians & 3 Months After & Post-Hoc & 0.03 & 0.072 & 0.408 & 0.684 & 1 \\
\hline $\begin{array}{l}\text { Democratic } \\
\text { Accountability }\end{array}$ & Warmth towards Inparty Politicians & Immediately & Tertiary & 0.036 & 0.051 & 0.721 & 0.472 & 1 \\
\hline
\end{tabular}


Table OA3: Numerical Results and Variable Classification: Study 1 (Continued)

\begin{tabular}{|c|c|c|c|c|c|c|c|c|}
\hline Category & Measure Name & Time Period & DV Type & Estimate & SE & $\mathbf{t}$ & $\begin{array}{l}\text { Unadjusted } \\
\text { p-value }\end{array}$ & $\begin{array}{r}\text { Adjusted } \\
\text { p-value }\end{array}$ \\
\hline $\begin{array}{l}\text { Democratic } \\
\text { Accountability }\end{array}$ & Warmth towards Outparty Politicians & Immediately & Tertiary & 0.12 & 0.058 & 2.077 & 0.039 & 0.377 \\
\hline Intergroup & $\begin{array}{l}\text { Meta-Perception that Outparty Respects } \\
\text { Inparty }\end{array}$ & Immediately & Primary & 0.457 & 0.069 & 6.579 & 0 & 0 \\
\hline Intergroup & Warmth towards Outparty Voters & Immediately & Primary & 0.34 & 0.061 & 5.626 & 0 & 0 \\
\hline Intergroup & Humanization of Outparty & Immediately & Secondary & -0.021 & 0.095 & -0.219 & 0.827 & 1 \\
\hline Intergroup & $\begin{array}{l}\text { Meta-Perception that Outparty Respects } \\
\text { Inparty }\end{array}$ & 3 Months After & Post-Hoc & 0.136 & 0.088 & 1.546 & 0.124 & 0.985 \\
\hline Intergroup & Warmth towards Inparty Voters & 3 Months After & Post-Hoc & 0.029 & 0.068 & 0.42 & 0.675 & 1 \\
\hline Intergroup & Warmth towards Outparty Voters & 3 Months After & Post-Hoc & -0.021 & 0.077 & -0.28 & 0.78 & 1 \\
\hline Intergroup & Warmth towards Inparty Voters & Immediately & Tertiary & 0.078 & 0.058 & 1.349 & 0.179 & 0.602 \\
\hline Manipulation Check & Partner is a Member of the Outparty & Immediately & Manipulation Check & 0.81 & 0.09 & 8.958 & 0 & 0.001 \\
\hline Manipulation Check & Talked about Perfect Day & Immediately & Manipulation Check & -0.104 & 0.102 & -1.026 & 0.306 & 0.89 \\
\hline Manipulation Check & Talked about Politics & Immediately & Manipulation Check & 0.361 & 0.108 & 3.346 & 0.001 & 0.012 \\
\hline Manipulation Check & Talked about Unrelated Topics & Immediately & Manipulation Check & -0.001 & 0.107 & -0.014 & 0.989 & 1 \\
\hline Mechanism & Outparty Perceived as Similar & Immediately & Mechanism & 0.179 & 0.09 & 1.975 & 0.05 & 0.377 \\
\hline Mechanism & $\begin{array}{l}\text { Partner Perceived as Doing Deep } \\
\text { Listening }\end{array}$ & Immediately & Mechanism & -0.137 & 0.103 & -1.322 & 0.188 & 0.602 \\
\hline Moderator & $\begin{array}{l}\text { Moderation of Choose Candidate } \\
\text { Aligned on Issues over Party by } \\
\text { Frequency Have Conversations with } \\
\text { Outparty }\end{array}$ & Immediately & Moderator & 0.062 & 0.099 & 0.631 & 0.529 & 1 \\
\hline
\end{tabular}


Table OA3: Numerical Results and Variable Classification: Study 1 (Continued)

\begin{tabular}{|c|c|c|c|c|c|c|c|c|}
\hline Category & Measure Name & Time Period & DV Type & Estimate & SE & $\mathbf{t}$ & $\begin{array}{c}\text { Unadjusted } \\
\text { p-value }\end{array}$ & $\begin{array}{l}\text { Adjusted } \\
\text { p-value }\end{array}$ \\
\hline Moderator & $\begin{array}{l}\text { Moderation of Choose Candidate } \\
\text { Aligned on Issues over Party by } \\
\text { Political Knowledge }\end{array}$ & Immediately & Moderator & -0.041 & 0.103 & -0.397 & 0.692 & 1 \\
\hline Moderator & $\begin{array}{l}\text { Moderation of Choose Candidate } \\
\text { Aligned on Issues over Party by } \\
\text { Receptiveness to Others with } \\
\text { Different Opinions }\end{array}$ & Immediately & Moderator & -0.074 & 0.09 & -0.826 & 0.411 & 1 \\
\hline Moderator & $\begin{array}{l}\text { Moderation of Meta-Perception that } \\
\text { Outparty Respects Inparty by Frequency } \\
\text { Have Conversations with Outparty }\end{array}$ & Immediately & Moderator & -0.05 & 0.064 & -0.781 & 0.436 & 1 \\
\hline Moderator & $\begin{array}{l}\text { Moderation of Meta-Perception that } \\
\text { Outparty Respects Inparty by } \\
\text { Political Knowledge }\end{array}$ & Immediately & Moderator & -0.113 & 0.065 & -1.734 & 0.085 & 0.426 \\
\hline Moderator & $\begin{array}{l}\text { Moderation of Meta-Perception that } \\
\text { Outparty Respects Inparty by } \\
\text { Receptiveness to Others with Different } \\
\text { Opinions }\end{array}$ & Immediately & Moderator & 0.028 & 0.066 & 0.421 & 0.675 & 1 \\
\hline Moderator & $\begin{array}{l}\text { Moderation of Warmth towards Outparty } \\
\text { Voters by Frequency Have Conversations } \\
\text { with Outparty }\end{array}$ & Immediately & Moderator & -0.067 & 0.066 & -1.012 & 0.313 & 0.89 \\
\hline Moderator & $\begin{array}{l}\text { Moderation of Warmth towards Outparty } \\
\text { Voters by Political Knowledge }\end{array}$ & Immediately & Moderator & -0.065 & 0.064 & -1.011 & 0.314 & 0.89 \\
\hline
\end{tabular}


Table OA3: Numerical Results and Variable Classification: Study 1 (Continued)

\begin{tabular}{|c|c|c|c|c|c|c|c|c|}
\hline Category & Measure Name & Time Period & DV Type & Estimate & $\mathbf{S E}$ & $\mathbf{t}$ & $\begin{array}{l}\text { Unadjusted } \\
\text { p-value }\end{array}$ & $\begin{array}{l}\text { Adjusted } \\
\text { p-value }\end{array}$ \\
\hline Moderator & $\begin{array}{l}\text { Voters by Receptiveness to Others } \\
\text { with Different Opinions }\end{array}$ & Immediately & Moderator & 0.103 & 0.059 & 1.736 & 0.086 & 0.426 \\
\hline
\end{tabular}


Table OA4: Numerical Results and Variable Classification: Study 2

\begin{tabular}{|c|c|c|c|c|c|c|c|c|}
\hline Category & Measure Name & DV Type & Condition Comparison & Estimate & SE & $\mathbf{t}$ & $\begin{array}{l}\text { Unadjusted } \\
\text { p-value }\end{array}$ & $\begin{array}{l}\text { Adjusted } \\
\text { p-value }\end{array}$ \\
\hline $\begin{array}{l}\text { Democratic } \\
\text { Accountability }\end{array}$ & $\begin{array}{l}\text { Behavioral Intention to } \\
\text { Engage with Outparty }\end{array}$ & Secondary & $\begin{array}{l}\text { Aware - Negative } \\
\text { Political vs. Placebo }\end{array}$ & -0.011 & 0.149 & -0.071 & 0.943 & 1 \\
\hline $\begin{array}{l}\text { Democratic } \\
\text { Accountability }\end{array}$ & $\begin{array}{l}\text { Behavioral Intention to } \\
\text { Engage with Outparty }\end{array}$ & Secondary & $\begin{array}{l}\text { Aware - Non-Political vs. } \\
\text { Placebo }\end{array}$ & 0.111 & 0.154 & 0.723 & 0.472 & 0.831 \\
\hline $\begin{array}{l}\text { Democratic } \\
\text { Accountability }\end{array}$ & $\begin{array}{l}\text { Behavioral Intention to } \\
\text { Engage with Outparty }\end{array}$ & Secondary & $\begin{array}{l}\text { Aware - Positive } \\
\text { Political vs. Aware - } \\
\text { Negative Political }\end{array}$ & 0.065 & 0.176 & 0.368 & 0.714 & 1 \\
\hline $\begin{array}{l}\text { Democratic } \\
\text { Accountability }\end{array}$ & $\begin{array}{l}\text { Behavioral Intention to } \\
\text { Engage with Outparty }\end{array}$ & Secondary & $\begin{array}{l}\text { Aware - Positive } \\
\text { Political vs. Placebo }\end{array}$ & 0.054 & 0.163 & 0.333 & 0.74 & 1 \\
\hline $\begin{array}{l}\text { Democratic } \\
\text { Accountability }\end{array}$ & $\begin{array}{l}\text { Importance of Cross-Party } \\
\text { Dialogue }\end{array}$ & Secondary & $\begin{array}{l}\text { Aware - Negative } \\
\text { Political vs. Placebo }\end{array}$ & 0.369 & 0.101 & 3.662 & 0 & 0.005 \\
\hline $\begin{array}{l}\text { Democratic } \\
\text { Accountability }\end{array}$ & $\begin{array}{l}\text { Importance of Cross-Party } \\
\text { Dialogue }\end{array}$ & Secondary & $\begin{array}{l}\text { Aware - Non-Political vs. } \\
\text { Placebo }\end{array}$ & -0.096 & 0.124 & -0.771 & 0.443 & 0.831 \\
\hline $\begin{array}{l}\text { Democratic } \\
\text { Accountability }\end{array}$ & $\begin{array}{l}\text { Importance of Cross-Party } \\
\text { Dialogue }\end{array}$ & Secondary & $\begin{array}{l}\text { Aware - Positive } \\
\text { Political vs. Aware - } \\
\text { Negative Political }\end{array}$ & -0.466 & 0.129 & -3.615 & 0.001 & 0.005 \\
\hline $\begin{array}{l}\text { Democratic } \\
\text { Accountability }\end{array}$ & $\begin{array}{l}\text { Importance of Cross-Party } \\
\text { Dialogue }\end{array}$ & Secondary & $\begin{array}{l}\text { Aware - Positive } \\
\text { Political vs. Placebo }\end{array}$ & -0.097 & 0.11 & -0.884 & 0.379 & 0.831 \\
\hline $\begin{array}{l}\text { Democratic } \\
\text { Accountability }\end{array}$ & $\begin{array}{l}\text { Policy Views Consistent } \\
\text { with Outparty (Moderate } \\
\text { Policy Attitudes) }\end{array}$ & Secondary & $\begin{array}{l}\text { Aware - Negative } \\
\text { Political vs. Placebo }\end{array}$ & 0.166 & 0.073 & 2.26 & 0.026 & 0.172 \\
\hline $\begin{array}{l}\text { Democratic } \\
\text { Accountability }\end{array}$ & $\begin{array}{l}\text { Policy Views Consistent } \\
\text { with Outparty (Moderate } \\
\text { Policy Attitudes) }\end{array}$ & Secondary & $\begin{array}{l}\text { Aware - Non-Political vs. } \\
\text { Placebo }\end{array}$ & 0.046 & 0.075 & 0.608 & 0.545 & 0.858 \\
\hline
\end{tabular}


Table OA4: Numerical Results and Variable Classification: Study 2 (Continued)

\begin{tabular}{|c|c|c|c|c|c|c|c|c|}
\hline Category & Measure Name & DV Type & Condition Comparison & Estimate & SE & $\mathbf{t}$ & $\begin{array}{l}\text { Unadjusted } \\
\text { p-value }\end{array}$ & $\begin{array}{r}\text { Adjusted } \\
\text { p-value }\end{array}$ \\
\hline $\begin{array}{l}\text { Democratic } \\
\text { Accountability }\end{array}$ & $\begin{array}{l}\text { Policy Views Consistent } \\
\text { with Outparty (Moderate } \\
\text { Policy Attitudes) }\end{array}$ & Secondary & $\begin{array}{l}\text { Aware - Positive } \\
\text { Political vs. Aware - } \\
\text { Negative Political }\end{array}$ & -0.201 & 0.083 & -2.424 & 0.018 & 0.134 \\
\hline $\begin{array}{l}\text { Democratic } \\
\text { Accountability }\end{array}$ & $\begin{array}{l}\text { Policy Views Consistent } \\
\text { with Outparty (Moderate } \\
\text { Policy Attitudes) }\end{array}$ & Secondary & $\begin{array}{l}\text { Aware - Positive } \\
\text { Political vs. Placebo }\end{array}$ & -0.035 & 0.073 & -0.476 & 0.635 & 0.982 \\
\hline $\begin{array}{l}\text { Democratic } \\
\text { Accountability }\end{array}$ & $\begin{array}{l}\text { Prioritize Norms over } \\
\text { Partisanship }\end{array}$ & Secondary & $\begin{array}{l}\text { Aware - Negative } \\
\text { Political vs. Placebo }\end{array}$ & -0.229 & 0.124 & -1.848 & 0.068 & 0.317 \\
\hline $\begin{array}{l}\text { Democratic } \\
\text { Accountability }\end{array}$ & $\begin{array}{l}\text { Prioritize Norms over } \\
\text { Partisanship }\end{array}$ & Secondary & $\begin{array}{l}\text { Aware - Non-Political vs. } \\
\text { Placebo }\end{array}$ & -0.144 & 0.104 & -1.377 & 0.172 & 0.504 \\
\hline $\begin{array}{l}\text { Democratic } \\
\text { Accountability }\end{array}$ & $\begin{array}{l}\text { Prioritize Norms over } \\
\text { Partisanship }\end{array}$ & Secondary & $\begin{array}{l}\text { Aware - Positive } \\
\text { Political vs. Aware - } \\
\text { Negative Political }\end{array}$ & -0.036 & 0.135 & -0.267 & 0.79 & 1 \\
\hline $\begin{array}{l}\text { Democratic } \\
\text { Accountability }\end{array}$ & $\begin{array}{l}\text { Prioritize Norms over } \\
\text { Partisanship }\end{array}$ & Secondary & $\begin{array}{l}\text { Aware - Positive } \\
\text { Political vs. Placebo }\end{array}$ & -0.265 & 0.121 & -2.196 & 0.031 & 0.189 \\
\hline $\begin{array}{l}\text { Democratic } \\
\text { Accountability }\end{array}$ & $\begin{array}{l}\text { Warmth towards Inparty } \\
\text { Politicians }\end{array}$ & Tertiary & $\begin{array}{l}\text { Aware - Negative } \\
\text { Political vs. Placebo }\end{array}$ & 0.007 & 0.098 & 0.07 & 0.944 & 1 \\
\hline $\begin{array}{l}\text { Democratic } \\
\text { Accountability }\end{array}$ & $\begin{array}{l}\text { Warmth towards Inparty } \\
\text { Politicians }\end{array}$ & Tertiary & $\begin{array}{l}\text { Aware - Non-Political vs. } \\
\text { Placebo }\end{array}$ & -0.023 & 0.093 & -0.245 & 0.807 & 1 \\
\hline $\begin{array}{l}\text { Democratic } \\
\text { Accountability }\end{array}$ & $\begin{array}{l}\text { Warmth towards Inparty } \\
\text { Politicians }\end{array}$ & Tertiary & $\begin{array}{l}\text { Aware - Positive } \\
\text { Political vs. Aware - } \\
\text { Negative Political }\end{array}$ & 0.155 & 0.109 & 1.423 & 0.159 & 0.504 \\
\hline $\begin{array}{l}\text { Democratic } \\
\text { Accountability }\end{array}$ & $\begin{array}{l}\text { Warmth towards Inparty } \\
\text { Politicians }\end{array}$ & Tertiary & $\begin{array}{l}\text { Aware - Positive } \\
\text { Political vs. Placebo }\end{array}$ & 0.162 & 0.092 & 1.75 & 0.084 & 0.338 \\
\hline
\end{tabular}


Table OA4: Numerical Results and Variable Classification: Study 2 (Continued)

\begin{tabular}{|c|c|c|c|c|c|c|c|c|}
\hline Category & Measure Name & DV Type & Condition Comparison & Estimate & SE & $\mathbf{t}$ & $\begin{array}{c}\text { Unadjusted } \\
\text { p-value }\end{array}$ & $\begin{array}{r}\text { Adjusted } \\
\text { p-value }\end{array}$ \\
\hline $\begin{array}{l}\text { Democratic } \\
\text { Accountability }\end{array}$ & $\begin{array}{l}\text { Warmth towards Outparty } \\
\text { Politicians }\end{array}$ & Tertiary & $\begin{array}{l}\text { Aware - Negative } \\
\text { Political vs. Placebo }\end{array}$ & 0.024 & 0.11 & 0.223 & 0.824 & 1 \\
\hline $\begin{array}{l}\text { Democratic } \\
\text { Accountability }\end{array}$ & $\begin{array}{l}\text { Warmth towards Outparty } \\
\text { Politicians }\end{array}$ & Tertiary & $\begin{array}{l}\text { Aware - Non-Political vs. } \\
\text { Placebo }\end{array}$ & 0.151 & 0.12 & 1.258 & 0.212 & 0.562 \\
\hline $\begin{array}{l}\text { Democratic } \\
\text { Accountability }\end{array}$ & $\begin{array}{l}\text { Warmth towards Outparty } \\
\text { Politicians }\end{array}$ & Tertiary & $\begin{array}{l}\text { Aware - Positive } \\
\text { Political vs. Aware - } \\
\text { Negative Political }\end{array}$ & -0.167 & 0.125 & -1.343 & 0.183 & 0.504 \\
\hline $\begin{array}{l}\text { Democratic } \\
\text { Accountability }\end{array}$ & $\begin{array}{l}\text { Warmth towards Outparty } \\
\text { Politicians }\end{array}$ & Tertiary & $\begin{array}{l}\text { Aware - Positive } \\
\text { Political vs. Placebo }\end{array}$ & -0.143 & 0.106 & -1.348 & 0.181 & 0.504 \\
\hline Intergroup & $\begin{array}{l}\text { Warmth towards Outparty } \\
\text { Voters }\end{array}$ & Primary & $\begin{array}{l}\text { Aware - Negative } \\
\text { Political vs. Placebo }\end{array}$ & 0.148 & 0.115 & 1.29 & 0.201 & 0.201 \\
\hline Intergroup & $\begin{array}{l}\text { Warmth towards Outparty } \\
\text { Voters }\end{array}$ & Primary & $\begin{array}{l}\text { Aware - Non-Political vs. } \\
\text { Placebo }\end{array}$ & 0.406 & 0.116 & 3.511 & 0.001 & 0.001 \\
\hline Intergroup & $\begin{array}{l}\text { Warmth towards Outparty } \\
\text { Voters }\end{array}$ & Primary & $\begin{array}{l}\text { Aware - Positive } \\
\text { Political vs. Aware - } \\
\text { Negative Political }\end{array}$ & -0.123 & 0.133 & -0.929 & 0.355 & 0.355 \\
\hline Intergroup & $\begin{array}{l}\text { Warmth towards Outparty } \\
\text { Voters }\end{array}$ & Primary & $\begin{array}{l}\text { Aware - Positive } \\
\text { Political vs. Placebo }\end{array}$ & 0.025 & 0.117 & 0.214 & 0.831 & 0.831 \\
\hline Intergroup & $\begin{array}{l}\text { Comfortable with } \\
\text { Outpartisans (Social } \\
\text { Distance) }\end{array}$ & Secondary & $\begin{array}{l}\text { Aware - Negative } \\
\text { Political vs. Placebo }\end{array}$ & 0.034 & 0.091 & 0.377 & 0.707 & 1 \\
\hline Intergroup & $\begin{array}{l}\text { Comfortable with } \\
\text { Outpartisans (Social } \\
\text { Distance) }\end{array}$ & Secondary & $\begin{array}{l}\text { Aware - Non-Political vs. } \\
\text { Placebo }\end{array}$ & -0.079 & 0.086 & -0.912 & 0.364 & 0.831 \\
\hline
\end{tabular}


Table OA4: Numerical Results and Variable Classification: Study 2 (Continued)

\begin{tabular}{|c|c|c|c|c|c|c|c|c|}
\hline Category & Measure Name & DV Type & Condition Comparison & Estimate & SE & $\mathbf{t}$ & $\begin{array}{c}\text { Unadjusted } \\
\text { p-value }\end{array}$ & $\begin{array}{l}\text { Adjusted } \\
\text { p-value }\end{array}$ \\
\hline Intergroup & $\begin{array}{l}\text { Comfortable with } \\
\text { Outpartisans (Social } \\
\text { Distance) }\end{array}$ & Secondary & $\begin{array}{l}\text { Aware - Positive } \\
\text { Political vs. Aware - } \\
\text { Negative Political }\end{array}$ & -0.07 & 0.113 & -0.62 & 0.537 & 0.858 \\
\hline Intergroup & $\begin{array}{l}\text { Comfortable with } \\
\text { Outpartisans (Social } \\
\text { Distance) }\end{array}$ & Secondary & $\begin{array}{l}\text { Aware - Positive } \\
\text { Political vs. Placebo }\end{array}$ & -0.036 & 0.107 & -0.333 & 0.74 & 1 \\
\hline Intergroup & $\begin{array}{l}\text { Meta-Perception that } \\
\text { Outparty Respects Inparty }\end{array}$ & Secondary & $\begin{array}{l}\text { Aware - Negative } \\
\text { Political vs. Placebo }\end{array}$ & 0.182 & 0.128 & 1.422 & 0.159 & 0.504 \\
\hline Intergroup & $\begin{array}{l}\text { Meta-Perception that } \\
\text { Outparty Respects Inparty }\end{array}$ & Secondary & $\begin{array}{l}\text { Aware - Non-Political vs. } \\
\text { Placebo }\end{array}$ & 0.078 & 0.136 & 0.573 & 0.568 & 0.864 \\
\hline Intergroup & $\begin{array}{l}\text { Meta-Perception that } \\
\text { Outparty Respects Inparty }\end{array}$ & Secondary & $\begin{array}{l}\text { Aware - Positive } \\
\text { Political vs. Aware - } \\
\text { Negative Political }\end{array}$ & 0.111 & 0.156 & 0.715 & 0.477 & 0.831 \\
\hline Intergroup & $\begin{array}{l}\text { Meta-Perception that } \\
\text { Outparty Respects Inparty }\end{array}$ & Secondary & $\begin{array}{l}\text { Aware - Positive } \\
\text { Political vs. Placebo }\end{array}$ & 0.293 & 0.136 & 2.157 & 0.034 & 0.195 \\
\hline Intergroup & $\begin{array}{l}\text { Warmth towards Inparty } \\
\text { Voters }\end{array}$ & Tertiary & $\begin{array}{l}\text { Aware - Negative } \\
\text { Political vs. Placebo }\end{array}$ & 0.124 & 0.123 & 1.008 & 0.316 & 0.709 \\
\hline Intergroup & $\begin{array}{l}\text { Warmth towards Inparty } \\
\text { Voters }\end{array}$ & Tertiary & $\begin{array}{l}\text { Aware - Non-Political vs. } \\
\text { Placebo }\end{array}$ & 0.13 & 0.107 & 1.216 & 0.228 & 0.583 \\
\hline Intergroup & $\begin{array}{l}\text { Warmth towards Inparty } \\
\text { Voters }\end{array}$ & Tertiary & $\begin{array}{l}\text { Aware - Positive } \\
\text { Political vs. Aware - } \\
\text { Negative Political }\end{array}$ & 0.017 & 0.12 & 0.14 & 0.889 & 1 \\
\hline Intergroup & $\begin{array}{l}\text { Warmth towards Inparty } \\
\text { Voters }\end{array}$ & Tertiary & $\begin{array}{l}\text { Aware - Positive } \\
\text { Political vs. Placebo }\end{array}$ & 0.141 & 0.103 & 1.367 & 0.175 & 0.504 \\
\hline
\end{tabular}


Table OA4: Numerical Results and Variable Classification: Study 2 (Continued)

\begin{tabular}{|c|c|c|c|c|c|c|c|c|}
\hline Category & Measure Name & DV Type & Condition Comparison & Estimate & SE & $\mathbf{t}$ & $\begin{array}{c}\text { Unadjusted } \\
\text { p-value }\end{array}$ & $\begin{array}{r}\text { Adjusted } \\
\text { p-value }\end{array}$ \\
\hline Intergroup & Felt Respected by Partner & Mechanism & $\begin{array}{l}\text { Aware - Negative } \\
\text { Political vs. Placebo }\end{array}$ & 0.019 & 0.135 & 0.143 & 0.886 & 1 \\
\hline Intergroup & Felt Respected by Partner & Mechanism & $\begin{array}{l}\text { Aware - Non-Political vs. } \\
\text { Placebo }\end{array}$ & -0.219 & 0.163 & -1.341 & 0.184 & 0.504 \\
\hline Intergroup & Felt Respected by Partner & Mechanism & $\begin{array}{l}\text { Aware - Positive } \\
\text { Political vs. Aware - } \\
\text { Negative Political }\end{array}$ & -0.364 & 0.185 & -1.964 & 0.053 & 0.255 \\
\hline Intergroup & Felt Respected by Partner & Mechanism & $\begin{array}{l}\text { Aware - Positive } \\
\text { Political vs. Placebo }\end{array}$ & -0.345 & 0.169 & -2.038 & 0.045 & 0.241 \\
\hline Intergroup & $\begin{array}{l}\text { Warmth towards Outparty } \\
\text { Voters }\end{array}$ & Primary (Unregistered) & $\begin{array}{l}\text { Aware - Either Political } \\
\text { vs. Placebo }\end{array}$ & 0.092 & 0.095 & 0.962 & 0.338 & 0.398 \\
\hline Intergroup & $\begin{array}{l}\text { Warmth towards Outparty } \\
\text { Voters }\end{array}$ & Primary (Unregistered) & $\begin{array}{l}\text { Aware - Either Political } \\
\text { vs. Aware - Non-Political }\end{array}$ & -0.319 & 0.112 & -2.846 & 0.006 & 0.015 \\
\hline $\begin{array}{l}\text { Manipulation } \\
\text { Check }\end{array}$ & $\begin{array}{l}\text { Partner is a Member of } \\
\text { the Outparty }\end{array}$ & Manipulation Check & $\begin{array}{l}\text { Aware - Negative } \\
\text { Political vs. Placebo }\end{array}$ & 1.271 & 0.11 & 11.552 & 0 & 0.001 \\
\hline $\begin{array}{l}\text { Manipulation } \\
\text { Check }\end{array}$ & $\begin{array}{l}\text { Partner is a Member of } \\
\text { the Outparty }\end{array}$ & Manipulation Check & $\begin{array}{l}\text { Aware - Non-Political vs. } \\
\text { Placebo }\end{array}$ & 0.257 & 0.128 & 2.003 & 0.049 & 0.246 \\
\hline $\begin{array}{l}\text { Manipulation } \\
\text { Check }\end{array}$ & $\begin{array}{l}\text { Partner is a Member of } \\
\text { the Outparty }\end{array}$ & Manipulation Check & $\begin{array}{l}\text { Aware - Positive } \\
\text { Political vs. Aware - } \\
\text { Negative Political }\end{array}$ & -0.034 & 0.129 & -0.261 & 0.795 & 1 \\
\hline $\begin{array}{l}\text { Manipulation } \\
\text { Check }\end{array}$ & $\begin{array}{l}\text { Partner is a Member of } \\
\text { the Outparty }\end{array}$ & Manipulation Check & $\begin{array}{l}\text { Aware - Positive } \\
\text { Political vs. Placebo }\end{array}$ & 1.238 & 0.119 & 10.42 & 0 & 0.001 \\
\hline $\begin{array}{l}\text { Manipulation } \\
\text { Check }\end{array}$ & Talked about Perfect Day & Manipulation Check & $\begin{array}{l}\text { Aware - Negative } \\
\text { Political vs. Placebo }\end{array}$ & -1.773 & 0.087 & -20.303 & 0 & 0.001 \\
\hline
\end{tabular}


Table OA4: Numerical Results and Variable Classification: Study 2 (Continued)

\begin{tabular}{|c|c|c|c|c|c|c|c|c|}
\hline Category & Measure Name & DV Type & Condition Comparison & Estimate & SE & $\mathbf{t}$ & $\begin{array}{l}\text { Unadjusted } \\
\text { p-value }\end{array}$ & $\begin{array}{r}\text { Adjusted } \\
\text { p-value }\end{array}$ \\
\hline $\begin{array}{l}\text { Manipulation } \\
\text { Check }\end{array}$ & Talked about Perfect Day & Manipulation Check & $\begin{array}{l}\text { Aware - Non-Political vs. } \\
\text { Placebo }\end{array}$ & 0.022 & 0.058 & 0.379 & 0.706 & 1 \\
\hline $\begin{array}{l}\text { Manipulation } \\
\text { Check }\end{array}$ & Talked about Perfect Day & Manipulation Check & $\begin{array}{l}\text { Aware - Positive } \\
\text { Political vs. Aware - } \\
\text { Negative Political }\end{array}$ & 0.2 & 0.123 & 1.633 & 0.106 & 0.414 \\
\hline $\begin{array}{l}\text { Manipulation } \\
\text { Check }\end{array}$ & Talked about Perfect Day & Manipulation Check & $\begin{array}{l}\text { Aware - Positive } \\
\text { Political vs. Placebo }\end{array}$ & -1.572 & 0.105 & -14.983 & 0 & 0.001 \\
\hline $\begin{array}{l}\text { Manipulation } \\
\text { Check }\end{array}$ & Talked about Politics & Manipulation Check & $\begin{array}{l}\text { Aware - Negative } \\
\text { Political vs. Placebo }\end{array}$ & 1.767 & 0.086 & 20.538 & 0 & 0.001 \\
\hline $\begin{array}{l}\text { Manipulation } \\
\text { Check }\end{array}$ & Talked about Politics & Manipulation Check & $\begin{array}{l}\text { Aware - Non-Political vs. } \\
\text { Placebo }\end{array}$ & 0.088 & 0.124 & 0.716 & 0.476 & 0.831 \\
\hline $\begin{array}{l}\text { Manipulation } \\
\text { Check }\end{array}$ & Talked about Politics & Manipulation Check & $\begin{array}{l}\text { Aware - Positive } \\
\text { Political vs. Aware - } \\
\text { Negative Political }\end{array}$ & -0.012 & 0.047 & -0.26 & 0.795 & 1 \\
\hline $\begin{array}{l}\text { Manipulation } \\
\text { Check }\end{array}$ & Talked about Politics & Manipulation Check & $\begin{array}{l}\text { Aware - Positive } \\
\text { Political vs. Placebo }\end{array}$ & 1.755 & 0.087 & 20.086 & 0 & 0.001 \\
\hline Mechanism & Warmth towards Partner & Secondary & $\begin{array}{l}\text { Aware - Negative } \\
\text { Political vs. Placebo }\end{array}$ & -0.05 & 0.141 & -0.354 & 0.724 & 1 \\
\hline Mechanism & Warmth towards Partner & Secondary & $\begin{array}{l}\text { Aware - Non-Political vs. } \\
\text { Placebo }\end{array}$ & -0.08 & 0.141 & -0.564 & 0.574 & 0.864 \\
\hline Mechanism & Warmth towards Partner & Secondary & $\begin{array}{l}\text { Aware - Positive } \\
\text { Political vs. Aware - } \\
\text { Negative Political }\end{array}$ & -0.262 & 0.196 & -1.341 & 0.184 & 0.504 \\
\hline
\end{tabular}


Table OA4: Numerical Results and Variable Classification: Study 2 (Continued)

\begin{tabular}{|c|c|c|c|c|c|c|c|c|}
\hline Category & Measure Name & DV Type & Condition Comparison & Estimate & SE & $\mathbf{t}$ & $\begin{array}{c}\text { Unadjusted } \\
\text { p-value }\end{array}$ & $\begin{array}{l}\text { Adjusted } \\
\text { p-value }\end{array}$ \\
\hline Mechanism & Warmth towards Partner & Secondary & $\begin{array}{l}\text { Aware - Positive } \\
\text { Political vs. Placebo }\end{array}$ & -0.312 & 0.174 & -1.79 & 0.077 & 0.338 \\
\hline Mechanism & $\begin{array}{l}\text { Anxious During } \\
\text { Conversation }\end{array}$ & Mechanism & $\begin{array}{l}\text { Aware - Negative } \\
\text { Political vs. Placebo }\end{array}$ & 0.17 & 0.142 & 1.195 & 0.235 & 0.583 \\
\hline Mechanism & $\begin{array}{l}\text { Anxious During } \\
\text { Conversation }\end{array}$ & Mechanism & $\begin{array}{l}\text { Aware - Non-Political vs. } \\
\text { Placebo }\end{array}$ & 0.026 & 0.132 & 0.195 & 0.846 & 1 \\
\hline Mechanism & $\begin{array}{l}\text { Anxious During } \\
\text { Conversation }\end{array}$ & Mechanism & $\begin{array}{l}\text { Aware - Positive } \\
\text { Political vs. Aware - } \\
\text { Negative Political }\end{array}$ & 0.021 & 0.168 & 0.124 & 0.902 & 1 \\
\hline Mechanism & $\begin{array}{l}\text { Anxious During } \\
\text { Conversation }\end{array}$ & Mechanism & $\begin{array}{l}\text { Aware - Positive } \\
\text { Political vs. Placebo }\end{array}$ & 0.19 & 0.142 & 1.342 & 0.183 & 0.504 \\
\hline Mechanism & $\begin{array}{l}\text { Felt Listened to by } \\
\text { Partner }\end{array}$ & Mechanism & $\begin{array}{l}\text { Aware - Negative } \\
\text { Political vs. Placebo }\end{array}$ & -0.181 & 0.151 & -1.199 & 0.234 & 0.583 \\
\hline Mechanism & $\begin{array}{l}\text { Felt Listened to by } \\
\text { Partner }\end{array}$ & Mechanism & $\begin{array}{l}\text { Aware - Non-Political vs. } \\
\text { Placebo }\end{array}$ & -0.08 & 0.113 & -0.705 & 0.483 & 0.831 \\
\hline Mechanism & $\begin{array}{l}\text { Felt Listened to by } \\
\text { Partner }\end{array}$ & Mechanism & $\begin{array}{l}\text { Aware - Positive } \\
\text { Political vs. Aware - } \\
\text { Negative Political }\end{array}$ & -0.487 & 0.207 & -2.354 & 0.021 & 0.149 \\
\hline Mechanism & $\begin{array}{l}\text { Felt Listened to by } \\
\text { Partner }\end{array}$ & Mechanism & $\begin{array}{l}\text { Aware - Positive } \\
\text { Political vs. Placebo }\end{array}$ & -0.668 & 0.176 & -3.793 & 0 & 0.004 \\
\hline Moderator & $\begin{array}{l}\text { Moderation of Warmth } \\
\text { towards Outparty Voters } \\
\text { by Extraversion }\end{array}$ & Moderator & $\begin{array}{l}\text { Aware - Negative } \\
\text { Political vs. Placebo }\end{array}$ & -0.121 & 0.117 & -1.035 & 0.304 & 0.695 \\
\hline
\end{tabular}


Table OA4: Numerical Results and Variable Classification: Study 2 (Continued)

\begin{tabular}{|c|c|c|c|c|c|c|c|c|}
\hline Category & Measure Name & DV Type & Condition Comparison & Estimate & SE & $\mathbf{t}$ & $\begin{array}{c}\text { Unadjusted } \\
\text { p-value }\end{array}$ & $\begin{array}{l}\text { Adjusted } \\
\text { p-value }\end{array}$ \\
\hline Moderator & $\begin{array}{l}\text { Moderation of Warmth } \\
\text { towards Outparty Voters } \\
\text { by Extraversion }\end{array}$ & Moderator & $\begin{array}{l}\text { Aware - Non-Political vs. } \\
\text { Placebo }\end{array}$ & 0.01 & 0.133 & 0.072 & 0.943 & 1 \\
\hline Moderator & $\begin{array}{l}\text { Moderation of Warmth } \\
\text { towards Outparty Voters } \\
\text { by Extraversion }\end{array}$ & Moderator & $\begin{array}{l}\text { Aware - Positive } \\
\text { Political vs. Aware - } \\
\text { Negative Political }\end{array}$ & -0.149 & 0.131 & -1.137 & 0.261 & 0.594 \\
\hline Moderator & $\begin{array}{l}\text { Moderation of Warmth } \\
\text { towards Outparty Voters } \\
\text { by Extraversion }\end{array}$ & Moderator & $\begin{array}{l}\text { Aware - Positive } \\
\text { Political vs. Placebo }\end{array}$ & -0.271 & 0.098 & -2.748 & 0.008 & 0.065 \\
\hline Moderator & $\begin{array}{l}\text { Moderation of Warmth } \\
\text { towards Outparty Voters } \\
\text { by Frequency Have } \\
\text { Conversations with } \\
\text { Outparty }\end{array}$ & Moderator & $\begin{array}{l}\text { Aware - Negative } \\
\text { Political vs. Placebo }\end{array}$ & -0.207 & 0.121 & -1.704 & 0.094 & 0.372 \\
\hline Moderator & $\begin{array}{l}\text { Moderation of Warmth } \\
\text { towards Outparty Voters } \\
\text { by Frequency Have } \\
\text { Conversations with } \\
\text { Outparty }\end{array}$ & Moderator & $\begin{array}{l}\text { Aware - Non-Political vs. } \\
\text { Placebo }\end{array}$ & -0.173 & 0.154 & -1.123 & 0.267 & 0.594 \\
\hline Moderator & $\begin{array}{l}\text { Moderation of Warmth } \\
\text { towards Outparty Voters } \\
\text { by Frequency Have } \\
\text { Conversations with } \\
\text { Outparty }\end{array}$ & Moderator & $\begin{array}{l}\text { Aware - Positive } \\
\text { Political vs. Aware - } \\
\text { Negative Political }\end{array}$ & 0.109 & 0.121 & 0.904 & 0.371 & 0.831 \\
\hline
\end{tabular}


Table OA4: Numerical Results and Variable Classification: Study 2 (Continued)

\begin{tabular}{|c|c|c|c|c|c|c|c|c|}
\hline Category & Measure Name & DV Type & Condition Comparison & Estimate & SE & $\mathbf{t}$ & $\begin{array}{c}\text { Unadjusted } \\
\text { p-value }\end{array}$ & $\begin{array}{r}\text { Adjusted } \\
\text { p-value }\end{array}$ \\
\hline Moderator & $\begin{array}{l}\text { Moderation of Warmth } \\
\text { towards Outparty Voters } \\
\text { by Frequency Have } \\
\text { Conversations with } \\
\text { Outparty }\end{array}$ & Moderator & $\begin{array}{l}\text { Aware - Positive } \\
\text { Political vs. Placebo }\end{array}$ & -0.098 & 0.119 & -0.824 & 0.413 & 0.831 \\
\hline Moderator & $\begin{array}{l}\text { Moderation of Warmth } \\
\text { towards Outparty Voters } \\
\text { by Openness }\end{array}$ & Moderator & $\begin{array}{l}\text { Aware - Negative } \\
\text { Political vs. Placebo }\end{array}$ & -0.14 & 0.119 & -1.175 & 0.245 & 0.593 \\
\hline Moderator & $\begin{array}{l}\text { Moderation of Warmth } \\
\text { towards Outparty Voters } \\
\text { by Openness }\end{array}$ & Moderator & $\begin{array}{l}\text { Aware - Non-Political vs. } \\
\text { Placebo }\end{array}$ & 0.008 & 0.133 & 0.062 & 0.951 & 1 \\
\hline Moderator & $\begin{array}{l}\text { Moderation of Warmth } \\
\text { towards Outparty Voters } \\
\text { by Openness }\end{array}$ & Moderator & $\begin{array}{l}\text { Aware - Positive } \\
\text { Political vs. Aware - } \\
\text { Negative Political }\end{array}$ & -0.107 & 0.142 & -0.751 & 0.456 & 0.831 \\
\hline Moderator & $\begin{array}{l}\text { Moderation of Warmth } \\
\text { towards Outparty Voters } \\
\text { by Openness }\end{array}$ & Moderator & $\begin{array}{l}\text { Aware - Positive } \\
\text { Political vs. Placebo }\end{array}$ & -0.246 & 0.14 & -1.758 & 0.084 & 0.338 \\
\hline Moderator & $\begin{array}{l}\text { Moderation of Warmth } \\
\text { towards Outparty Voters } \\
\text { by Political Knowledge }\end{array}$ & Moderator & $\begin{array}{l}\text { Aware - Negative } \\
\text { Political vs. Placebo }\end{array}$ & -0.143 & 0.148 & -0.962 & 0.341 & 0.779 \\
\hline Moderator & $\begin{array}{l}\text { Moderation of Warmth } \\
\text { towards Outparty Voters } \\
\text { by Political Knowledge }\end{array}$ & Moderator & $\begin{array}{l}\text { Aware - Non-Political vs. } \\
\text { Placebo }\end{array}$ & -0.229 & 0.146 & -1.574 & 0.122 & 0.465 \\
\hline
\end{tabular}


Table OA4: Numerical Results and Variable Classification: Study 2 (Continued)

\begin{tabular}{|c|c|c|c|c|c|c|c|c|}
\hline Category & Measure Name & DV Type & Condition Comparison & Estimate & SE & $\mathbf{t}$ & $\begin{array}{c}\text { Unadjusted } \\
\text { p-value }\end{array}$ & $\begin{array}{r}\text { Adjusted } \\
\text { p-value }\end{array}$ \\
\hline Moderator & $\begin{array}{l}\text { Moderation of Warmth } \\
\text { towards Outparty Voters } \\
\text { by Political Knowledge }\end{array}$ & Moderator & $\begin{array}{l}\text { Aware - Positive } \\
\text { Political vs. Aware - } \\
\text { Negative Political }\end{array}$ & -0.111 & 0.19 & -0.582 & 0.564 & 0.864 \\
\hline Moderator & $\begin{array}{l}\text { Moderation of Warmth } \\
\text { towards Outparty Voters } \\
\text { by Political Knowledge }\end{array}$ & Moderator & $\begin{array}{l}\text { Aware - Positive } \\
\text { Political vs. Placebo }\end{array}$ & -0.254 & 0.2 & -1.267 & 0.211 & 0.562 \\
\hline Moderator & $\begin{array}{l}\text { Moderation of Warmth } \\
\text { towards Outparty Voters } \\
\text { by Self-Monitoring }\end{array}$ & Moderator & $\begin{array}{l}\text { Aware - Negative } \\
\text { Political vs. Placebo }\end{array}$ & -0.101 & 0.139 & -0.727 & 0.471 & 0.831 \\
\hline Moderator & $\begin{array}{l}\text { Moderation of Warmth } \\
\text { towards Outparty Voters } \\
\text { by Self-Monitoring }\end{array}$ & Moderator & $\begin{array}{l}\text { Aware - Non-Political vs. } \\
\text { Placebo }\end{array}$ & -0.078 & 0.16 & -0.486 & 0.629 & 0.982 \\
\hline Moderator & $\begin{array}{l}\text { Moderation of Warmth } \\
\text { towards Outparty Voters } \\
\text { by Self-Monitoring }\end{array}$ & Moderator & $\begin{array}{l}\text { Aware - Positive } \\
\text { Political vs. Aware - } \\
\text { Negative Political }\end{array}$ & 0.143 & 0.126 & 1.137 & 0.261 & 0.594 \\
\hline Moderator & $\begin{array}{l}\text { Moderation of Warmth } \\
\text { towards Outparty Voters } \\
\text { by Self-Monitoring }\end{array}$ & Moderator & $\begin{array}{l}\text { Aware - Positive } \\
\text { Political vs. Placebo }\end{array}$ & 0.042 & 0.124 & 0.336 & 0.739 & 1 \\
\hline
\end{tabular}


Table OA5: Means and Standard Deviations of Primary Outcomes, by Condition and Time (a) Study 1

\begin{tabular}{|c|c|c|c|c|}
\hline Outcome & Time Measured & Entire Sample & Placebo & Aware - Non-Political \\
\hline \multirow{3}{*}{$\begin{array}{l}\text { Warmth towards } \\
\text { Outparty Voters }\end{array}$} & Baseline & $\begin{array}{c}37.29 \\
(25.34)\end{array}$ & $\begin{array}{c}38.83 \\
(24.74)\end{array}$ & $\begin{array}{c}35.99 \\
(25.81)\end{array}$ \\
\hline & Immediately After & $\begin{array}{l}47.38 \\
(26.5)\end{array}$ & $\begin{array}{l}44.29 \\
(25.9)\end{array}$ & $\begin{array}{c}49.98 \\
(26.77)\end{array}$ \\
\hline & 3 Months Later & $\begin{array}{c}32.76 \\
(24.36)\end{array}$ & $\begin{array}{c}34.7 \\
(23.55)\end{array}$ & $\begin{array}{c}31.25 \\
(24.92)\end{array}$ \\
\hline \multirow{3}{*}{$\begin{array}{l}\text { Meta-Perception that } \\
\text { Outparty Respects } \\
\text { Inparty }\end{array}$} & Baseline & $\begin{array}{c}2.15 \\
(0.82)\end{array}$ & $\begin{array}{c}2.19 \\
(0.82)\end{array}$ & $\begin{array}{c}2.13 \\
(0.82)\end{array}$ \\
\hline & Immediately After & $\begin{array}{l}2.62 \\
(0.8)\end{array}$ & $\begin{array}{c}2.44 \\
(0.79)\end{array}$ & $\begin{array}{c}2.78 \\
(0.78)\end{array}$ \\
\hline & 3 Months Later & $\begin{array}{c}1.96 \\
(0.76)\end{array}$ & $\begin{array}{l}1.96 \\
(0.8)\end{array}$ & $\begin{array}{c}1.97 \\
(0.72)\end{array}$ \\
\hline $\begin{array}{l}\text { Choose Candidate } \\
\text { Aligned on Issues } \\
\text { over Party }\end{array}$ & Immediately After & $\begin{array}{c}0.82 \\
(0.38)\end{array}$ & $\begin{array}{c}0.84 \\
(0.37)\end{array}$ & $\begin{array}{c}0.8 \\
(0.4)\end{array}$ \\
\hline
\end{tabular}

Notes: The Table shows the means and standard deviations (in parentheses) for the primary outcome measures at each time. The means at all time points, including baseline, only include participants who were eligible for inclusion in the analysis (e.g., started a conversation).

(b) Study 2

\begin{tabular}{llccccc}
\hline Primary Outcome & $\begin{array}{l}\text { Time } \\
\text { Measured }\end{array}$ & $\begin{array}{c}\text { Entire } \\
\text { Sample }\end{array}$ & Placebo & $\begin{array}{c}\text { Aware - } \\
\text { Non-Political }\end{array}$ & $\begin{array}{c}\text { Aware - } \\
\text { Positive } \\
\text { Political }\end{array}$ & $\begin{array}{c}\text { Aware - } \\
\text { Negative } \\
\text { Political }\end{array}$ \\
\hline Warmth towards & Baseline & 35.23 & 37.06 & 30.92 & 33.06 & 39.12 \\
Outparty Voters & $(22.27)$ & $(22.75)$ & $(20.01)$ & $(21.26)$ & $(24.05)$ \\
& Immediately & 43.53 & 41.05 & 46.55 & 40.38 & 47.04 \\
& After & $(24.37)$ & $(24.62)$ & $(23.37)$ & $(25.34)$ & $(23.61)$ \\
\hline
\end{tabular}

Notes: The Table shows the means and standard deviations (in parentheses) for the primary outcome measures at each time. The means at all time points, including baseline, only include participants who were eligible for inclusion in the analysis (e.g., started a conversation). 


\section{B Relevant previous literature}

Given space constraints in the main text, we previous previous research relevant to our study in more detail in this section. Our research builds on other research on the impacts of cross-partisan conversations in several important ways. Most notably, our study is the first to study face-to-face (i.e., video) conversations between outpartisans outside the context of a broader intervention; our study is the first to examine the long-run effects of such contact; and our study is the first to examine a broad variety of outcomes relevant to democratic accountability.

Table OA6 reviews existing studies that focus on conversations between outpartisans only, and not combined interventions that include both cross-partisan conversation and other intervention components. Beyond this paper, the only other study to do so is an important working paper by Rossiter (2021), who studies text-based conversations between copartisan strangers. Our study builds on Rossiter (2021) in several ways: we measure effects on outcomes relevant to democratic accountability, we measure attitudinal polarization, and we measure long-run effects. We also examine the effects of conversations more explicitly about partisanship and-inspired by research about the differences between text- and video-based conversations (Schroeder, Kardas and Epley, 2017)_ which take place over video calls.

Table OA7 reviews existing studies of interventions that include both conversations with outpartisans and other components. These studies are extremely valuable studies of particular in-

terventions, but cannot speak directly to the effects of cross-partisan conversations because they manipulate both cross-partisan contact and other interventions. A representative example is Baron et al. (2021), who study a day-long depolarization event run by the non-profit Better Angles that involves reflections on intergroup stereotypes, discussions of intergroup bias, a listening exercise, and action-oriented exercises. The pathbreaking study by Baron et al. (2021) is extremely valuable, although it is not focused on cross-partisan conversation per se. Cross-partisan conversation is only one component of the intervention the authors study; the results speak to the effects of the 
intervention but leave unclear the effects of just the cross-partisan conversation component. None of the studies in Table OA7 study effects on outcomes relevant to democratic accountability, except for one somewhat outcome in Baron et al. (2021), whether individuals donate to a depolarization NGO.

Table OA8 expands our scope to studies of vicarious, imagined, simulated, or reported contact between outpartisans. These are studies that pertain to the impact of cross-partisan conversations but do not randomly assign contact between real outpartisans. For example, Voelkel, Ren and Brandt (2019) study the effects of imagined contact (Study 1) and text-based conversations with confederates (Studies 2 and 3); although Voelkel, Ren and Brandt (2019) produce valuable insights about their research question (the effect of political inclusion in interpersonal conversations), it is unclear whether their findings would generalize to how individuals would react when conversing with an outpartisan who behaves as real people do, instead of how their confederates did. None of these studies examine long-run effects, effects on attitudinal polarization, nor effects on democratic accountability.

Finally, Table OA9 provides a non-exhaustive list of examples of other studies that examine effects of various interventions related to the topics of either conversations or affective polarization, but do not concern the effects of cross-partisan conversations on affective polarization. For example, Jahani et al.(2021) study the effects of providing different primes to individuals engaged in a text-based conversation with an outpartisan chatbot; but because Jahani et al. (2021) are interested in the effects of the primes, not of the conversation, there is no control group and so the study does not (and cannot) examine the effects of the conversation. Jahani et al. (2021) are also not concerned with affective polarization and, like all the studies in Table OA9 except for Levendusky (2018), do not measure effects on affective polarization. 
Table OA6: Studies of Conversations with Outpartisans

\begin{tabular}{|c|c|c|c|c|c|c|}
\hline \multirow[b]{2}{*}{ Citation } & \multicolumn{3}{|c|}{ Research Design } & \multicolumn{3}{|c|}{ Measures... } \\
\hline & $\begin{array}{c}\text { Outpartisan Conversation } \\
\text { Treatment(s) }\end{array}$ & $\begin{array}{c}\text { Additional Components } \\
\text { of Intervention }\end{array}$ & $\begin{array}{l}\text { Conversation } \\
\text { Format }\end{array}$ & $\begin{array}{c}\text { Democratic } \\
\text { Accountability? }\end{array}$ & $\begin{array}{l}\text { Intergroup } \\
\text { Attitudes? }\end{array}$ & $\begin{array}{l}\text { Long-Run } \\
\text { Effects? }\end{array}$ \\
\hline This paper & $\begin{array}{l}\text { Non-political conversation with an } \\
\text { outpartisan; Conversation with an } \\
\text { outpartisan about group divides (either } \\
\text { about inparty or outparty) }\end{array}$ & - & $\begin{array}{l}\text { Video } \\
\text { conversation with } \\
\text { a stranger }\end{array}$ & $\begin{array}{l}\text { Yes (e.g., Party } \\
\text { Loyalty, } \\
\text { Democratic Norms, } \\
\text { Bipartisanship) }\end{array}$ & Yes & $\begin{array}{l}\text { Yes, approx. } \\
\text { three months } \\
\text { post-intervention }\end{array}$ \\
\hline Rossiter (2021) & $\begin{array}{l}\text { Non-political conversation with an } \\
\text { outpartisan; Conversation with an } \\
\text { outpartisan about an issue (gun control) }\end{array}$ & - & $\begin{array}{l}\text { Text-based } \\
\text { conversation with } \\
\text { a stranger }\end{array}$ & - & Yes & - \\
\hline
\end{tabular}

Table OA7: Studies of Interventions that Include Both Conversations with Outpartisans and Other Components

\begin{tabular}{|c|c|c|c|c|c|c|}
\hline Citation & $\begin{array}{c}\text { Outpartisan Conversation } \\
\text { Treatment(s) }\end{array}$ & $\begin{array}{l}\text { Research Design } \\
\text { Additional Components } \\
\text { of Intervention }\end{array}$ & $\begin{array}{l}\text { Conversation } \\
\text { Format }\end{array}$ & $\begin{array}{c}\text { Democratic } \\
\text { Accountability? }\end{array}$ & $\begin{array}{l}\text { Measures... } \\
\text { Intergroup } \\
\text { Attitudes? }\end{array}$ & $\begin{array}{l}\text { Long-Run } \\
\text { Effects? }\end{array}$ \\
\hline Klar 2014) & $\begin{array}{l}\text { Politically heterogenous discussion } \\
\text { group (vs. homogenous discussion } \\
\text { or a no-contact control) }\end{array}$ & $\begin{array}{l}\text { Ambivalent vs univalent partisan } \\
\text { prime; All members read about policy }\end{array}$ & $\begin{array}{l}\text { In-person in } \\
\text { groups }\end{array}$ & - & - & - \\
\hline \begin{tabular}{|l|} 
Levendusky \\
and Stecula \\
Forthcoming
\end{tabular} & $\begin{array}{l}\text { Heterogeneous political discussion } \\
\text { group about commonalities } \\
\text { between parties (vs. homogenous } \\
\text { political discussion group or } \\
\text { non-political discussion group) }\end{array}$ & $\begin{array}{l}\text { Heterogenous group reads article about } \\
\text { common ground between parties; } \\
\text { homogenous group reads article about } \\
\text { partisan division and polarization; } \\
\text { Non-political discussion group reads } \\
\text { article about beach towns }\end{array}$ & $\begin{array}{l}\text { In-person in } \\
\text { groups }\end{array}$ & - & Yes & $\begin{array}{l}\text { Yes, one week } \\
\text { later }\end{array}$ \\
\hline $\begin{array}{l}\text { Kalla and } \\
\text { Broockman } \\
2021 b \\
\end{array}$ & $\begin{array}{l}\text { Implementing door-to-door } \\
\text { persuasion campaigns; targeted } \\
\text { voters include outpartisans }\end{array}$ & $\begin{array}{l}\text { Training and implementation of } \\
\text { two-way narrative exchanges, } \\
\text { perspective-getting exercises }\end{array}$ & $\begin{array}{l}\text { In-person, } \\
\text { door-to-door }\end{array}$ & - & Yes & $\begin{array}{l}\text { Only measure is } \\
\text { approx. one week } \\
\text { later }\end{array}$ \\
\hline $\begin{array}{l}\text { Fishkin et al. } \\
\text { (2021) }\end{array}$ & $\begin{array}{l}\text { Work in heterogenous groups to } \\
\text { devise questions for experts and } \\
\text { discuss political issues in five areas } \\
\text { as part of deliberation event (vs. } \\
\text { pure control) }\end{array}$ & $\begin{array}{l}\text { Cooperation to devise questions; expert } \\
\text { testimony; briefing materials with } \\
\text { evidence for against/proposals; } \\
\text { Attendance at deliberation event }\end{array}$ & $\begin{array}{l}\text { In-person in } \\
\text { groups }\end{array}$ & - & Yes & - \\
\hline $\begin{array}{l}\text { Baron et al. } \\
\text { (2021) }\end{array}$ & $\begin{array}{l}\text { Guided heterogeneous group } \\
\text { discussion as part of reciprocal } \\
\text { group reflection exercises }\end{array}$ & $\begin{array}{l}\text { Depolarization workshop, including } \\
\text { reflections on stereotypes, listening } \\
\text { exercise, action-oriented exercises }\end{array}$ & $\begin{array}{l}\text { In-person, as part } \\
\text { of depolarization } \\
\text { workshop }\end{array}$ & $\begin{array}{l}\text { Yes (donation to a } \\
\text { depolarization } \\
\text { NGO) }\end{array}$ & Yes & Yes, six months \\
\hline
\end{tabular}


Table OA8: Vicarious, imagined, simulated or reported contact between outpartisans

\begin{tabular}{|c|c|c|c|c|c|c|}
\hline \multirow[b]{2}{*}{ Citation } & \multicolumn{3}{|c|}{ Research Design } & \multicolumn{3}{|c|}{ Measures... } \\
\hline & $\begin{array}{c}\text { Outpartisan Conversation } \\
\text { Treatment(s) }\end{array}$ & $\begin{array}{l}\text { Additional Components } \\
\text { of Intervention }\end{array}$ & $\begin{array}{l}\text { Conversation } \\
\text { Format }\end{array}$ & $\begin{array}{c}\text { Democratic } \\
\text { Accountability? }\end{array}$ & $\begin{array}{l}\text { Intergroup } \\
\text { Attitudes? }\end{array}$ & $\begin{array}{l}\text { Long-Run } \\
\text { Effects? }\end{array}$ \\
\hline $\begin{array}{l}\text { Voelkel, Ren } \\
\text { and Brandt } \\
2019)\end{array}$ & $\begin{array}{l}\text { Imagined contact (Study } \\
\text { 1); Conversations with } \\
\text { confederates (Studies } 2 \\
\text { and 3) }\end{array}$ & $\begin{array}{l}\text { Participants excluded or } \\
\text { included by outpartisans }\end{array}$ & $\begin{array}{l}\text { Imagined contact (Study 1); } \\
\text { Text-based conversations with } \\
\text { confederates (Studies } 2 \text { and } 3 \text { ) }\end{array}$ & - & Yes & - \\
\hline $\begin{array}{l}\text { Wojcieszak and } \\
\text { Warner (2020) }\end{array}$ & $\begin{array}{l}\text { Read about or imagine } \\
\text { contact an outparty } \\
\text { member (vs. inparty or } \\
\text { control) }\end{array}$ & $\begin{array}{l}\text { Contact type is positive / } \\
\text { cooperative, negative, or } \\
\text { neutral (studies } 2 \text { and } 3 \text { ) }\end{array}$ & $\begin{array}{l}\text { Reported (Study } 1 \text { ), vicarious } \\
\text { (Study } 2 \text { ) or imagined contact } \\
\text { (Study } 3 \text { ) }\end{array}$ & - & Yes & - \\
\hline \begin{tabular}{|l|} 
Warner and \\
Villamil (2017)
\end{tabular} & $\begin{array}{l}\text { Imagined contact with } \\
\text { outpartisans }\end{array}$ & $\begin{array}{l}\text { Valence of contact } \\
\text { (positive vs. negative) }\end{array}$ & Imagine contact & - & Yes & - \\
\hline \begin{tabular}{|l|} 
Amsalem, \\
Merkley and \\
Loewen $(2021)$ \\
\end{tabular} & $\begin{array}{l}\text { Self-reported contact (not } \\
\text { randomized; observational } \\
\text { study) }\end{array}$ & $\mathrm{n} / \mathrm{a}$ & $\begin{array}{l}\text { Self-reported participation in online } \\
\text { and face-to-face heterogenous } \\
\text { discussions }\end{array}$ & - & Yes & - \\
\hline
\end{tabular}

Table OA9: Examples of other studies that do not examine effects of contact between partisan groups

\begin{tabular}{|c|c|c|c|c|c|c|}
\hline \multirow[b]{2}{*}{ Citation } & \multicolumn{3}{|c|}{ Research Design } & \multicolumn{3}{|c|}{ Measures... } \\
\hline & $\begin{array}{l}\text { Outpartisan Conversation } \\
\text { Treatment(s) }\end{array}$ & $\begin{array}{l}\text { Additional Components } \\
\text { of Intervention }\end{array}$ & $\begin{array}{l}\text { Conversation } \\
\text { Format }\end{array}$ & $\begin{array}{c}\text { Democratic } \\
\text { Accountability? }\end{array}$ & $\begin{array}{l}\text { Intergroup } \\
\text { Attitudes? }\end{array}$ & $\begin{array}{l}\text { Long-Run } \\
\text { Effects? }\end{array}$ \\
\hline $\begin{array}{l}\text { Kubin et al. (2021, } \\
\text { Study 5) }\end{array}$ & $\begin{array}{l}\text { Conversation with confederate who disagrees on gun } \\
\text { issues; no control without a conversation }\end{array}$ & $\begin{array}{l}\text { Confederate shares } \\
\text { personal experience or fact }\end{array}$ & $\begin{array}{l}\text { In-person } \\
\text { conversation with a } \\
\text { confederate }\end{array}$ & - & - & - \\
\hline Jahani et al. (2021) & $\begin{array}{l}\text { All participants had conversation with automated } \\
\text { outpartisan chatbot; no control condition without an } \\
\text { outpartisan conversation so cannot examine effects of } \\
\text { conversations; treatments of interest are primes }\end{array}$ & $\begin{array}{l}\text { Prime (e.g., common } \\
\text { enemy or patricotic event) }\end{array}$ & $\begin{array}{l}\text { Text conversation } \\
\text { with a bot }\end{array}$ & - & - & - \\
\hline Levendusky (2018) & None & $\begin{array}{l}\text { Common ingroup identity } \\
\text { prime }\end{array}$ & $\mathrm{n} / \mathrm{a}$ & - & Yes & - \\
\hline Bail et al. (2018) & None & $\begin{array}{l}\text { Exposure to outpartisan } \\
\text { politicians' messages on } \\
\text { Twitter }\end{array}$ & $\mathrm{n} / \mathrm{a}$ & - & - & - \\
\hline
\end{tabular}




\section{References for Online Appendix}

\section{References for Online Appendix}

Amsalem, Eran, Eric Merkley and Peter John Loewen. 2021. "Does Talking to the Other Side Reduce Inter-party Hostility? Evidence from Three Studies.” Political Communication 0(0):118.

Bail, Christopher A, Lisa P Argyle, Taylor W Brown, John P Bumpus, Haohan Chen, MB Fallin Hunzaker, Jaemin Lee, Marcus Mann, Friedolin Merhout and Alexander Volfovsky. 2018. “Exposure to opposing views on social media can increase political polarization." Proceedings of the National Academy of Sciences 115(37):9216-9221.

Baron, Hannah, Robert Blair, Donghyun Danny Choi, Laura Gamboa, Jessica Gottlieb, Amanda Lea Robinson, Steven Rosenzweig, Megan Turnbull and Emily A West. 2021. "Can Americans Depolarize? Assessing the Effects of Reciprocal Group Reflection on Partisan Polarization." Available at https://osf .io/3x7z8

Fishkin, James, Alice Siu, Larry Diamond and Norman Bradburn. 2021. "Is Deliberation an Antidote to Extreme Partisan Polarization? Reflections on "America in One Room"." American Political Science Review Forthcoming.

Jahani, Eaman, Natalie McDaniel Gallagher, Friedolin Merhout, Nicolo Cavalli, Douglas Guilbeault, Yan Leng and Christopher A. Bail. 2021. "Exposure to Common Enemies can Increase Political Polarization: Evidence from a Cooperation Experiment with Automated Partisans." Working paper, available at https://osf .io/preprints/socarxiv/x2dby/

Kalla, Joshua L. and David E. Broockman. 2021. "Voter outreach campaigns can reduce affective polarization among implementing political activists." Working paper, available at https:// osf.io/5yahr/. 
Klar, Samara. 2014. "Partisanship in a social setting." American Journal of Political Science 58(3):687-704.

Kubin, Emily, Curtis Puryear, Chelsea Schein and Kurt Gray. 2021. "Personal experiences bridge moral and political divides better than facts." Proceedings of the National Academy of Sciences 118(6).

Levendusky, Matthew and Dominik Stecula. Forthcoming. We Need to Talk: How Cross-Party Dialogue Reduces Affective Polarization. Cambridge University Press.

Levendusky, Matthew S. 2018. "Americans, not partisans: Can priming American national identity reduce affective polarization?" The Journal of Politics 80(1):59-70.

Rossiter, Erin. 2021. "The Consequences of Interparty Conversation on Outparty Affect and Stereotypes." Working Paper, available at http://erossiter.com/files/ conversations.pdf.

Schroeder, Juliana, Michael Kardas and Nicholas Epley. 2017. "The humanizing voice: Speech reveals, and text conceals, a more thoughtful mind in the midst of disagreement." Psychological science 28(12):1745-1762.

Voelkel, Jan G, Dongning Ren and Mark Brandt. 2019. "Political inclusion reduces political prejudice." Working paper, available at https: / / psyarxiv.com/dxwpu/.

Warner, Benjamin R and Astrid Villamil. 2017. "A test of imagined contact as a means to improve cross-partisan feelings and reduce attribution of malevolence and acceptance of political violence." Communication Monographs 84(4):447-465.

Wojcieszak, Magdalena and Benjamin R Warner. 2020. "Can interparty contact reduce affective polarization? A systematic test of different forms of intergroup contact." Political Communication 37(6):789-811. 